\title{
DINÂMICA DA FLORESTA ATLÂNTICA EM LINHARES (ES) (1980-1995)
}

\section{SAMIR GONÇALVES ROLIM \\ Engenheiro Agrônomo}

Orientador: Prof. Dr. HILTON THADEU Z. DO COUTO

Dissertação apresentada à Escola Superior de Agricultura "Luiz de Queiroz", Universidade de São Paulo, para obtenção do título de Mestre em Ciências, Área de Concentração Ciências Florestais. 
Dados Internacionais de Catalogação na Publicação (CIP) DIVISÃO DE BIBLIOTECA E DOCUMENTAÇÃO - Campus "Luiz de Queiroz"/USP

Rolim, Samir Gonçalves

Dinâmica da Floresta Atlantica em Linhares (ES) / Samir Gonçalves Rolim. - Piracicaba, 1997.

$87 \mathrm{p}$.

Dissertação (mestrado) - Escola Superior de Agricultura Luiz de Queiroz, 1997. Bibliografia.

1. Dinâmica de população 2. Estatistica florestal 3. Floresta tropical 4. Manejo florestal 5. Mata Atlântica 6. Variabilidade temporal I. Titulo 


\section{DINÂMICA DA FLORESTA ATLÂNTICA EM LINHARES (ES) (1980-1995)}

SAMIR GONÇALVES ROLIM

Aprovada em: 09/09/1997

Comissão Julgadora:

Prof. Dr. Hilton Thadeu Z. do Couto

ESALQ/USP

Prof. Dr. João Luís F. Batista

ESALQ/USP

Prof. Dr. Flávio A. M. dos Santos

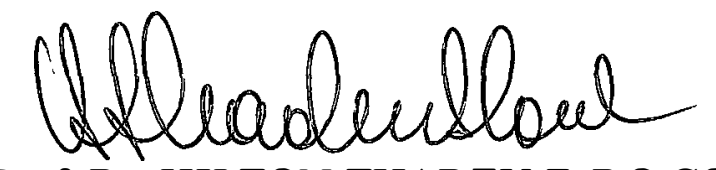

Prof. Dr. HILTON THADEU Z. DO COUTO Orientador 


\begin{abstract}
À meus avós que viveram da terra, à meu pai que estudou a terra, à minha mãe e meus irmãos por seu carinho, minha profunda gratidão.
\end{abstract}

Este trabalho, fruto de tantas ausências, dedico à Valéria e Amanda. 


\section{AGRADECIMENTOS}

À caá-etê

Quero expressar minha gratidão ao Prof. Thadeu não só pela amizade e pelos ensinamentos como também pelo apoio, incentivo e pela orientação segura que me permitiu a liberdade de "viajar" em meio a tantos dados e informações. À Florestas Rio Doce e ao Renato pela cessão dos dados para análise e pelo interesse demonstrado na elaboração deste trabalho. Ao Conselho Nacional de Desenvolvimento Científico e Tecnológico pela bolsa concedida. Aos componentes da banca pelas sugestões apresentadas. Ao Prof. João Batista cujas idéias, críticas e sugestões sempre foram um estímulo. Ao apoio e incentivo de meu pai, que foi fundamental para me encorajar a realizar o curso de mestrado. À Valéria cuja paciência e dedicação tornaram este trabalho possivel. Também agradeço a Nadja $\bullet$ Henrique, pelas revisões e discussões sempre estimulantes.

Ao Natal, representando os professores do Departamento, pelo exemplo e dedicação. À Marialice, Fátima, Margareth, Creiza, Magali, Jefferson e Paulinho, pela qualidade dos serviços prestados e pelo apoio sempre concedido.

Não posso me esquecer dos amigos de inúmeras reuniões que, como diria Marcus Pereira, aconteceram a propósito de qualquer coisa como uma sinuca, uma cerveja ou um baralho, mas, principalmente a propósito de não se fazer nada: Xola, Spermão, Negação, Serjão, Martelo, Mofo e Zé.

Para os companheiros desta jornada, cujos momentos e a amizade conquistada não podem se expressos aqui: Rê, Klaus( $\bullet$ Mônica), Marli, Girlei( Mônica), Gabriela, Henrique, Cristina, Paulo Maurício, Nely, Waldir, Renata, Ary, Peroba, Chico, Lau, Lothar, Isabel, Madeira, Márcia, Alexandre, Melô, Sérgio, Ana Rosa, Edson, Lina e Gláucia.

\footnotetext{
"Velhos amigos quando se encontram trocam noticias e recordaçס̃es, bebem cerveja no bar de costume e cantam, voz rouca, antigas cançס̃es. Os velhos amigos quase nunca se perdem, se guardam prá certas ocasiöes. Velhos amigos só rejuvenescem, lembrando loucuras de outros veróes, e brindam alegre seus vivos e mortos e acabam a noite com novas cançסes.
} Conhecem o perigo, mas fazem de conta que o tempo não ronda mais seus coraçס̃es. " 


\section{SUMÁRIO}

Página

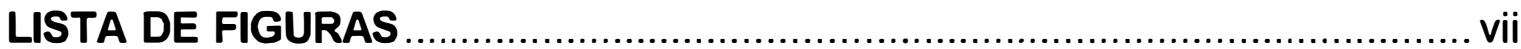

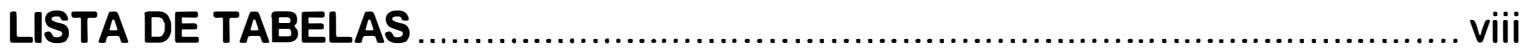

RESUMO

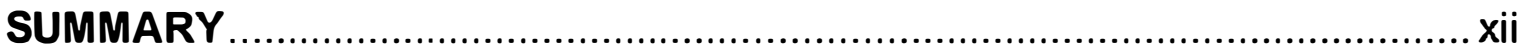

CAPITULO I: INTRODUÇÃO GERAL

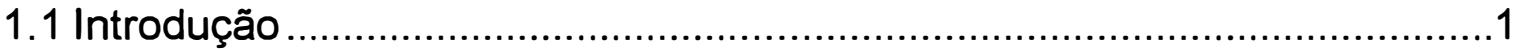

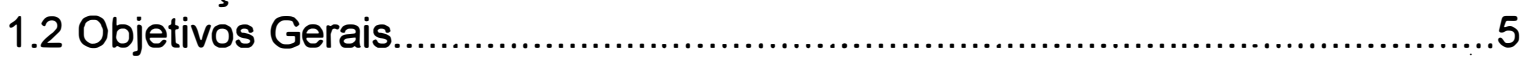

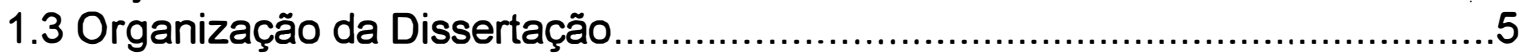

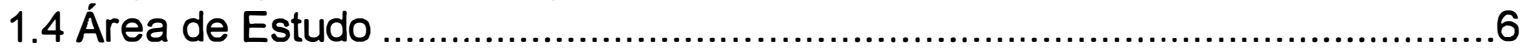

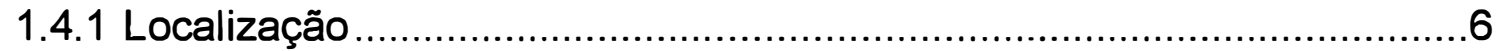

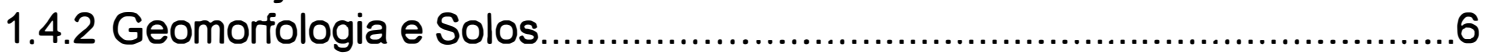

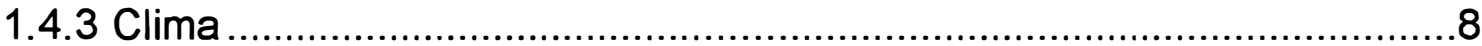

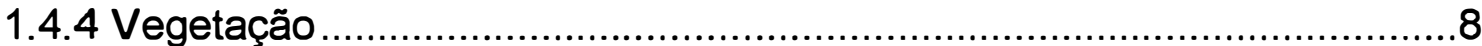

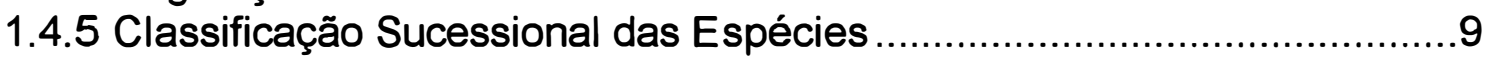

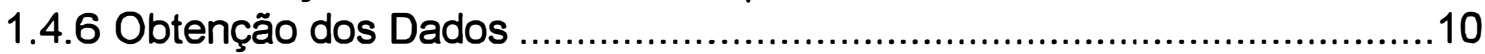

\section{CAPÍTULO II: REVISÃO DE LITERATURA - DINÂMICA DE FLORESTAS TROPICAIS}

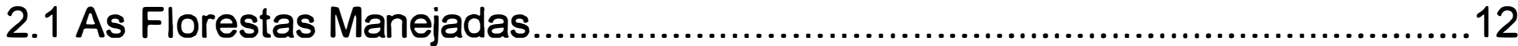

2.2 Equilíbrio Vs. Não-Equilibrio de Florestas Tropicais ..............................13

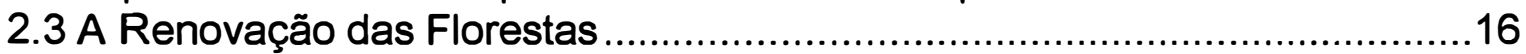

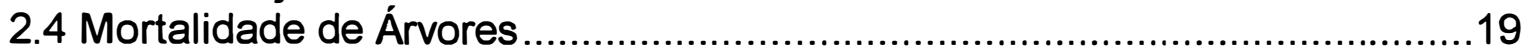

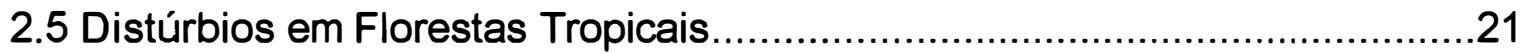

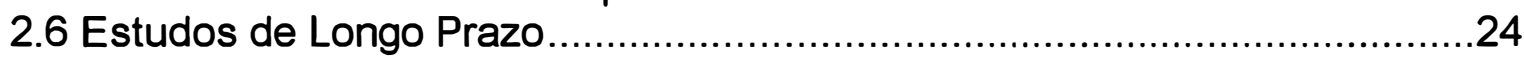

CAPÍTULO III: MORTALIDADE E RECRUTAMENTO NA FLORESTA ATLÂNTICA EM LINHARES (ES)

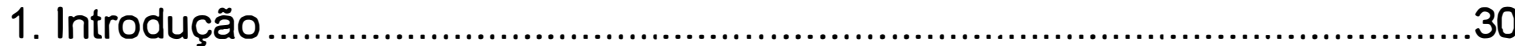

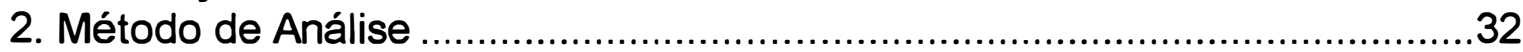

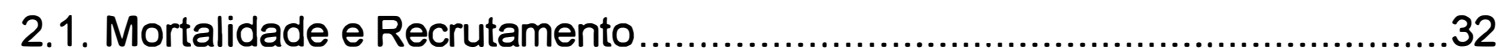

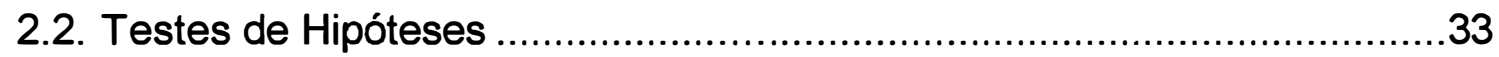

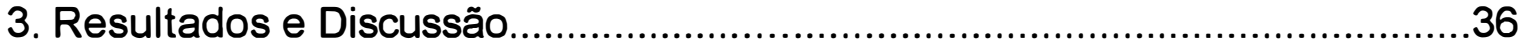

3.1. Densidade Total e Densidade dos Grupos Ecológicos...........................36

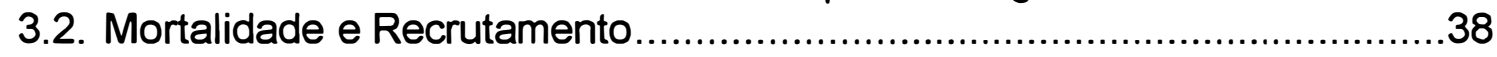

3.3. Mortalidade nas Classes de Tamanho ................................................4

3.4. Análise de Correlação e Classes de Abundância......................................43

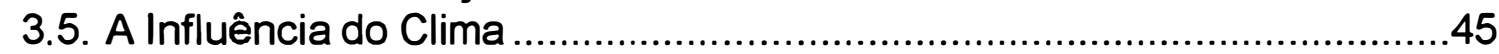

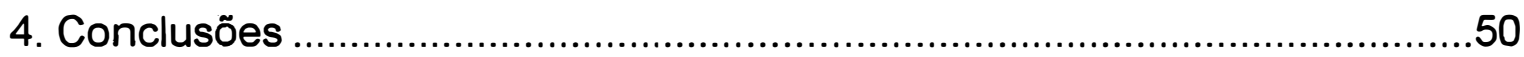




\section{CAPITULO IV: VARIAÇÕES TEMPORAIS E ESPACIAIS NA COMPOSIÇÃO}

FLORISTICA DA FLORESTA ATLÂNTICA DE TABULEIRO: 1980 a 1995

1. Introdução 51

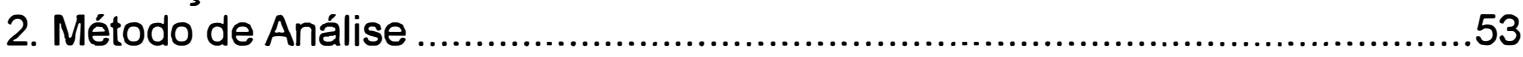

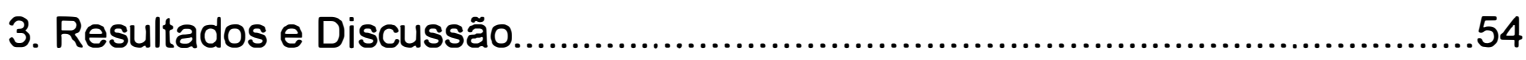

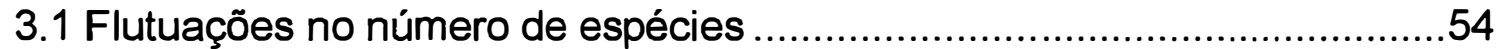

3.2 Alterações na composição florística.....................................................6

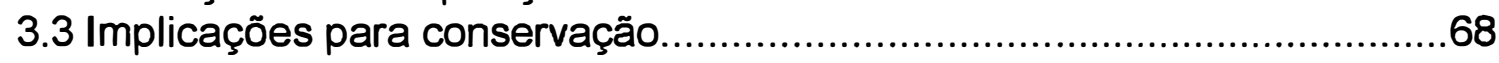

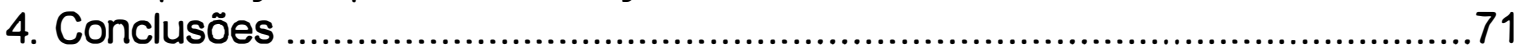

\section{CAPITULO V: CONSIDERAÇÕES FINAIS}

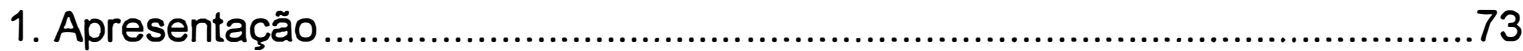

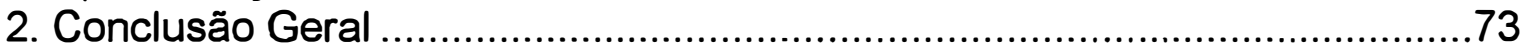

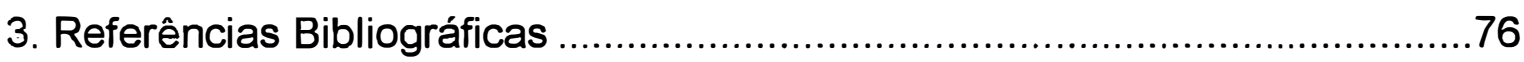




\section{LISTA DE FIGURAS}

Página

Figura 01: Localização da Reserva Florestal de Linhares (ES). As letras no mapa indicam as 5 parcelas experimentais (fonte: Batista, 1994).

Figura 02: Flutuação da Densidade ( $\mathrm{n} / \mathrm{ha}$ ) na Floresta Atlântica em Linhares (ES) ao Longo do Período de Estudo.

Figura 03: Porcentagem de Mortalidade de Árvores nas Classes de Tamanho ao Longo do Período.

Figura 04: Distribuição da precipitação em 1987 e a média dos últimos 21 anos (RFL: 1975 a 1995).

Figura 05: Distribuição da precipitação nos dois anos de inverno mais seco de 1975 a 1995 (RFL: maio a agosto).

Figura 06: Flutuações Temporais no Número de Espécies Arbóreas (nesp) por Grupo Ecológico e para a Área Total na Floresta Atlântica em Linhares (ES).

Figura 07: Representação esquemática do potencial florístico para cada grupo ecológico e para o total de espécies arbóreas amostradas no estudo. A linha cheia indica o numero de espécies potenciais (considerando-se apenas as espécies amostradas ao longo do período) e os pontos indicam o numero de espécies amostradas em cada ano. 


\section{LISTA DE TABELAS}

Tabela 1: Variações na densidade (D) de árvores por grupo ecológico e para o total da comunidade no período de 1980 a 1995 na RFL.

Tabela 2: Características dos grupos ecológicos em relação à mortalidade e recrutamento de árvores no periodo de 1980 a 1995 na RFL. A mortalidade é apresentada em valores absolutos e por halano. Foram contadas as árvores recrutadas e sobreviventes (Nrecrut.sobrev.) e as árvores recrutadas que morreram (Nrecrut.mortas).

Tabela 3: Mortalidade e recrutamento de árvores ao longo do tempo em cada uma das unidades de amostra.

Tabela 4: Mortalidade absoluta nas classes de tamanho de árvores, ao longo do período (número entre parenteses refere-se à porcentagem de mortas em relação às árvores vivas na classe no levantamento anterior).

Tabela 5: $\quad$ Número de espécies $(\mathrm{S})$ e indivíduos $(\mathrm{N})$ em relação ao levantamento de 1980, mortalidade total (MT95) e recrutamento total (RT95) no período, para as classes de abundância das espécies presentes em 1980.

Tabela 6: Número de espécies por grupo ecológico de 1980 a 1995 em 5 parcelas permanentes de 0,5 ha na RFL.

Tabela 7: Variações temporais do número de espécies em cada grupo ecológico e para o total da floresta (os resultados referem-se à média de 5 parcelas em cada levantamento). 
Tabela 8: Variações espaciais do número de espécies em cada grupo ecológico e para o total da floresta (os resultados referem-se à média de 6 levantamentos em cada parcela).

Tabela 9: Espécies que desapareceram de 1980 a 1995 nas 5 parcelas de monitoramento e suas abundâncias (número de indivíduos) numa amostra de 40 ha não contínuos de floresta 


\title{
DINÂMICA DA FLORESTA ATLÂNTICA EM LINHARES (ES)
}

(1980-1995)

\author{
Autor: SAMIR GONÇALVES ROLIM \\ Orientador: Prof. Dr. HILTON THADEU Z. DO COUTO
}

\section{RESUMO}

Esse Trabalho analisa o comportamento dos indivíduos arbóreos com DAP $\geq 10 \mathrm{~cm}$ ao longo de 15 anos na Floresta Atlântica em Linhares (ES). $O$ estudo se deu sobre 5 parcelas de $50 \times 100 \mathrm{~m}$ que fazem parte do projeto de manejo florestal da Reserva Florestal de Linhares, denominado " RFL 001/80 ", que foi instalado em 1980 e é medido periodicamente de 3 em 3 anos. As análise se deram basicamente sobre a mortalidade e recrutamento de novos indivíduos no período.

O principal componente das variações temporais, detectado neste estudo, foi uma seca mais intensa e prolongada, que durou aproximadamente 4 meses no ano de 1987. Assim, foram apresentadas hipóteses para se verificar as influências das variações temporais sobre parâmetros estruturais da floresta (densidade de árvores e número de espécies), sendo utilizado para tal um modelo em blocos ao acaso (onde os anos foram considerados como blocos e as parcelas como tratamento). Também foi utilizada a estatística não-paramétrica do qui-quadrado $\left(\chi^{2}\right)$ para as análises de mortalidade e recrutamento.

O distúrbio ocorrido teve uma profunda influência sobre a estrutura da floresta ao longo do período. De 1986 a 1989 (período em que ocorreu o distúrbio) morreram aproximadamente $50 \%$ de todas as árvores que morreram nos 15 anos de monitoramento. Apesar disto a taxa de mortalidade de árvores da Floresta Atlântica em Linhares, em torno de 1,52\% ao ano, está 
dentro do esperado para uma floresta tropical sob condições naturais de distúrbios. Essa taxa foi significativamente maior para o grupo de espécies pioneiras $(3,62 \%)$ em relação às climácicas $(1,26 \%)$, fato que demonstra a maior longevidade deste último grupo de espécies. As árvores de maior porte (DAP $\geq 90 \mathrm{~cm}$ ) foram mais sensiveis ao distúrbio que as árvores de menor porte $(10 \leq \mathrm{DAP}<50 \mathrm{~cm})$.

Nem mortalidade, nem recrutamento ocorreram uniformemente no espaço, mas as taxas de mortalidade foram plenamente balanceadas pelas taxas de recrutamento, indicando um equilibrio estrutural da floresta no período.

As espécies de maior densidade na floresta são mais adaptadas às condições de distúrbios e ao mesmo tempo em que perdem mais indivíduos também recrutam mais, tendendo a manter suas abundâncias.

Apesar deste equilíbrio na estrutura da floresta e nas populações de espécies mais comuns, foi constatada uma sensivel modificação na composição florística no período, podendo-se concluir que ela não é estática, havendo uma intensa movimentação das espécies, pelo menos num nivel local.

Estas flutuações observadas na estrutura da floresta indicam a necessidade de grandes áreas para a conservação "in situ", que sejam capazes de absorver as mudanças sem prejudicar as estruturas genéticas e demográficas das populações. 


\title{
DYNAMIC OF ATLANTIC FOREST AT LINHARES (ES)
}

(1980-1995)

\author{
Author: SAMIR GONÇALVES ROLIM \\ Adviser: Dr. HILTON THADEU Z. DO COUTO
}

\section{SUMMARY}

The behavior of trees of $\mathrm{DBH} \geq 10 \mathrm{~cm}$ during 15 years in 5 permanent plots of 0,5 ha $(50 \times 100 \mathrm{~m})$ in the Atlantic Forest (Linhares - ES) was studied in terms of mortality and recruitment of news individuals.

The main component of the variations detected was a prolonged drought period (may to august of 1987). Thus, some hypotheses were of temporal variations on the forest structural parameters (tree density and number of species) were tested.

$50 \%$ of trees that died during the total period (1980 to 1995), died during the disturbance period (1986 to 1989). The estimated annual mortality rate $(1,52 \%)$ is similar to other tropical forest ( 1 to $2 \%$ ), but this rate was significantly different among ecological groups: pioneer $(3,62 \%) \geq$ climax $(1,26 \%)$. Larger trees $(\mathrm{DBH} \geq 90 \mathrm{~cm})$ showed a significantly higher mortality than the others ones $(10 \mathrm{~cm}<D B H \leq 50 \mathrm{~cm})$. Neither mortality nor recruitment were evenly distributed on space, but mortality was completely balanced by recruitment, indicating a structural equilibrium of the forest during this period.

Species with a higher density in the forest are more adapted to disturbance conditions, while they lose more individuals, they either recruit more, tending to maintain their abundance.

Although forest structure and common species population are stable it was verified a sensible change in the florist composition in the period, showing that florist composition is no static. 
This changes observed in the forest showed that are necessary the larger reserves for conservation "in situ", that to be able to absorb the changes without prejudice the genetic and demography structure of populations. 


\title{
CAPÍTULO I
}

\section{INTRODUÇÃO GERAL}

\author{
"Crianças, vocês vivem em um deserto, \\ vamos Ihes contar a historia de \\ como vocês foram deserdadas."
} Warren Dean (1996) sobre a Mata Atlântica

\subsection{Introdução}

A Mata Atlântica e seus ecossistemas associados abrangeram até o início deste século 16 estados brasileiros, cobrindo uma área de aproximadamente $1.100 .000 \mathrm{Km}^{2}$, equivalentes a $12 \%$ do território nacional. O processo de ocupação do Brasil promoveu intensa degradação deste conjunto de ecossistemas, levando a uma redução da cobertura florestal para índices inferiores a $10 \%$ de sua área original (Fundação SOS Mata Atlântica \& INPE, 1993).

Grande parte dos problemas de degradação ambiental, no Brasil, relaciona-se com a ausência de uma cultura de ocupação dos espaços intertropicais, respeitando as características dos diversos ecossistemas, notadamente sua riqueza e diversidade. A deterioração ambiental teve sempre o impulso de empreendimentos econômicos que não consideraram as alterações do meio em seus custos (Mantovani, 1993).

Viana (1995) remonta estes aspectos à colonização européia. O processo de fragmentação na Mata Atlântica brasileira é subproduto de um processo lógico de uso de recursos naturais por fazendeiros e comunidades locais. A percepção dos antigos colonos europeus era de que os recursos florestais estavam ali para serem explorados, sem perspectiva de longo prazo. O manejo florestal a longo prazo não era viável nem atraente 
como uma opção de uso da terra. Os colonizadores europeus da América Latina não tinham tradição de manejo florestal. Ao contrário, eles tinham uma tradição agrícola. Portanto, as florestas estavam condenadas a serem substituídas pelo último paradigma do desenvolvimento rural: as monoculturas agrícolas.

Segundo Graziano Neto (1985), as condições da época foram propícias ao extrativismo e essa foi a primeira atividade pensada pela Coroa Portuguesa. O ouro não apareceu de imediato - o que decerto causou decepções. A única riqueza descoberta encontrava-se verdejante ao longo da costa brasileira: o pau-brasil (Caesalpinia echinata), madeira da qual se extraía uma matéria corante empregada na tinturaria. Até meados do século XVI , a exploração do pau-brasil, sob monopólio da Coroa Portuguesa, mas com interferência dos franceses, foi a primeira atividade econômica em nosso país.

Essa foi também a primeira extração em grande escala na região Neotropical, levando à degradação das populações naturais e ao colapso da atividade extrativa iniciando um processo de devastação da floresta litorânea (Viana, 1995). Somente nos primeiros 100 anos de colonização portuguesa estima-se em aproximadamente 2.000 .000 de árvores de pau-brasil que deram entrada oficialmente na Europa e provavelmente o mesmo tanto se perdeu em naufrágios e contrabandos (Dean, 1996). Todo esse modelo de degradação se intensificou a partir da divisão do território nas chamadas capitanias hereditárias (revisão em: Prado Júnior, 1973, Graziano Neto, 1985, Dean, 1996). Esse padrão de exploração se repetiu inúmeras vezes com espécies como jacarandá (Dalbergia nigra), pinheiro-do-paraná (Araucaria angustifolia), cedro (Cedrela odorata), peroba (Aspidosperma polyneuron) e palmito (Euterpe edulis) (Viana, 1995).

Para se ter uma possível idéia do que ocorreu neste ecossistema basta olharmos para o processo de ocupação desordenada que vem ocorrendo na Amazônia desde a década de 70 (Almeida, 1996). Entretanto 
nesta região, segundo Lobato (1988), um zoneamento do uso do solo ainda pode nortear a adoção de políticas ocupacionais. Mas para a Floresta Atlântica a situação é alarmante (Fundação SOS Mata Atlântica \& INPE, 1993), estando quase que inteiramente dizimada nos Estados nordestinos e restrita às áreas íngremes na Serra do Mar, de São Paulo ao Paraná (Leitão Filho, 1993).

A importância das florestas no desenvolvimento dos países tropicais e de terceiro mundo vai muito além do valor econômico de seus recursos madeireiros. São nestas regiões que se encontram os centros de extrema diversidade genética - os chamados Centros de Vavilov - cuja destruição pode causar impacto direto sobre a viabilidade de futuros recursos alimentícios (Mooney, 1987). A "Carta da Terra dos Campos de Piratininga" elaborada pelo plenário do $2^{\circ}$ Congresso Nacional Sobre Essências Nativas em 1992, chama a atenção para o fato do setor químico-farmacêutico do primeiro mundo movimentar US\$200 bilhões/ano com medicamentos oriundos de plantas de origem tropical. Ou seja, o pool genético existente nas florestas é de inestimável valor, seja para melhoramento genético ou para a utilização dos compostos secundários das plantas.

Quanto ao manejo florestal, ainda existe uma dicotomia do ponto de vista técnico, entre os próprios pesquisadores, sobre os sistemas de manejo a serem adotados para as florestas tropicais (Gomez-Pompa \& Burley, 1990; Yared \& Souza, 1993; Reis et al., 1993). Em linhas gerais essa dicotomia vem da ausência de conhecimento sobre qual é o nível de intervenção suportado por uma floresta sob manejo. Os principais grupos de pesquisa, entretanto, admitem que exploração e conservação dos recursos florestais não são incompativeis. As florestas tropicais estão plenamente adaptadas às condições de distúrbios e, como colocam Roberts \& Gilliam (1995), as atividades de manejo nada mais são que distúrbios aplicados sob diferentes formas e intensidades. Obviamente que não há uma fórmula única a ser 
aplicada em toda região tropical e cada situação deve ser analisada de acordo com suas reais necessidades.

A discussão em torno da sustentabilidade das florestas tropicais é de extrema importância para a aplicação de técnicas de manejo. Entretanto não podemos mais adiar a união de esforços em todos os níveis, tanto a nível político como de pesquisa, para implementarmos técnicas de manejo à luz do atual conhecimento ecológico. Yared \& Souza (1993) enfatizam que um bom plano de manejo deve ser flexível o bastante para permitir ajustes posteriores na sua estratégia de ação, de modo que alterações possam ser incorporadas ao longo da rotação ou nos sucessivos ciclos de corte. Para Jesus et al. (1992) os critérios técnicos (econômicos, ecológicos e sociais) só podem ser obtidos com a prática de manejo.

Essa urgência na união de esforços pode ser melhor constatada pela recente compilação e sumarização feita pela Fundação SOS Mata Atlântica \& INPE (1993) mostrando que a cobertura florestal vem diminuindo progressivamente em todos os Estados analisados até $O$ ano de 1990: Bahia, Espirito Santo, Minas Gerais, Goiás, Rio de Janeiro, São Paulo, Mato Grosso do Sul, Paraná, Santa Catarina e Rio Grande do Sul.

Diversos trabalhos sobre manejo florestal foram conduzidos recentemente no Brasil visando não somente mudar este quadro como também criar, a partir da informação, um corpo técnico atuante na área (por exemplo: Higuchi, 1987; Yared, 1988; Silva, 1989; Souza, 1989; Higuchi \& Vieira, 1990; Higuchi, 1991; Garcia, 1991; Jesus et al., 1992; Carvalho, 1992; Uhl et al., 1992; Yared \& Souza, 1993; Lopes, 1993; Silva, 1993; Souza \& Jardim, 1993; Reis et al., 1993; Batista, 1994; Jardim, 1995; Jesus \& Souza, 1995; Higuchi, 1995; Barreto et al., 1997).

Alguns destes trabalhos são baseados no uso de parcelas permanentes para se avaliar a regeneração da floresta após uma determinada intervenção silvicultural. Entretanto também há uma outra linha de pesquisa 
baseada em parcelas permanentes, que procura estudar a dinâmica florestal em condições naturais de distúrbios ou sob intenso efeito da fragmentação (Rankin-de-Merona et al. 1990; Jardim, 1990; Felfili, 1995; Santos et al., não publicado; Nascimento, 1997). O valor das informações obtidas a partir destes estudos é praticamente inestimável, pois delas podem resultar métodos e técnicas de manejo florestal que conduzam ao uso sustentável dos recursos florestais.

\subsection{Objetivos Gerais}

No período abrangido por este estudo ocorreu um distúrbio caracterizado como de alta intensidade na floresta atlântica em Linhares (ES): uma seca mais prolongada durou aproximadamente 4 meses. Nesse sentido o trabalho analisou as mudanças na estrutura da floresta sob a ótica deste distúrbio. As hipóteses específicas são detalhadas nos devidos capítulos.

\subsection{Organização da Dissertação}

Este trabalho foi desenvolvido em cinco capítulos. No presente capítulo foi apresentada uma introdução geral da dissertação, os objetivos gerais e a seguir serão feitas algumas considerações sobre a área de estudo - a Reserva Florestal de Linhares (ES)/RFL - e sobre o experimento de manejo florestal, de onde foram coletados os dados para este trabalho.

No Capítulo II é feita uma revisão sobre a dinâmica das florestas tropicais, enfatizando o papel dos distúrbios como fonte de geração e manutenção da diversidade de espécies.

No Capítulo III são apresentados os dados de mortalidade e recrutamento de árvores ao longo de 15 anos de monitoramento na RFL.

No Capítulo IV há uma ênfase nas alterações que ocorreram na composição florística ao longo deste período.

E finalmente no Capítulo $V$ há uma análise geral de todo o trabalho. 


\section{4 Área de Estudo}

\subsubsection{Localização}

O estudo foi desenvolvido na Reserva Florestal de Linhares (RFL), que se distribui sobre quase 22.000 ha entre os municípios de Linhares e Jaguaré, ao norte do Estado do Espírito Santo, distando do centro urbano do primeiro $30 \mathrm{Km}$ e do segundo $39 \mathrm{Km}$. Geograficamente situa-se entre os paralelos $19^{\circ} 06^{\prime}-19^{\circ} 18^{\prime}$ de latitude sul e entre os meridianos $39^{\circ} 45^{\prime}-40^{\circ} 19^{\prime}$ de longitude W Gr. (Jesus, 1987). O acesso principal se dá pela estrada BR101 norte, na altura do $\mathrm{Km} \mathrm{122,} \mathrm{no} \mathrm{trecho} \mathrm{que} \mathrm{interliga} \mathrm{aqueles} \mathrm{dois}$ municípios. A Figura 1 mostra a localização da RFL.

\subsubsection{Geomorfologia e Solos}

Suguio et al. (1982), citado por Jesus et al. (1992), divide a área da RFL em duas províncias geomorfológicas: a Planície dos Tabuleiros e a Planície Costeira. A Planície dos Tabuleiros predomina na RFL e ocorre sobre sedimentos da Formação Barreira, de origem Terciária, caracterizandose por interflúvios tabulares com declividade para o mar da ordem de 1,2 $\mathrm{m} / \mathrm{Km}$. Já a Planície Costeira ocorre sobre sedimentos litorâneos arenosos e depósitos areno-argilosos fluviais, de origem Quaternária.

Segundo Jesus et al. (1992), os solos da RFL já foram genericamente descritos por Heinsdijk (1965), Brasil (1970), Embrapa (1976) e Ferreira (1981). Os autores citam estudos mais recentes enfocando maiores detalhes como os realizados por Gallip et al. (1990), Correia et al. (1991), Garay et al. (1991) e Garay \& Jesus (1992). Em geral, para a área experimental os solos são "Podzólicos Vermelho-Amarelo, distróficos, com horizonte B textural de atividade baixa (não hidromórfico) e horizonte $A$ moderado com textura variável de argilosa a areno-argilosa. $O$ relevo é suavemente ondulado formando os chamados platôs litorâneos, com uma altitude que varia de 28 a $65 \mathrm{~m}$. 


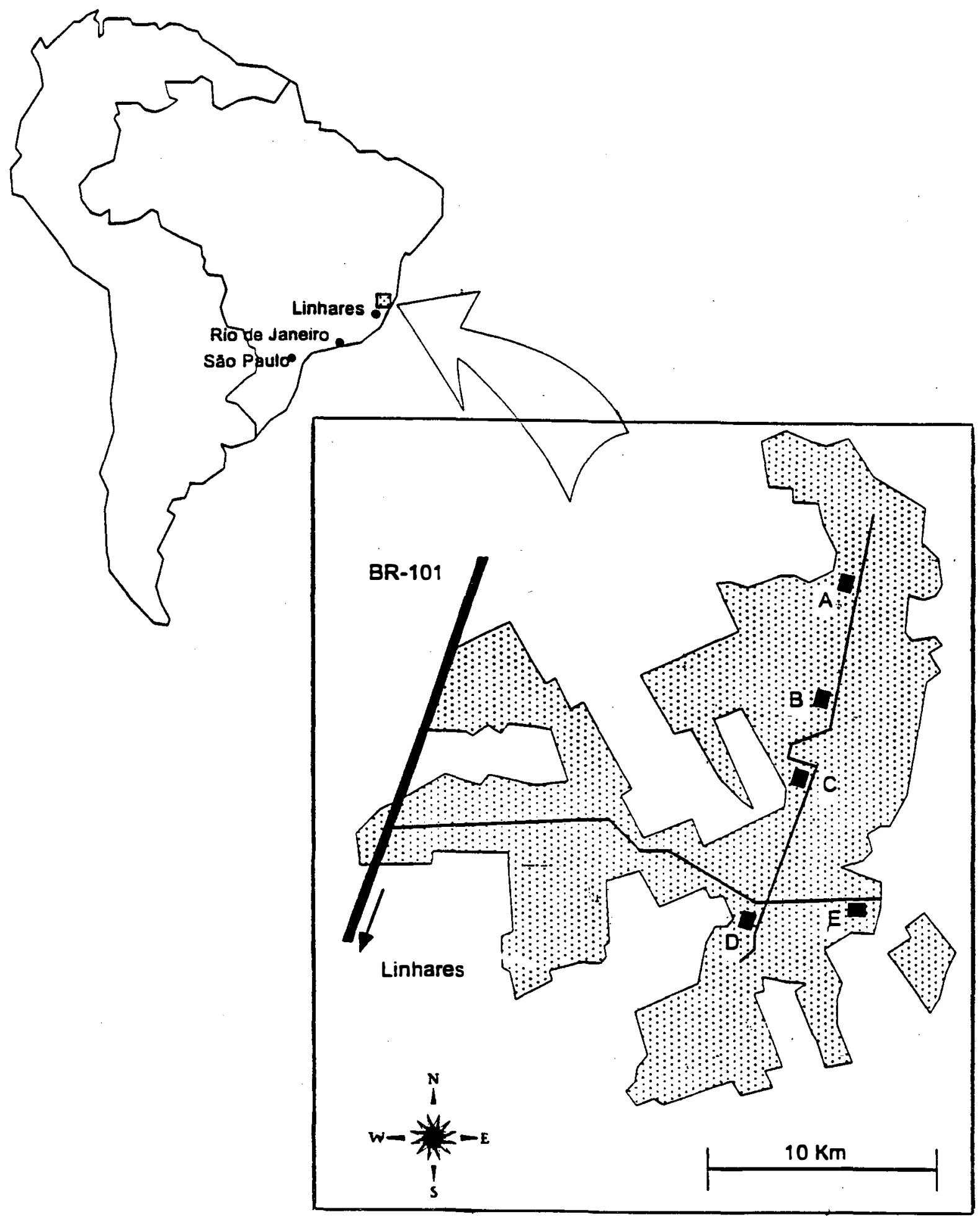

Figura 01: Localização da Reserva Florestal de Linhares (ES). As letras no mapa indicam as 5 parcelas experimentais (fonte: Batista, 1994). 


\subsubsection{Clima}

O clima do local é do tipo AWi (tropical úmido), com estação chuvosa no verão e seca no inverno. A análise climatológica foi obtida por Jesus et al. (1992) a partir dos dados coletados na Estação Meteorológica da RFL, no período de 1975 a 1990. Os excedentes hídricos são bastante reduzidos, ao redor de $47 \mathrm{~mm}$, e a deficiência distribui-se de janeiro a setembro, com $66 \mathrm{~mm}$. A precipitação pluviométrica média anual foi estimada em 1230,7 mm (816,6 a 1638,8 mm), temperatura média de $23{ }^{\circ} \mathrm{C}(8,3$ a 39,8 ${ }^{\circ} \mathrm{C}$ ) e umidade relativa do ar de $83,5 \%$ (81 a $85,5 \%$ ). O balanço hídrico de Thornthwaite indica um clima do tipo Subúmido Tropical, típico da faixa litorânea, que se estende do Sul da Bahia até o Rio Benevente ao Sul do Espirito Santo.

\subsubsection{Vegetação}

Leitão Filho et al. (1993) colocam que embora represente o maior e mais diversificado ecossistema florestal remanescente do Sudeste do Brasil, a Floresta Atlântica ainda é muito pouco conhecida sob o ponto de vista florístico. Uma análise de ordenação de 64 estudos sobre a composição florística da Floresta Atlântica realizada por Siqueira (1994) permitiu separar o Ecossistema em dois blocos distintos de vegetação: um presente no Nordeste e outro na Região Sudeste/Sul, com o Estado do Espirito Santo abrigando uma flora intermediária entre os dois blocos. Distingue ainda dentro dos dois blocos mais oito: três no Nordeste e cinco no Sudeste/Sul, sendo que a separação é mais nítida no Nordeste.

A vegetação da região já foi motivo de classificação por diversos autores. Para Rizzini (1963) a região está inserida na "Província Atlântica, subprovíncia Austro-Oriental do Litoral".

Segundo Heinsdijk et al. (1965) a tipologia da região é classificada como sendo do tipo "Floresta Tropical Pluvial", a qual Ferreira (1981) chamou de "Floresta Tropical Pluvial Atlântica" (Jesus et al., 1992). 
Essas classificações correspondem, no recente Sistema Fitogeográfico Brasileiro - SFB - (Veloso \& Góes-Filho, 1982;IBGE, 1992), à "Floresta Ombrófila Densa". Jordy (1987) a diferencia de outras florestas litorâneas classificando-a como "Floresta Ombrófila Hileiana".

O SFB apresenta as subdivisões desta classificação, inserindo a tipologia da região na "Floresta Ombrófila Densa de Terras Baixas" ou na "Floresta Estacional Semi-decidual de Terras Baixas". Essa classificação é a mais correta, estando de acordo com estudos recentes na Reserva (R.M. de Jesus, comunicação pessoal) que levam em conta as curvas de precipitação e as fenofases das espécies florestais ocorrentes.

A Reserva possui aproximadamente $95 \%$ de sua área total coberta com vegetação, sendo $63 \%$ classificada vulgarmente como "Floresta Densa de cobertura uniforme sem interferência", $5 \%$ de "Floresta Densa de cobertura uniforme com interferência", 7,9\% de Mussununga, 7,6\% de Brejo, $6 \%$ de Nativo, $4 \%$ de Floresta de Várzea e 1,2\% de Capoeira.

\subsubsection{Classificação Sucessional das Espécies}

As espécies arbóreas foram classificadas na RFL baseandose nas categorias sucessionais apresentadas abaixo, que longe de serem definitivas são reconhecidamente uma abstração de um contínuo existente entre as espécies arbóreas:

a) Pioneiras: espécies intolerantes, colonizadoras de grandes clareiras, formando banco de sementes no solo, crescimento muito rápido, ciclo de vida curto e madeira caracteristicamente muito leve;

b) Secundárias iniciais: muito semelhantes às espécies do primeiro grupo, entretanto não formam banco de sementes no solo e apresentam um ciclo de vida um pouco mais longo. Constituem um grupo bastante heterogêneo;

c) Secundárias Tardias: as características do ciclo de vida começam a se tornar bem diferenciadas neste grupo, em relação aos 
anteriores com crescimento mais lento, ciclo de vida mais longo, madeira dura, sementes amplamente dispersas pelo vento e tolerantes;

d) Climácicas: constituem praticamente um extremo em relação ao primeiro grupo com madeira dura e de alta densidade, crescimento muito lento, ciclo de vida muito longo, tolerantes à sombra e apresentando grandes sementes, geralmente dispersas por grandes animais.

\subsubsection{Obtenção dos Dados}

No ano de 1980 foi instalado na RFL um ensaio de manejo florestal, que vem sendo monitorado, desde então, em intervalos de 3 em 3 anos $(1980,1983,1986,1989,1992,1995)$. O ensaio foi instalado em blocos ao acaso, com 9 tratamentos e 5 repetições, onde cada parcela mede $50 \times 100$ m (0,5 ha). Uma descrição completa deste ensaio e dos tratamentos que foram aplicados pode ser encontrada em Jesus et al. (1992) e Batista (1994).

Para atender os objetivos deste estudo foi selecionado o tratamento 1 do ensaio onde não foi aplicada nenhuma forma de intervenção (testemunha), resultando em 5 parcelas, cada uma distribuída numa área de floresta densa de cobertura uniforme, sem interferência. Todas as parcelas foram alocadas paralelamente a uma estrada de acesso, distando $75 \mathrm{~m}$ da estrada, visando diminuir o efeito de borda (Jesus et al., 1992). A Figura 1 mostra a localização das parcelas na RFL.

No ano de 1980, em cada parcela, foram amostradas todas as árvores com diâmetro à altura do peito (DAP) maior ou igual a $10 \mathrm{~cm}$. Cada árvore foi etiquetada, recebeu uma numeração e teve medido o seu DAP. Nas medições sucessivas cada árvore que atingia ou ultrapassava o limite mínimo de DAP era etiquetada, recebendo uma numeração seqüencial.

O termo recrutamento foi utilizado como sinônimo de ingresso, ou seja, define a passagem dos indivíduos abaixo de $10 \mathrm{~cm}$ de DAP para a classe acima (DAP $\geq 10 \mathrm{~cm})$. 
A coleta de material botânico, sua herborização e identificação taxonômica se deu ao longo de todo o período de monitoramento, já que muitas espécies novas foram recrutadas no período e também devido à necessidade de se obter material botânico fértil. Os materiais foram enviados a especialistas nacionais e estrangeiros (Jesus et al., 1992). 


\title{
CAPÍTULO II
}

\section{REVISÃO DE LITERATURA: DINÂMICA DE FLORESTAS TROPICAIS}

\author{
E como não se sentirá o homem pequeno \\ diante desta gigantesca majestade esmagadora? \\ E como se furtará ele de ser orgulhoso quando \\ se lembrar que basta um aceno de sua mão \\ para destruir toda a obra de uma quase etemidade? \\ Alberto Loefgren (In: Dean, 1996)
}

\subsection{As Florestas Manejadas}

A fragilidade de florestas tropicais tem sido muito enfatizada, tendo havido pouca ênfase com relação à sua capacidade de resiliência. Estudos recentes conduzidos por A. Gomez-Pompa e colaboradores suportam a hipótese de que florestas, que acreditamos serem primárias, são de fato um produto de distúrbios e manejo pelas antigas populações Maias (Lugo, 1995).

Diegues (1994) cita uma série de estudos, como os de A. Gomez-Pompa $(1971,1972)$ e mais recentemente os de Balée $(1988,1992)$ que afirmam que a manutenção, e mesmo aumento da diversidade biológica nas florestas tropicais, está relacionada intimamente com as práticas tradicionais da agricultura itinerante dos povos primitivos. Espécies dominantes nas florestas mexicanas são na verdade espécies úteis que o homem do passado protegeu e que sua abundância atual está relacionada a esse fato. $O$ mesmo pode ter ocorrido com o mogno na Amazônia (O'Brien \& O'Brien, 1995).

Evidências paleoecológicas foram colocadas por Sanford et. al. (1985) para mostrar que populações indígenas, na Bacia Amazônica, se utilizavam de queimadas para o manejo da floresta desde pelo menos mil anos atrás. 
Hubbell \& Foster (1990a) citam que os estudos paleoecológicos conduzidos por Piperno (1989) em Barro Colorado, Panamá, também demostram o manejo da floresta por populações pré-colombianas, através de pequenas aberturas de $1000 \mathrm{~m}^{2}$. A última destas aberturas, datadas por radiocarbono, atingiu 550 anos atrás.

Neves (1996) coloca que os índios da Amazônia exercem, por meio do manejo dos recursos naturais, uma ação transformadora no ambiente em que vivem, recriando continuamente a floresta. Os trabalhos de Anna Roosevelt e colaboradores na caverna da Pedra Pintada, município de Monte Alegre (PA), indicam que essa ação transformadora remonta a milhares de anos antes do presente, deixando claro que a floresta é, além de um patrimônio ecológico, um patrimônio histórico resultante da ação humana ao longo de milhares de anos.

Onde quer que tenha havido uma análise detalhada nos trópicos, a vegetação encontrada é um produto de distúrbios passados, sejam antrópicos ou causados por eventos naturais, como fogo, furacões, tempestades, inundações, erupções ou causas bióticas (Lugo, 1995).

\subsection{Equilíbrio Vs. Não-Equilíbrio de Florestas Tropicais}

A manutenção da alta diversidade de espécies em florestas tropicais tem sido colocada sob duas óticas: a do equilíbrio e a do nãoequilibrio das florestas. Essa discussão, em torno das condições sob as quais as florestas tropicais estão organizadas, remonta ao início do século.

Elton (1927), apoiado pela idéia tradicional de comunidade clímax (sensu Clements, 1916), enfatizou o papel das interações interespecíficas (por exemplo: predação e competição) como determinantes da estrutura de comunidades. Estas interações permitiriam às espécies manter suas abundâncias estáveis ao longo do tempo. Num ambiente relativamente constante a composição de espécies da comunidade retornaria ao original após um distúrbio. É o que se chamou de teoria do equilíbrio. 
Contemporaneamente, Gleason (1926) defendia os processos ambientais como determinantes da estrutura da comunidade. A presença ou ausência de um dado grupo taxonômico seria o resultado de processos aleatórios de colonização e da variabilidade ambiental, culminando na chamada teoria do não-equilíbrio (Reice, 1994).

Mais recentemente estas duas teorias tiveram seus refinamentos (revisão em Connell, 1978; Reice, 1994; Roberts \& Gilliam, 1995). Primack (1990) cita que a hipótese do equilíbrio prevê que as espécies podem coexistir na floresta tropical porque cada espécie tem uma especialização num nicho, no qual ela é competitivamente superior a outras espécies. Essa coexistência também pode ocorrer devido a mortalidade dependente da densidade (causada por predadores, herbívoros e patógenos) que limitam o tamanho da população de espécies arbóreas, impedindo que se tornem comuns. Roberts \& Gilliam (1995) colocam que em linhas gerais, no modelo de equilíbrio, após um distúrbio, a composição de espécies retornaria ao estado original e a máxima diversidade seria mantida neste nível indefinidamente ou até a ocorrência de um novo distúrbio.

Em contraste, os modelos de não-equilíbrio impõem que mortalidades aleatórias (ou catastróficas), causadas por distúrbios, impeçam as comunidades naturais de alcançar o equilíbrio. Estes distúrbios impediriam competidores superiores de tornarem-se dominantes (Roberts \& Gilliam, 1995). A composição florística e abundância das espécies são então determinadas, em parte, por fatores aleatórios, como por exemplo: quais seriam as sementes viáveis quando da ocorrência de uma abertura no dossel da floresta. Essa hipótese prediz que haveria uma troca de espécies na floresta, com algumas espécies sendo extintas e outras se estabelecendo (Primack,1990).

Connell (1978) discute três hipóteses para cada uma das situações: a hipótese da diversificação de nichos, a hipótese das redes circulares e a hipótese da mortalidade compensatória se adequam ao modelo 
de equilíbrio das florestas tropicais. A hipótese de distúrbios intermediários, a hipótese da igualdade de oportunidades e a hipótese das mudanças graduais se adequam ao modelo de não-equilíbrio das florestas tropicais. Huston (1979) propôs alternativamente a hipótese do equilíbrio dinâmico, que para Connell (1978) nada mais é que uma extensão da hipótese de distúrbios intermediários. Neste modelo os fatores controladores da diversidade são as reduções periódicas nas populações e as flutuações ambientais em função, principalmente, da periodicidade de distúrbios. Chesson \& Warner (1981) apresentam o modelo de loterias fornecendo um exemplo de coexistência de espécies fora de um equilíbrio estável.

Petraitis et al. (1989) também apresentam um modelo no qual incluem elementos dos modelos de equilíbrio e de não-equilíbrio, sendo a diversidade regulada por taxas de imigração e extinção de espécies. As probabilidades de imigração e extinção são função do número de espécies, como previsto na teoria da biogeografia de ilhas. Estas taxas também são dependentes das características entre e dentro de mosaicos, como microclima e disponibilidade de recursos (Roberts \& Gilliam, 1995).

O grupo de trabalho conduzido por S. P. Hubbell (Hubbell \& Foster, 1990b) em Barro Colorado, Panamá, numa parcela de 50 ha, tem encontrado evidências para ambos os modelos, havendo uma complexa mistura de forças entre eles, o que segundo Primack (1990) desafia uma simples explanação, havendo necessidade de muitos anos de estudos e análises.

Connell (1978) já reconhecia que as teorias não são mutuamente exclusivas, apresentando vários trabalhos nos quais uma ou outra se apresenta de maneira mais clara. Para Swaine (1989) as conclusões que se podem tirar de um curto período de estudo são muito limitadas e a questão de a floresta estar ou não em equilíbrio numa escala local não pode ser propriamente respondida. Shugart (1987) coloca que em ecossistemas que são 
dominados por organismos sésseis a dinâmica temporal, numa escala de organismos individuais, é, por necessidade, uma dinâmica não equilibrada.

Para Primack (1990) este debate acadêmico sobre os modelos de equilíbrio e não-equilíbrio tem uma significância prática na conservação e manejo de florestas. Num modelo de não-equilíbrio, em áreas de conservação isoladas, sem fontes externas de sementes muitas espécies raras seriam eliminadas permanentemente, resultando num empobrecimento gradual da floresta. Fica então a questão: qual seria a área mínima de floresta necessária para viabilizar as populações de espécies arbóreas?

Roberts \& Gilliam (1995) numa ampla revisão sobre o assunto concluem que ainda que estes modelos sejam úteis na organização de nossas idéias sobre a diversidade, eles tem limitada aplicação para o manejo de florestas tropicais devido à sua generalidade. Entretanto destacam, e concluem como diversos autores, que os distúrbios são um fator chave para a manutenção da diversidade de espécies e de extrema importância para o manejo florestal, já que as atividades de manejo nada mais são que distúrbios aplicados sob diferentes formas e intensidades.

\subsection{A Renovação das Florestas}

Os distúrbios naturais provocados pela queda de galhos, de uma ou poucas árvores rompem com a estrutura do dossel da floresta produzindo as chamadas "clareiras". Para Uhl et al. (1988) o fenômeno da formação de clareiras é o principal agente de distúrbio natural nos trópicos.

A importância dos distúrbios na ecologia de florestas tropicais têm sido colocada por muitos autores nos últimos anos, sendo reconhecidos como a força organizadora das comunidades, contribuindo com a manutenção da alta diversidade de espécies e determinando a composição e estrutura da floresta (por exemplo: Miller, 1982; Bazzaz, 1983; Souza, 1984; Brokaw, 1985a e 1985b; Martínez-Ramos, 1985; White \& Pickett, 1985; 
Denslow, 1987; Platt \& Strong, 1989; Vandermeer et. al., 1990; Primack, 1992 e Lugo, 1995).

Diferentes distúrbios removem diferentes espécies, em diferentes graus, entretanto o distúrbio por si só não determina a diversidade, ele cria oportunidades para a colonização de espaços vagos por novas espécies (Reice, 1994). Denslow (1980) coloca que a floresta pode ser considerada como um mosaico de distúrbios com diferentes características ambientais. A idéia de mosaico florestal já é bastante antiga, sendo desenvolvida por Aubrèville (1938) nas florestas africanas.

A partir de meados da década de 70 este tema ganhou especial atenção para pesquisa em florestas tropicais, destacando os trabalhos de Strong (1977), Hartshorn (1978, 1980), Withmore (1978), Oldeman (1978), Hallé et al. (1978), Denslow (1980), Uhl \& Murphy (1981), Brokaw (1982a, 1982b) e Orians (1982).

Em todas as florestas há um ciclo iniciado por um distúrbio (Withmore, 1989). Este e outros autores como Watt (1947) e Brokaw (1985b) tem procurado definir as fases deste ciclo para proporcionar um melhor entendimento do processo sucessional, mas apesar de bastante didáticas são reconhecidas como abstrações e não entidades separadas no espaço ou no tempo. Trata-se basicamente das fases de abertura, crescimento e fechamento do dossel.

A origem dos distúrbios está ligada às condições climáticas e fisiográficas de cada local (Brokaw, 1985a, 1985b), sendo que de acordo com estas características, em cada local, pode predominar um ou outro agente indutor de clareiras, influenciando inclusive a distribuição e abundância relativa de clareiras com diferentes tamanhos (Martínez-Ramos, 1985).

Como principais agentes físicos da formação de clareiras temos a ocorrência de ventos e precipitações intensas, aliadas à solos rasos e de baixa coesão ou à sobrecarga proporcionada pela ocorrência de umidade e 
epífitas, que podem inclusive multiplicar o efeito da queda de uma árvore pelo entrelaçamento das copas, resultando em quedas múltiplas (Strong, 1977; Brokaw, 1982b, 1985a, 1985b; O'Brien \& O'Brien, 1995). Como agentes biológicos destaca-se a ocorrência de insetos e microorganismos que causam uma abertura mais lenta através de uma desintegração gradual da árvore (Brokaw, 1985a, 1985b) que também pode ocorrer devido à senescência da árvore.

Martínez-Ramos (1985) cita que a freqüência anual da formação de clareiras é praticamente a mesma nas florestas tropicais da América, África e Ásia. A ocorrência de clareiras pequenas, causadas pela queda de galhos e lianas, é muito maior que a ocorrência de clareiras grandes, causadas pela queda de uma ou mais árvores. Entretanto a superfície produzida pelas grandes clareiras é superior à de pequenas clareiras.

As modificações ambientais que ocorrem no local de abertura de uma clareira são muito contrastantes com a área sob o dossel da floresta. Muitos autores discutiram aspectos ligados à luz, umidade relativa, umidade do solo, temperatura, nutrientes microfauna, avifauna; etc., em clareiras de diferentes formas e tamanhos. Denslow (1987) chama a atenção para o fator luz, como o mais imediato e talvez mais importante efeito da abertura de clareiras sobre as plantas.

Lieberman et. al. (1989) colocam que criou-se um paradigma onde há uma dicotomia de clareiras vs. não-clareiras. No desenho de muitos estudos fica implícita a noção de que a não-clareira é um padrão contra o qual as clareiras podem ser avaliadas. Esse conceito, que considera a floresta como um "queijo-suiço", não faz justiça à real complexidade de fatores atuantes no ambiente florestal. De fato as áreas de não-clareiras são tão heterogêneas quanto as clareiras e não devemos simplesmente entender a clareira como um buraco na floresta. Mais importante que o tamanho da clareira é o contínuo nível de luz ou grau de fechamento do dossel, experimentado pelas árvores 
dentro da floresta. Após o processo de abertura temos basicamente três fontes para crescimento e fechamento da clareira: plantas previamente estabelecidas no local (crescimento via rebrota ou não), sementes (via solo ou dispersão) e expansão vegetativa das árvores marginais (Brokaw, 1985b).

Vandermeer et al. (1990) questionam que o processo de regeneração de uma clareira seria dominado pelas espécies pioneiras e que ocorreria uma diminuição drástica na diversidade de espécies depois de um evento catastrófico. Os autores baseiam-se nos resultados encontrados 4 meses após a passagem de um furacão que ocasionou uma clareira de 4000 $\mathrm{m}^{2}$, na costa nicaragüense. $O$ processo de crescimento foi caracterizado pelo crescimento de espécies já existentes, via rebrotação epicórnica ou plântulas. Aproximadamente $97 \%$ das espécies e $77 \%$ dos indivíduos encontrados apresentavam rebrota, de tal maneira que a diversidade de espécies se alterou muito pouco.

\subsection{Mortalidade de Árvores}

Franklin et al. (1987) citam que a morte de uma árvore geralmente é o resultado de uma complexa interação entre múltiplos fatores, podendo ser classificada de diversas maneiras: biótica ou abiótica, alogênica ou autogênica e intrínsica ou extrínsica. Entretanto todas estas classificações falham na descrição das complicadas interações entre árvores, seu ambiente e vários agentes de mortalidade. A morte de uma árvore remove um indivíduo geneticamente distinto da população, mas ela também provê recursos adicionais ao ecossistema como luz, água, nutrientes e energia, disponibilizando-os para outros organismos, num processo que pode permanecer por séculos, dependendo da estrutura da madeira em decomposição.

Árvores mortas, em pé ou caídas, oferecem um grande número de micro-hábitats para pequenos animais. A fauna da madeira em decomposição modifica-se com os vários estágios do apodrecimento de modo 
que ocorre uma sucessão de comunidades animais, cada uma dependente de um tipo peculiar de micro-hábitat, até que a árvore seja inteiramente incorporada à camada de serapilheira no piso florestal (Cloudsley-Thompson, 1980).

As taxas e causas de mortalidade de árvores mostram uma dramática variação com a sucessão (Harcombe, 1987; Peet \& Christensen, 1987). As taxas de mortalidade são extremamente altas na fase de plântula, principalmente em função de calor, luz e aridez, destacando-se também fatores como herbivoria e patógenos. Superando-se esta fase, temos a seguir, como fator de destaque, a competição, que pode ser relativamente mais branda para espécies que atingem rapidamente a maturidade, mas podendo durar 100 a 150 anos num outro extremo. Finalmente, com o inerente declínio no vigor e no crescimento o indivíduo se torna menos hábil para resistir a uma variedade de agentes danificantes, dos quais se destacam ventos, patógenos, senescência, competição e estresse ambiental.

Putz \& Milton (1982), na floresta de Barro Colorado, Panamá, encontraram em 95 árvores mortas após 5 anos de monitoramento os seguintes tipos de mortalidade: $52 \%$ quebradas no tronco, $17 \%$ arrancadas, $14 \%$ em pé, $8 \%$ quebradas ao nível do chão e $9 \%$ com morte desconhecida.

Após 13 anos de monitoramento em 12,4 ha de floresta em La Selva, Costa Rica, Peralta et al. (1987) encontraram entre as 1386 árvores que morreram: $37 \%$ completamente decompostas, $26 \%$ mortas em pé, $31 \%$ tombadas e $7 \%$ suprimidas sob outras árvores ou ramos caídos. As árvores tombadas apresentaram a maior média de DAP $(40,1 \mathrm{~cm})$, em seguida vieram as árvores mortas em pé $(32,0 \mathrm{~cm})$, as decompostas $(22,1 \mathrm{~cm})$ e as suprimidas $(21,2 \mathrm{~cm})$.

Arriaga (1988) encontrou numa floresta mexicana o seguinte padrão de mortalidade: $40,2 \%$ das árvores desenraizadas, $22,2 \%$ com troncos quebrados e $10 \%$ mortas em pé. Prado et al. (1992) analisaram o padrão de 
mortalidade de árvores na Reserva Florestal de Linhares (ES) encontrando o seguinte resultado: $43,7 \%$ arrancadas, $23,5 \%$ quebradas, $17,6 \%$ soterradas (quebradas ou arrancadas que foram soterradas pela queda de outras) e $15,1 \%$ mortas em pé.

\subsection{Distürbios em Florestas Tropicais}

Muito se enfatizou até aqui sobre o papel dos distúrbios em florestas tropicais, mas o que seria propriamente um distúrbio?

Clark (1990) apresenta uma revisão sobre o assunto abordando duas definições:

- Bazzaz (1983) define distúrbio como uma súbita mudança numa unidade da paisagem que é expressa como uma mudança rapidamente detectável pelas respostas das populações.

- Para White \& Pickett (1985) distúrbio é qualquer evento relativamente discreto no tempo que rompe com a estrutura do ecossistema, comunidades ou populações e muda a disponibilidade de recursos e o ambiente físico.

Uma das críticas feita por Clark (1990) em relação à estas definições diz respeito à idéia de distúrbio como uma ruptura no "estado normal" do ecossistema, comunidades ou populações. Desde que muitas espécies dependem de distúrbios para sua existência, a idéia de distúrbio como uma ruptura no estado normal é inapropriada. Segundo o autor uma definição mais apropriada para distúrbios em ecossistemas terrestres seria: "um evento relativamente discreto causando uma mudança na estrutura física do ambiente".

Dentre os componentes que caracterizam um distúrbio destacam-se o tipo, a freqüência, o tamanho e a intensidade. Os termos são essencialmente conceituais, havendo uma extensa lista de sinônimos e definições. Uma revisão pode ser encontrada em Bazzaz (1983), em White \& Pickett (1985), ou em Attiwill (1994): 
- Tipo: os distúrbios naturais mais comumente citados são os furacões, o fogo, a seca, chuvas intensas, inundações, deslizamentos e movimentos de terra em geral;

- Freqüência: é o número médio de eventos (um distúrbio qualquer) por unidade de tempo. Também é expressa como a probabilidade anual de ocorrência do evento;

- Intensidade: (igual a severidade sensu White \& Pickett, 1985) são os impactos ocorridos sobre organismos, comunidades ou ecossistemas (por exemplo: diminuição na biomassa ou na área basal, perda ou aumento de espécies);

- Tamanho: pode ser interpretado como a área afetada, expressa como uma porcentagem da área total, ou expressa por evento, ou ainda por unidade de tempo.

Existem dois componentes que definem ou caracterizam a estabilidade de uma comunidade ou ecossistema, durante e após um distúrbio: a resistência e a resiliência.

- Resistência: pode ser interpretada como uma força de reação contrária, da comunidade ou ecossistema, contra o deslocamento em alguma propriedade funcional;

- Resiliência: é a capacidade da comunidade ou ecossistema em absorver mudanças e retornar ao estado original (estado pré-distúrbio).

Já foi colocado a importância de pequenos distúrbios naturais em florestas tropicais, como a queda de galhos e de uma ou poucas árvores. Outros distúrbios, bem mais intensos, mas de menor freqüência também podem ser citados.

Os mais intensos distúrbios observados em florestas tropicais recentemente são os ciclones ou furacões, como os Furacões Hugo (Porto Rico), Juana (Nicarágua), Gilbert (México). Ou os Ciclones Agnes, Winifred, Charlie, Aivu e Ivor que segundo Herwitz \& Young (1994) ocorreram 
entre 1982 e 1992 numa floresta tropical ao norte de Quensland, Austrália. A área de floresta afetada pelo Juana na Nicarágua foi estimada entre 300 e 500 mil ha no ano de 1988 (Vandermeer, 1990).

De menor intensidade, mas de freqüência relativamente maior destacam-se as tempestades com ventos fortes e chuvas de alta intensidade. As tradicionais florestas de Barro Colorado (Panamá), La Selva (Costa Rica), Los Tuxtlas (México), San Carlos (Venezuela) e Amazônica (Manaus, Brasil), onde se desenvolvem estudos de longo prazo, estão sujeitos a estes distúrbios, que são comuns em toda zona tropical (Clark, 1990). Outros distúrbios também citados são as inundações, temporárias ou permanentes, como as que ocorrem nas florestas de várzea e igapó na Amazônia, e os abalos sísmicos e deslizamentos de terras. A ocorrência do fogo em florestas tropicais também já está bastante documentada, inclusive por datação radiocarbônica, tendo ocorrido repetidas vezes nos últimos milênios (J. S. Clark, 1989; D. B. Clark, 1990; Whitmore, 1990; Attiwill, 1994).

Placas tectônicas, mudanças geomorfológicas e flutuações climáticas durante o terciário e quaternário operam como distúrbios numa escala geológica, influenciando a flora, fauna e a evolução da vegetação nas florestas tropicais (Bruenig, 1996). Nos últimos 1,6 milhões de anos o clima da Terra vem sendo caracterizado por longos intervalos de tempo (aproximadamente 100.000 anos) com temperaturas muito baixas (glaciações) intercalados por curtos intervalos (aproximadamente 20.000 anos) de temperaturas mais quentes, como $\circ$ atual (interglaciais) (Salgado-Labouriau, 1994).

Segundo a autora o mais drástico efeito de uma glaciação é a redução da área onde a maioria dos seres vivos podem habitar. Com as seguidas reduções e avanços da floresta as condições foram muito propícias à especiação nos trópicos, resultando na grande diversidade de flora e fauna tropical (revisão em: Flenley, 1979; Prance, 1982; Vanzolini, 1992; Salgado- 
Labouriau, 1994 e Bruenig, 1996). Evidências desta hipótese são citadas por Whitmore (1990) para florestas americanas, africanas e asiáticas.

Estudos palinológicos diversos, citados em SalgadoLabouriau (1994), mostram que a composição de vários tipos de floresta foi diferente em cada interglacial na América do Norte. E mesmo nos últimos 12.000 anos a composição das florestas deciduais e de coníferas variou à medida que cada espécie chegava e se estabelecia numa região, sendo que o sentido de movimento e a velocidade de migração é diferente e independente das outras espécies arbóreas. Diversas situações fazem supor que o mesmo tenha acontecido nas florestas da América do Sul e outras zonas tropicais.

Whitmore (1990) conclui numa revisão sobre distúrbios que a floresta tropical úmida, sem distúrbios e estável é um mito. A instabilidade, de extensões variáveis, ocorre sobre diferentes escalas de tempo. Bruenig (1996) também coloca que a composição florística da floresta tropical não é estática, mas varia em pequenas e médias escalas temporais e espaciais. A riqueza florística e a diversidade não são constantes, mas mudam em resposta a distúrbios de curto a longo prazo.

\subsection{Estudos de Longo Prazo}

A metodologia de parcelas permanentes para estudos de longo prazo não é fato novo em florestas tropicais: J. Wyatt Smith iniciou em 1947 na Malásia um trabalho em 2,02 ha nos quais todas as árvores com 30 $\mathrm{cm}$ ou mais de altura eram identificadas e marcadas.

Crow (1980) estudou as mudanças na composição e estrutura de uma floresta em El Verde, Porto Rico, através de uma parcela de 60×120 m (0,72 ha). O período de observação foi de 1943 a 1976 (33 anos), sendo amostrados todos os indivíduos com DAP $\geq 4 \mathrm{~cm}$. $O$ autor distinguiu duas fases durante o período: a primeira de 1943 a 1951 caracterizada por uma alta taxa de recrutamento, aumento no número de espécies, diversidade, área basal e biomassa. A segunda fase caracterizou-se pela redução na taxa 
de crescimento em área basal e biomassa, e diminuição no recrutamento, diversidade e número de espécies. Atribuiu essa diferença a distúrbios periódicos causados por furacões nas décadas de 20 e 30, em conjunto com a extração madeireira, anterior ao estabelecimento da parcela. Mesmo com distúrbios posteriores, numa menor freqüência e intensidade, a floresta apresentou uma tendência a estabilização de sua estrutura.

Uhl (1982) numa floresta amazônica de terra firme na Venezuela estudou as mudanças por um período de 5 anos, sendo medidos todos os indivíduos com DAP $\geq 10 \mathrm{~cm}$ numa parcela de 1 ha. A mortalidade no período foi de $4,96 \%$, com um recrutamento de $7,12 \%$. A taxa anual de mortalidade foi de $1,01 \%$.

Putz \& Milton (1982) analisaram a floresta de Barro Colorado, Panamá, num período de 5 anos (1975 a 1980). Foram observados todos os indivíduos com CAP $\geq 60 \mathrm{~cm}$ em 7 parcelas de 1 ha. Foram alocadas 2 parcelas numa floresta madura (200 anos) e 5 parcelas numa floresta mais jovem (100 anos). A mortalidade foi de $5,18 \%$ (1,06\% ao ano) na floresta mais velha e de $8,83 \%$ ( $1,85 \%$ ao ano) na floresta mais jovem.

Lang \& Knight (1983) também analisaram a floresta de Barro Colorado. O período de observação foi de 10 anos (1968 a 1978), em 150 quadrados contíguos de $10 \times 10 \mathrm{~m}$ (1,5 ha), sendo medidos todos os indivíduos com $\mathrm{DAP} \geq 2,5 \mathrm{~cm}$. A composição florística mudou muito pouco. A mortalidade foi de aproximadamente $20 \%$, com um recrutamento de $9 \%$. Apesar do declínio apresentado na densidade total a área basal aumentou de 25,7 para 31,4 $\mathrm{m}^{2} /$ ha (aumento de $22 \%$ na área basal total). A taxa anual de mortalidade foi calculada para DAP $\geq 20 \mathrm{~cm}$ e resultou em $1,6 \%$. Os autores também anotaram a formação de clareiras no período, resultando em $7,3 \%$ da área total amostrada, o que sugere uma taxa de renovação da floresta ao redor de 137 anos. 
Lieberman et al. (1987) e Peralta et al. (1987) analisaram 12,4 ha da floresta de La Selva, Costa Rica, entre 1969 e 1982 (13 anos). Em 3 parcelas de aproximadamente 4 ha foram amostrados todos os indivíduos com DAP $\geq 10 \mathrm{~cm}$. A mortalidade no período foi de $23,2 \%$, ou $2,03 \%$ ao ano e ocorreu independentemente da classe de tamanho das árvores. 0 recrutamento no período foi igual à mortalidade. A área basal diminuiu de 30,08 para $27,82 \mathrm{~m}^{2} /$ ha.

Swaine et al. (1987a) estudaram as mudanças em 2 parcelas de 1 ha numa floresta semidecídua em Kade, Ghana, num período de 12 anos (1970 a 1982). Foram amostrados todos os indivíduos com DAP $\geq 10 \mathrm{~cm}$. Do total de árvores amostradas em 1970,19,13\% morreram até 1982, numa taxa anual de $1,77 \%$. O recrutamento no período foi praticamente o mesmo, indicando uma razoável estabilidade em termos de densidade total. Também a composição de espécies se mostrou estável, com um ganho de 7 espécies e perda de outras 7 no período.

Manokaran \& Kochummen (1987) estudaram uma floresta de dipterocarpos na Malásia num período de 34 anos (1947 a 1981), através de uma parcela de $2 \mathrm{ha}$, onde foram medidos todos os indivíduos com DAP $\geq 10$ $\mathrm{cm}$. A densidade de árvores apresentou um declínio de $10 \%$, entretanto várias amostragens intermediárias mostraram uma flutuação em torno de 492 indivíduos/ha. A mesma flutuação pode ser observada para a área basal, ao redor de $32,4 \mathrm{~m}^{2} / \mathrm{ha}$. $\mathrm{O}$ número de espécies apresentou um declínio entre os anos de 1959 e 1971, se recuperando a seguir. Em 0,4 ha da área experimental houve influência por distúrbios provocados por uma plantação de seringueira. Até 1981, 50,1\% das árvores amostradas em 1947 haviam morrido, numa taxa anual de $2,02 \%$, entretanto um recrutamento de $48,4 \%$ demostra um balanço adequado entre mortalidade e recrutamento no período.

Rankin-de-Merona et al. (1990) analisaram uma floresta de terra firme em Manaus, Amazônia, num período de 5 anos (1981 a 1986). O 
estudo em 5 parcelas de 1 ha, incluiu todos os individuos com DAP $\geq 10 \mathrm{~cm}$. Do levantamento inicial morreram $5,63 \%$ dos indivíduos, numa taxa anual de $1,13 \%$. O recrutamento foi de $4,41 \%$.

Jardim (1990) analisou os dados de crescimento e mortalidade numa floresta equatorial, também próxima a Manaus. Em 3 parcelas de 4 ha amostrou todos os indivíduos com DAP $\geq 25 \mathrm{~cm}$, nos anos de 1980 e 1985. A mortalidade total do periodo foi de 7,14\% (variando de 6,99 a $7,38 \%$ nas parcelas), plenamente recompensada por um recrutamento de $7,24 \%$. A taxa anual de mortalidade foi de $1,48 \%$.

Lieberman et al. (1990), continuando os estudos de longo prazo em La Selva, analisaram a floresta de 1969 a 1985 (16 anos). A taxa de mortalidade anual que no período anterior de estudo (1969 a 1982) estava em $2,03 \%$, subiu para 2,34\%. A densidade total que em 1982 era praticamente idêntica à densidade de 1969, se encontrava 0,82\% menor em 1985.

Hubbell \& Foster (1990a) analisaram as mudanças numa parcela de 50 ha em Barro Colorado, num período de 3 anos (1982 a 1985), sendo incluídos todos os indivíduos com DAP $\geq 1 \mathrm{~cm}$. Morreram no período $8,78 \%$ das plantas, com um recrutamento de 14,04\%. Um importante registro deste estudo foi que $2,6 \%$ das plantas sofreram uma drástica redução no DAP. A principal explicação para esse fato é a quebra de muitas plantas e posterior rebrota, entretanto insuficiente para a inclusão na amostra de 1985 . A mortalidade no período foi considerada alta e o fato foi atribuído a distúrbios provocados pelo "El Niño" em 1983. Aproximadamente 40\% das plantas apresentaram um mínimo de $10 \%$ de mudança na sua abundância. As taxas de mortalidade foram maiores nas grandes árvores, indicando que foram mais afetadas pelo "EI Niño" do que as plantas do sub-bosque.

Gentry \& Terborgh (1990) estudaram uma floresta às margens do Rio Manú, no Perú, num intervalo de 10 anos (1975 a 1985). Foram medidos todos os indivíduos com DAP $\geq 10 \mathrm{~cm}$ em 2 parcelas que 
totalizaram 0,94 ha. Morreram no período $16,4 \%$ dos indivíduos, numa taxa anual de $1,6 \%$. O recrutamento foi de $8,3 \%$.

Van Daalen (1991) analisou uma floresta na África do Sul num período de 15 anos (1972 a 1987). Foram incluídos numa amostra de 44 ha todos os indivíduos com DAP $\geq 10 \mathrm{~cm}$. A área basal mudou de 32,7 para $35,3 \mathrm{~m}^{2} / \mathrm{ha}$. A densidade total aumentou em $5,02 \%$ e a mortalidade foi de $10,6 \%$ no período.

Primack \& Hall (1992) estudaram 3 florestas na Malásia. O período de monitoramento foi de 20 anos (1965 a 1985) e em cada floresta foram distribuídas 4 a 5 parcelas de 0,6 ha, incluindo na amostragem todos os indivíduos com DAP $\geq 10 \mathrm{~cm}$. Em duas das florestas a mortalidade e recrutamento apresentaram um equilíbrio, em outra houve um declínio de $14 \%$ na densidade de árvores, provavelmente devido a uma seca mais severa em anos passados que ocasionou uma maior mortalidade de árvores. O número de espécies no período aumentou entre 3,1 a 17,6\% em cada floresta, entretanto esse aumento não foi estatisticamente significativo. A extinção local de espécies foi de aproximadamente 12\% (todas com no máximo 5 indivíduos em 1965). A imigração de espécies (ausentes em 1965 e presentes em 1985) foi de 16 a $24 \%$.

Condit et al. (1992) analisaram novamente a parcela de 50 ha em Barro Colorado. O período de estudo agora foi de 8 anos (1982 a 1990). As espécies pareceram apresentar uma recuperação em relação ao período 82-85, afetado pelo "El Niño". O número de espécies foi praticamente constante ao longo do período, entretanto 10 espécies presentes em 1982 não se encontravam em 1990 e 9 espécies ausentes em 1982 foram amostradas em 1990.

Carey et al. (1994) analisaram dois tipos florestais na Venezuela num período de 25 anos. Em 17 parcelas de 0,25 ha foram medidos todos os indivíduos com DAP $\geq 10 \mathrm{~cm}$. A taxa anual de mortalidade variou de 
0,5 a 3,3\% entre parcelas. A mortalidade foi recompensada pelo recrutamento, mas diferiu entre os tipos florestais.

Herwitz \& Young (1994) estudaram uma floresta tropical na Austrália, num período de 10 anos (1982 a 1992). Todas as árvores com DAP $\geq$ $30 \mathrm{~cm}$ foram amostradas, numa área de 0,39 ha. Dividiram a área em duas partes: uma na parte mais baixa da encosta e outra na parte mais alta. A mortalidade total foi de $17 \%$, sendo plenamente recompensada pelo recrutamento na parte mais alta. Já na parte mais baixa a mortalidade foi maior que o recrutamento, resultando numa diminuição de $7,1 \%$ na densidade. Houve uma sensível redução na área basal em ambas as áreas.

Felfili (1995) estudou uma floresta de galeria ao longo do Rio Gama em Brasília, Distrito Federal, num periodo de 6 anos (1985 a 1991). Foram amostrados todos os indivíduos com DAP $\geq 10 \mathrm{~cm}$ em 151 parcelas de $10 \times 20 \mathrm{~m}$. A mortalidade foi de $19 \%$, numa taxa anual de $3,5 \%$. O recrutamento foi de $16 \%$.

Em todos esses estudos pode ser notada uma certa constância dos parâmetros estruturais da floresta como densidade, área basal e número de espécies, flutuando em torno de um valor médio, ou ainda, que estes parâmetros tendem a retornar a um valor médio após um distúrbio mais intenso. Essa flutuação pode ser maior ou menor, em cada floresta dependendo principalmente do tipo, intensidade e freqüência de distúrbios a que a floresta está submetida.

Os processos de crescimento, mortalidade e recrutamento em florestas são influenciados por distúrbios, os quais podem operar sobre uma ampla variedade de escalas temporais e espaciais (White \& Pickett, 1985), estando plenamente adaptada a estes distúrbios, em cada local. 


\section{CAPÍTULO III}

\section{MORTALIDADE E RECRUTAMENTO NA FLORESTA ATLÂNTICA EM LINHARES (ES)}

\section{Introdução}

Estudos de longo prazo instalados em florestas tropicais da África, Ásia, Austrália e América Latina, têm permitido uma melhor compreensão sobre aspectos dinâmicos destes ecossistemas, podendo levar a uma estratégia adequada de manejo e conservação da biodiversidade.

Estes estudos ecológicos examinam as mudanças nas populações usando informações de censos, com a contagem e posterior recontagem de indivíduos sobreviventes, perdas e ganhos, sendo as informações comumente sumarizadas na forma de taxas de mortalidade e recrutamento (Sheil \& May, 1996). Diversos trabalhos nos últimos 10 anos têm apresentado uma sumarização dos resultados encontrados nas diversas florestas onde se usa a metodologia de parcelas permanentes (Swaine et al.,1987b; Swaine, 1989; Hartshorn, 1990; Phillips \& Gentry, 1994).

As parcelas permanentes utilizadas possuem as mais variadas formas e tamanhos; o limite mínimo de DAP não é o mesmo entre os trabalhos, o método de cálculo para taxas anuais de mortalidade diferem, além disso alguns estudos incluem palmeiras, lianas ou arbustos, outros apenas espécies arbóreas; os tipos florestais são também variados, havendo florestas de várzea, de terra firme, de terras baixas, de encosta, de galerias, etc.; cada uma submetida ainda a diferentes precipitações anuais, em diferentes altitudes, com diferentes históricos de perturbação, etc. 
Apesar de toda essa variabilidade os estudos indicam que as mudanças e flutuações na estrutura da floresta madura seguem um padrão em toda a área tropical. Há uma constância dos parâmetros estruturais da floresta como densidade, área basal e número de espécies, flutuando em torno de um valor médio ao longo do tempo. Essa constância é mantida através de um balanço adequado entre mortalidade e recrutamento de árvores (Lieberman et al., 1987; Peralta et al., 1987; Swaine et al., 1987; Lieberman et al., 1990; Jardim, 1990).

Alguns trabalhos mostram que estes parâmetros podem ser sensivelmente modificados por distúrbios mais intensos, tendendo a retornar ao valor médio, em seguida. Por exemplo, um furacão que atingiu El Verde (Porto Rico) modificou sensivelmente a estrutura da floresta, que em seguida apresentou uma tendência à recuperação (Crow, 1980). Distúrbios antrópicos afetaram uma floresta na Malásia e num período posterior houve uma tendência à recuperação (Manokaram \& Kochummen, 1987). O fenômeno conhecido com "El Niño" provocou uma seca severa na floresta de Barro Colorado (Panamá) elevando a taxa de mortalidade (Hubbell \& Foster, 1990a), mas também é mostrado uma tendência a recuperação da floresta em períodos posteriores (Condit et al., 1992). Períodos prolongados de seca também afetaram aspectos da estrutura de florestas na Malásia (Primack \& Hall, 1992) demostrando ser um distúrbio importante e amplamente distribuído na região tropical.

\footnotetext{
Neste trabalho pretende-se analisar a mortalidade $e$ recrutamento de árvores com DAP $\geq 10 \mathrm{~cm}$, ocorridos de 1980 a $1995 \mathrm{na}$ floresta atlântica em Linhares (ES) e avaliar a influência de uma seca severa, ocorrida no ano de 1987, sobre aspectos estruturais da floresta.
} 


\section{Método de Análise}

\subsection{Mortalidade e Recrutamento}

A taxa anual de mortalidade têm sido calculada de duas maneiras: através do modelo algébrico descrito em Primack et al. (1985) ou do modelo logarítmico descrito em Swaine \& Lieberman (1987).

Sheil et al. (1995) fazem uma análise dos dois modelos e concluem que não ocorrem discrepâncias entre os valores obtidos em ambos os modelos para baixas porcentagens de mortalidade. Por exemplo, com $2 \%$ de mortalidade a diferença entre os modelos é de $0,02 \%$, mas com $50 \%$ de mortalidade a diferença entre ambos chega a $19 \%$. A questão para se utilizar um ou outro modelo é mais conceitual pois enquanto o modelo algébrico fornece a verdadeira taxa anual de mortalidade $(\mathrm{m})$, o modelo logarítmico fornece um coeficiente exponencial de mortalidade $(\lambda)$.

O modelo utilizado neste trabalho foi o algébrico:

- $m=1-\left(N_{1} / N_{0}\right)^{1 / t}$, onde:

- m é a taxa anual de mortalidade;

- $N_{0}$ é o número de indivíduos na amostra inicial (ano de 1980);

- $\mathrm{N}_{1}$ é o número de indivíduos na amostra final (ano de 1995);

- té o tempo de observação em anos ( $t=15$ anos).

A meia-vida $\left(t_{0,5}\right)$ da floresta ou o tempo estimado para que a população inicial caia pela metade (Swaine \& Lieberman, 1987) foi obtido por:

- $t_{0,5}=(\operatorname{Ln} 0,5) / \operatorname{Ln}(1-m)$, onde Ln é o logaritmo neperiano.

Foi utilizado o Coeficiente de Correlação de Spearman $\left(r_{s}\right)$ (Sokal \& Rohlf, 1981) para se testar as correlações entre 3 variáveis NT80, MT95 e RT95, onde:

- NT80 = o número de indivíduos de cada espécie em 1980; 
- MT95 = o número de indivíduos mortos de cada uma das espécies da amostra inicial, no período (1980 a 1995);

- RT95 = o número de árvores recrutadas de cada uma das espécies da amostra inicial, no período (1980 a 1995) para a classe de $10 \mathrm{~cm}$ de DAP.

\subsection{Testes de Hipóteses}

Para se analisar as influências das variaçōes temporais na densidade de árvores da floresta atlântica em Linhares (ES) considerou-se ano e parcela como variáveis independentes, construindo-se um delineamento experimental em blocos ao acaso, onde os anos de amostragem foram considerados como blocos e as parcelas como tratamentos. As parcelas foram utilizadas como fonte de variação do delineamento visando diminuir o número de graus de liberdade do resíduo e, consequentemente, o erro experimental devido ao acaso. Desse modo para um total de 6 blocos e 5 tratamentos aplicou-se $\circ$ teste $F$ para $\circ$ teste de hipótese e $\circ$ teste de Tukey para a comparação das médias referentes a blocos (anos), ambos os testes a $5 \%$ de probabilidade.

Foi considerada a seguinte hipótese de nulidade $\left(H_{0}\right)$ com a respectiva hipótese alternativa $\left(\mathrm{H}_{\mathrm{a}}\right)$ :

$\Rightarrow$ 2.2.1) $H_{0}$ : As estimativas de densidade (D) não diferem estatisticamente entre os anos de amostragem:

$$
D_{1980}=D_{1983}=D_{1986}=D_{1989}=D_{1992}=D_{1995}
$$

$H_{a}$ : a densidade de árvores apresentou diferença estatística significativa entre pelo menos dois dos anos de amostragem.

A mesma hipótese foi testada para o parâmetro densidade em relação aos grupos ecológicos de espécies arbóreas. 
A estatistica não-paramétrica do qui-quadrado $\left(\chi^{2}\right)$ foi utilizada para as análises de mortalidade e recrutamento.

$\Rightarrow$ 2.2.2) $H_{0}$ : a mortalidade total no periodo (MT95 - equivalente à taxa) foi igual em todos os grupos ecológicos:

$$
\text { MT95 } \text { Pioneiras }=\text { MT95 sec. iniciais }=\text { MT95 Sec. tardias }=\text { MT95 Climácicas }
$$

$\Rightarrow$ 2.2.3) $H_{0}$ : a mortalidade de árvores (M) não diferiu estatisticamente entre os anos de amostragem. Como a mortalidade no ano de 1983 foi igual a zero em todas as parcelas, esse ano não foi considerado na análise:

$$
M_{1986}=M_{1989}=M_{1992}=M_{1995}
$$

$\Rightarrow$ 2.2.4) $H_{0}$ : o recrutamento de árvores $(R)$ não diferiu estatisticamente entre os anos de amostragem:

$$
R_{1983}=R_{1986}=R_{1989}=R_{1992}=R_{1995}
$$

$\Rightarrow$ 2.2.5) $H_{0}$ : a mortalidade de árvores (M) não diferiu estatisticamente entre parcelas:

$$
M_{\text {parcela } 1}=M_{\text {parcela 2 }}=M_{\text {parcela } 3}=M_{\text {parcela 4 }}=M_{\text {parcela } 5}
$$

$\Rightarrow$ 2.2.6) $H_{0}$ : o recrutamento de árvores $(R)$ não diferiu estatisticamente entre parcelas:

$$
R_{\text {parcela 1 }}=R_{\text {parcela 2 }}=R_{\text {parcela 3 }}=R_{\text {parcela 4 }}=R_{\text {parcela } 5}
$$

$\Rightarrow$ 2.2.7) $H_{0}$ : a mortalidade de árvores $\left(M_{i}\right)$ não diferiu estatisticamente do recrutamento $\left(R_{i}\right)$ em nenhum ano de levantamento (1986, 1989, 1992 e 1995), ou seja, o balanço $B_{i}\left(M_{i}-R_{i}\right)$ foi igual a zero:

$$
M_{i}=R_{i} \text {, onde } i \text { é um dos anos de levantamento }
$$

$\Rightarrow$ 2.2.8) $H_{0}$ : a mortalidade de árvores $\left(M_{i}\right)$ não diferiu estatisticamente do recrutamento $\left(R_{i}\right)$ em nenhuma das 5 parcelas, ou seja, o balanço $B_{i}$ $\left(M_{i}-R_{i}\right)$ foi igual a zero em todas as parcelas: 


$$
M_{i}=R_{i} \text {, onde } i \text { é um dos anos de levantamento }
$$

$\Rightarrow$ 2.2.9) $\mathbf{H}_{0}$ : em cada levantamento $(1986,1989,1992$ e 1995) a mortalidade $\left(M_{i}\right)$ não difere estatisticamente entre classes de tamanho de árvores. Para esta hipótese considerou-se arbitrariamente três classes de tamanho de árvores, segundo o diâmetro à altura do peito (DAP): I) $10 \leq \mathrm{DAP}<50$, II) 50 $\leq$ DAP $<90$ e III) DAP $\geq 90$. A mortalidade de cada levantamento foi analisada em relação à distribuição do levantamento anterior (ou seja, quando todas as árvores estavam vivas):

$M_{i \text { classe I }}=M_{i \text { classe II }}=M_{i}$ classe III, onde $i$ é um dos anos de levantamento 


\section{Resultados e Discussão}

\subsection{Densidade Total e Densidade dos Grupos Ecológicos}

$O$ número de árvores, com DAP $\geq 10 \mathrm{~cm}$, amostradas no período de monitoramento foi de 1681, divididas em 266 espécies (sendo 9 identificadas como morfo-espécies e 20 a nível genérico), 154 gêneros e 52 famílias, de acordo com o Sistema de Cronquist.

A Tabela 1 mostra os resultados de densidade para os levantamentos de 1980 a 1995 na RFL.

Tabela 1. Variações na densidade ( $D$ - $n /$ ha) de árvores por grupo ecológico e para o total da comunidade no período de 1980 a 1995 na RFL.

\begin{tabular}{ccccccccc}
\hline \hline $\mathbf{D}(\mathbf{n} / \mathbf{h a})$ & $\mathbf{1 9 8 0}$ & $\mathbf{1 9 8 3}$ & $\mathbf{1 9 8 6}$ & $\mathbf{1 9 8 9}$ & $\mathbf{1 9 9 2}$ & $\mathbf{1 9 9 5}$ & $\mathbf{F}$ & Pr>F \\
\hline \hline Pioneiras & 12,4 & 14,0 & 12,4 & 12,0 & 12,0 & 12,8 & 0,71 & 0,621 \\
\hline $\begin{array}{c}\text { Sec. } \\
\text { Iniciais }\end{array}$ & 119,2 & 125,6 & 127,6 & 119,6 & 120,0 & 122,8 & 1,48 & 0,241 \\
\hline $\begin{array}{c}\text { Sec. } \\
\text { Tardias }\end{array}$ & 134,8 & 138,4 & 137,2 & 130,0 & 136,0 & 138,8 & 2,65 & 0,054 \\
\hline Climácicas & 254,0 & 266,4 & 264,4 & 258,4 & 274,4 & 279,6 & 6,23 & 0,012 \\
\hline \hline Total & $\begin{array}{c}520,4 \\
\text { b }\end{array}$ & $\begin{array}{c}544,4 \\
\text { ab }\end{array}$ & $\begin{array}{c}541,6 \\
\text { ab }\end{array}$ & $\begin{array}{c}520,0 \\
\text { b }\end{array}$ & $\begin{array}{c}542,4 \\
\text { ab }\end{array}$ & $\begin{array}{c}554,0 \\
\text { a }\end{array}$ & $\mathbf{5 , 0 2}$ & $\mathbf{0 , 0 0 3}$ \\
\hline \hline & & & & & & & & \\
\hline
\end{tabular}

Entre o primeiro e o último levantamento foi observado um acréscimo geral de $6,45 \%$ na densidade. Para todos os grupos ecológicos ocorreu um acréscimo na densidade de árvores entre o primeiro e o último levantamento: 3,22\% para pioneiras, 3,02\% para secundárias iniciais, 2,96\% para secundárias tardias e 10,07\% para climácicas.

Nota-se pela Tabela 1 que nenhum acréscimo ou diminuição ocorre de forma linear, havendo muito mais uma flutuação nos valores de densidade ao longo do tempo, conforme pode ser visualizado na Figura 2. 


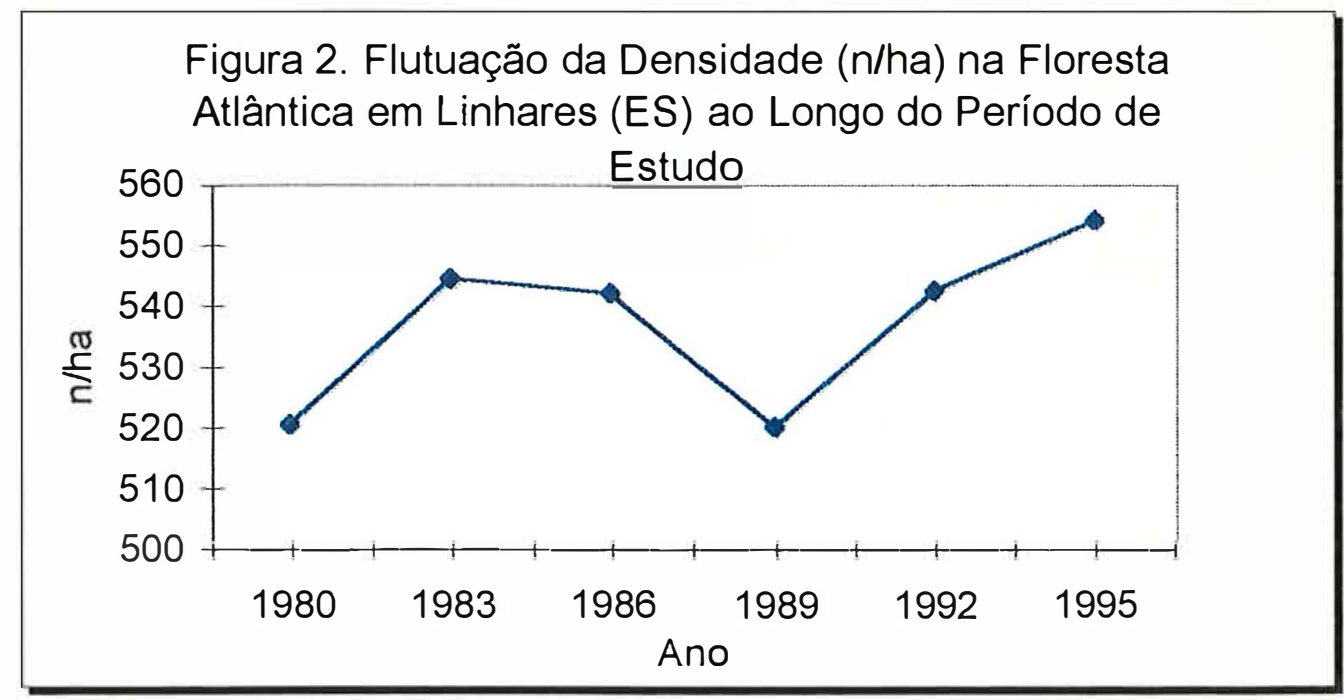

Um detalhe importante é que a flutuação pode ser mascarada em períodos mais curtos de monitoramento ou intervalos muito longos entre uma medição e outra. Por exemplo se tivéssemos em mãos apenas os levantamentos de 1980, 1986 e 1995, poderíamos interpretar que a densidade de árvores estaria aumentando linearmente, ou seja, poderíamos tirar conclusões erradas sobre os processos dinâmicos que estariam ocorrendo na floresta. Esse fato demostra a importância de intervalos curtos entre medições e de períodos longos para estudos sobre a dinâmica de florestas.

As variações observadas na densidade total da comunidade e na densidade do grupo ecológico de climácicas foram significativas pelo teste F, rejeitando-se a hipótese de nulidade (hipótese 2.2.1). Para os outros grupos a hipótese de nulidade foi aceita, ou seja, não foram encontradas diferenças significativas na densidade, ao longo do período de estudo.

Em linhas gerais o recrutamento de árvores na floresta se iguala à mortalidade proporcionando um balanço relativamente constante na densidade de árvores e refletindo uma flutuação na densidade que pode ser maior ou menor, em cada floresta, dependendo do tipo, intensidade e freqüência de distúrbios a que a floresta está submetida. 


\subsection{Mortalidade e Recrutamento}

Dos 1301 indivíduos amostrados em 1980, 265 morreram até 1995, resultando numa mortalidade de $20,36 \%$ (7,06 árvores mortas/ha/ano) num período de 15 anos ou numa taxa anual de 1,52\%, de acordo com o modelo algébrico utilizado, fornecendo uma estimativa de meia-vida para a floresta de 45,6 anos.

O recrutamento de árvores após o ano de 1980 foi de 29,20\% (380 árvores novas incluídas na classe de DAP mínimo). Deste total 31 árvores morreram antes de chegar a 1995, revelando mais um outro parâmetro que pode ser subestimado em intervalos muito longos entre medições.

Os 265 indivíduos mortos que pertenciam à amostra inicial foram subdivididos em: $4,9 \%$ para $\circ$ grupo de pioneiras, $27,16 \%$ para $\circ$ grupo de sec. iniciais, $26,41 \%$ para 0 grupo de sec. tardias e $41,5 \%$ para 0 grupo de climácicas. Dos 380 indivíduos recrutados em todo o período $5,0 \%$ foram do grupo de pioneiras, $22,63 \%$ sec. iniciais, $23,42 \%$ sec. tardias e $48,94 \%$ climácicas, mas como já colocado, nem todos os indivíduos recrutados sobreviveram até 1995.

Entretanto, apesar da baixa porcentagem de árvores mortas e recrutadas no grupo de pioneiras, em relação ao total, a situação praticamente se inverte ao calcularmos as porcentagem dentro de cada grupo, como mostra a Tabela 2.

Morreram $41,93 \%$ dos indivíduos de espécies pioneiras que estavam presentes na amostragem inicial (1980), contra 45,16\% de árvores pioneiras que foram recrutadas e sobreviveram até 1995. Nos outros grupos a mortalidade foi de $23,48 \%, 21,36 \%$ e $17,32 \%$, enquanto que o recrutamento das árvores que sobreviveram até 1995 (em relação ao total do grupo em 1980) foi de $26,51 \%, 24,33 \%$ e $27,40 \%$, para sec. iniciais, sec. tardias e climácicas, respectivamente. 
Tabela 2. Características dos grupos ecológicos em relação à mortalidade e recrutamento de árvores no período de 1980 a 1995 na RFL. A mortalidade é apresentada em valores absolutos e por halano. Foram contadas as árvores recrutadas e sobreviventes (Nrecrut.sobrev.) e as árvores recrutadas que morreram (Nrecrut.mortas).

\begin{tabular}{lcccc}
\hline Características & Pioneiras & Sec. Iniciais & Sec. Tardias & Climácicas \\
\hline \hline Ninicial 1980 & 31 & 298 & 337 & 635 \\
\hline Nmortos & 13 & 70 & 72 & 110 \\
\hline Nmortos/ha/ano & 0,35 & 1,86 & 1,92 & 2,93 \\
\hline Nrecrut.(sobrev.) & 14 & 79 & 82 & 174 \\
\hline Nrecrut.(mortas) & 5 & 7 & 7 & 12 \\
\hline Nfinal 1995 & 32 & 307 & 347 & 699 \\
\hline$\%$ Mortas & $41,93 \%$ & $23,48 \%$ & $21,36 \%$ & $17,32 \%$ \\
\hline$\%$ Recrut. & $45,16 \%$ & $26,51 \%$ & $24,33 \%$ & $27,40 \%$ \\
\hline Taxa mortalid. & $3,62 \%$ ao ano & $1,78 \%$ ao ano & $1,60 \%$ ao ano & $1,26 \%$ ao ano \\
\hline Meia-Vida & 19,1 anos & 38,9 anos & 43,3 anos & 55,0 anos \\
\hline \hline
\end{tabular}

As estimativas de meia-vida projetadas para os grupos ecológicos variaram de 19 anos para as pioneiras até 55 anos para as climácicas. A porcentagem de mortalidade foi estatisticamente diferente entre grupos ecológicos $\left(\chi^{2}=15,198,3\right.$ g.l., $\left.p=0,02\right)$ : pioneiras > sec. iniciais > climácicas e pioneiras > sec. tardias (hipótese 2.2.2).

A taxa anual de mortalidade de árvores na floresta atlântica em Linhares (ES) está dentro do esperado para uma floresta madura em condições naturais de distúrbios, que têm variado de 1 a 2\% (Swaine et al.,1987b; Swaine, 1989; Hartshorn, 1990; Phillips \& Gentry, 1994). A maior taxa de mortalidade de pioneiras em relação às climácicas mostra as diferenças na longevidade entre estes dois grupos, como já detectado por Manokaram \& Kochummen (1987).

Algumas localidades apresentam valores superiores ao intervalo de 1 a $2 \%$, como é o caso de fragmentos florestais na região de Piracicaba (SP) com uma taxa de 5,11\% (Nascimento, 1997), devido principalmente à alta mortalidade de Trema micrantha (responsável por $52 \%$ das árvores mortas). Segundo o autor o resultado pode estar associado às 
geadas, a períodos secos ou ao ciclo de vida curto da espécie. Uma severa estação seca detectada no ano de 1983 também elevou a taxa de mortalidade na floresta de Barro Colorado (Hubbell \& Foster, 1990a). Entretanto nestes casos a taxa de mortalidade tende a ser superestimada se estiver associada a distúrbios de baixa freqüência medidos durante um curto intervalo de monitoramento.

Também em áreas perturbadas por exploração florestal as taxas de mortalidade são sensivelmente maiores (Lopes, 1993), mas segundo Graaf (1986), tendem a declinar para taxas normais após 10 anos da exploração inicial.

Nota-se então a importância de se conhecer os distúrbios naturais (particularmente sua freqüência, intensidade e duração) para uma correta interpretação dos processos dinâmicos que ocorrem na floresta.

A Tabela 3 apresenta os resultados de mortalidade e recrutamento ao longo do período e em cada parcela.

Tabela 3. Mortalidade e recrutamento de árvores ao longo do tempo em cada uma das unidades de amostra.

\begin{tabular}{|c|c|c|c|c|c|c|c|c|c|c|c|c|}
\hline & \multicolumn{2}{|c|}{1983} & \multicolumn{2}{|c|}{1986} & \multicolumn{2}{|c|}{1989} & \multicolumn{2}{|c|}{1992} & \multicolumn{2}{|c|}{1995} & \multicolumn{2}{|c|}{ Total } \\
\hline Parcela & $\bar{M}$ & $\mathrm{R}$ & $M$ & $\bar{R}$ & $\bar{M}$ & $\overline{\bar{R}}$ & $\bar{M}$ & $\overline{\mathrm{R}}$ & $\bar{M}$ & $\overline{\bar{R}}$ & $\bar{M}$ & $\bar{R}$ \\
\hline$\overline{11}$ & $\overline{0}$ & 8 & $\overline{9}$ & 0 & $\bar{~} 16$ & 17 & 1 & 15 & $\overline{11}$ & 18 & 37 & 58 \\
\hline 2 & 0 & 15 & 19 & 22 & 47 & 18 & 10 & 27 & 14 & 17 & 90 & 99 \\
\hline 3 & 0 & 3 & 4 & 7 & 38 & 19 & 8 & 15 & 10 & 17 & 60 & 61 \\
\hline 4 & 0 & 19 & 16 & 19 & 23 & 22 & 10 & 16 & 8 & 16 & 57 & 92 \\
\hline 5 & 0 & 15 & 10 & 3 & 25 & 19 & 6 & 18 & 11 & 15 & 52 & 70 \\
\hline Total & 0 & $\overline{60}$ & $\overline{58}$ & $\overline{51}$ & $\overline{149}$ & $\overline{995}$ & $\overline{35}$ & 91 & $\overline{54}$ & $\overline{83}$ & 296 & 380 \\
\hline
\end{tabular}

Verificou-se que tanto mortalidade $\left(\chi^{2}=105,77,3\right.$ g.l., $p=0,001)$ como o recrutamento $\left(\chi^{2}=20,518,4\right.$ g.l., $\left.p=0,001\right)$ variaram significativamente entre anos (hipóteses 2.2 .3 e 2.2.4). A análise espacial (entre parcelas) também mostrou diferenças significativas para mortalidade $\left(\chi^{2}=14,885,4\right.$ g.l., $\left.p=0,005\right)$ e para recrutamento $\left(\chi^{2}=19,367,4\right.$ g.l., $\left.p=0,001\right)$ 
de árvores na floresta (hipóteses 2.2 .5 e 2.2.6). O mesmo teste indicou que em pelo menos um dos anos de amostragem (hipótese 2.2.7) a mortalidade e o recrutamento diferiram estatisticamente entre si $\left(\chi^{2}=42,557,3\right.$ g.l., $\left.p=0,001\right)$. Entretanto a mortalidade foi estatisticamente igual ao recrutamento $\left(\chi^{2}=5,605\right.$, 4 g.l., $p=0,231$ ) em todas as parcelas (hipótese 2.2.8), denotando que houve equilíbrio entre perdas e ganhos em diferentes trechos da floresta $(p>0,05)$.

Os estudos conduzidos por Lieberman \& Lieberman (1987), Swaine et al. (1987), Welden et al. (1991) e Carey et al. (1994) também mostram a mortalidade variando dentro de um mesmo sítio. Outros estudos também mostraram a variação entre períodos sucessivos de monitoramento (Manokaram \& Kochummen, 1987; Uhl et al., 1988; Condit et al., 1992).

Dessa forma, tanto mortalidade como recrutamento não são uniformemente distribuídas no espaço e no tempo (hipóteses 2.2.3, 2.2.4, 2.2 .5 e 2.2.6).

Franklin et al. (1987) discutem esta questão relatando que as taxas e mecanismos de mortalidade diferem dramaticamente numa paisagem, sendo que muitos agentes de mortalidade têm padrões distintos na paisagem. As taxas variam entre espécies arbóreas, tipos florestais, estágio sucessional, com alguns episódios prediziveis e outros determinados pelo acaso como os associados a eventos climáticos extremos. Podemos chamar de prediziveis aqueles episódios que podem ser adequadamente mensuráveis em determinadas condições como por exemplo as taxas de herbivoria e predação das espécies.

\subsection{Mortalidade nas Classes de Tamanho}

Os resultados de freqüência (em 2,5 ha) para a mortalidade nas classes de tamanho de árvores são apresentados na Tabela 4, enquanto que a Figura 3 apresenta graficamente os resultados em porcentagens: 
Tabela 4. Mortalidade absoluta nas classes de tamanho de árvores, ao longo do período (número entre parenteses refere-se à porcentagem de mortas em relação às árvores vivas na classe no levantamento anterior).

\begin{tabular}{cccccc}
\hline Classe & 1986 & 1989 & 1992 & 1995 & Total \\
\hline \hline I) $10 \leq$ DAP $<50$ & 56 & 134 & 32 & 52 & 274 \\
& $(4,39 \%)$ & $(10,56 \%)$ & $(2,61 \%)$ & $(4,05 \%)$ & \\
\hline II) $50 \leq$ DAP $<90$ & 2 & 10 & 3 & 2 & 17 \\
& $(2,77 \%)$ & $(14,49 \%)$ & $(4,83 \%)$ & $(3,2 \%)$ & \\
\hline III) $90 \leq$ DAP & 0 & 5 & 0 & 0 & 5 \\
\hline \hline Total & 58 & $(31,25 \%)$ & & & 296 \\
\hline \hline
\end{tabular}

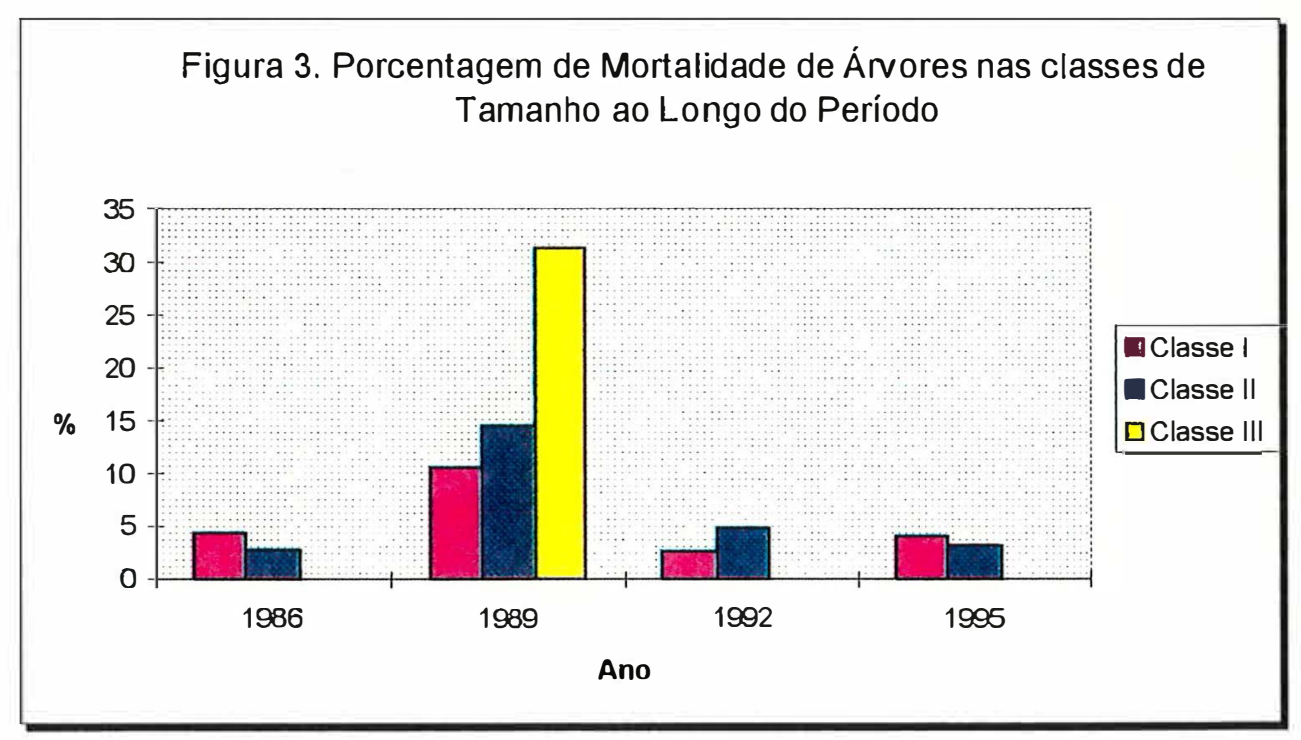

A mortalidade ocorreu independentemente da classe de tamanho em todos os anos à exceção do ano de $1989\left(\chi^{2}=7,81,2\right.$ g.l., $\left.p=0,02\right)$. Neste ano a classe de tamanho III apresentou maior mortalidade que a classe I (hipótese 2.2.9), com 5 das 16 árvores (ou $31,25 \%$ ) com DAP $\geq 90 \mathrm{~cm}$ que estavam presentes no levantamento de 1986 morrendo até 1989. Nota-se ainda que $50,33 \%$ da mortalidade ocorrida nos 15 anos de monitoramento ocorreu de 1986 a 1989.

Geralmente se observa na maioria dos estudos de longo prazo que a mortalidade ocorre independente da classe de tamanho das 
árvores com DAP $\geq 10 \mathrm{~cm}$ (em intervalos de classes $10 \mathrm{~cm}$ ) (Swaine, 1989). Entretanto em florestas onde foram detectados distúrbios mais severos durante o monitoramento (Hubbell \& Foster, 1990a), nota-se claramente uma maior taxa de mortalidade para grandes árvores. As taxas e causas de mortalidade de árvores mostram uma dramática variação com a sucessão (Harcombe, 1987; Peet \& Christensen, 1987).

Com 0 inerente declínio no vigor e no crescimento o indivíduo se torna menos hábil para resistir a uma variedade de agentes danificantes, dos quais se destacam ventos, patógenos, senescência, competição e estresse ambiental (Franklin et al., 1987). Em períodos curtos de seca, as árvores maiores sobreviveriam devido ao extensivo sistema radicular, mas para plântulas e arvoretas bastam 4 a 8 semanas de baixa precipitação para elevar a taxa de mortalidade (Hartshorn, 1990).

\subsection{Análise de Correlação e Classes de Abundância}

A análise de correlação mostrou que o número de indivíduos de cada espécie em 1980 foi altamente correlacionado $(p<0,01)$ com o número de indivíduos mortos de cada espécie no período (coeficiente de correlação de Spearman $=0,5372$ ). Para o número de árvores recrutadas em cada uma das espécies a correlação foi igualmente significativa (coeficiente de correlação de Spearman $=0,5604)$. A mortalidade de árvores também foi positiva e significativamente correlacionada com 0 recrutamento (coeficiente de correlação de Spearman $=0,4317$ ).

Constata-se então que para o período analisado as espécies com mais indivíduos apresentaram maior recrutamento tendendo a manter suas abundâncias, resultado também encontrado por Felfili (1993). Só que também apresentam alta mortalidade, o que impede estas espécies de elevar indefinidamente suas densidades e dominar por completo a comunidade. 
Segundo Denslow (1987) são os distúrbios e taxas de mortalidade dependente da densidade que interrompem a dominância da comunidade por poucas espécies, proporcionando a alta diversidade do subbosque da floresta tropical. Estas espécies mais comuns da floresta demonstram uma estabilidade estrutural de suas populações, estando o fato relacionado a uma maior adaptação ao regime de distúrbios das florestas onde ocorrem (Denslow, 1980; Hartshorn, 1980).

O agrupamento das espécies em classes de abundância e os resultados para mortalidade e recrutamento resultou na Tabela 5, a seguir:

Tabela 5. Percentual de espécies $(S)$ e indivíduos $(N)$ em relação ao levantamento de 1980, mortalidade total (MT95) e recrutamento total (RT95) no período, para as classes de abundância das espécies presentes em 1980.

\begin{tabular}{cccccc}
\hline Classe & $\begin{array}{c}\text { Amplitude } \\
\text { (n/ha) }\end{array}$ & $\begin{array}{c}\mathbf{S} \% \\
\mathbf{1 9 8 0}\end{array}$ & $\begin{array}{c}\mathbf{N} \% \\
\mathbf{1 9 8 0}\end{array}$ & $\begin{array}{c}\text { MT95 abs. } \\
\text { (\%) }\end{array}$ & $\begin{array}{c}\text { RT95 abs. } \\
\text { (\%) }\end{array}$ \\
\hline \hline Comuns & $\mathbf{N} \geq 9,6$ & 3,3 & 23,7 & $46(14,9 \%)$ & $71(23,0 \%)$ \\
\hline Intermed. & $1,2<\mathrm{N}<9,6$ & 40,6 & 60,0 & $186(23,8 \%)$ & $208(26,6 \%)$ \\
\hline Raras & $\mathbf{N} \leq 1,2$ & 56,1 & 16,3 & $60(28,3 \%)$ & $69(32,5 \%)$ \\
\hline \hline $\begin{array}{c}\text { Total } \\
\text { Absoluto }\end{array}$ & -- & $\mathbf{2 4 1}$ & $\mathbf{1 3 0 1}$ & $\mathbf{2 9 2}$ & $\mathbf{3 4 8}$ \\
\hline \hline
\end{tabular}

É característico das florestas tropicais um baixo número de espécies arbóreas deter uma considerável porcentagem de indivíduos na floresta, com a maioria das espécies possuindo baixa densidade populacional (Hubbell \& Foster, 1986; Rolim \& Nascimento, submetido).

Nota-se que as três classes de abundância apresentaram crescimento na densidade de árvores de 1980 a 1995. O acréscimo foi maior na classe de comuns $(8,1 \%)$ do que na classe de raras $(4,2 \%)$, com a classe de comuns apresentando a menor porcentagem de mortalidade $(14,9 \%)$ e recrutamento $(23 \%)$.

A classe de raras apresentou a maior porcentagem de recrutamento $(32,5 \%)$ e mortalidade $(28,3 \%)$. Portanto, apesar das espécies de 
maior número de indivíduos apresentarem maior recrutamento e mortalidade (correlação altamente significativa pelo coeficiente de Spearman), o conjunto de espécies de baixa densidade (classe de abundância rara) apresentou maior recrutamento e mortalidade que o conjunto de espécies com alta densidade (classe de abundância comum). Na realidade são nestas duas classes mais baixas de abundância (intermediárias e raras) que o distúrbio age como mantenedor da diversidade, realizando o rodízio de espécies na comunidade através de mortalidade e recrutamento de novos indivíduos.

\subsection{A Influência do Clima}

Para se entender melhor a situação apresentada deve-se ter em mente o papel dos distúrbios naturais na dinâmica da floresta. $O$ ano de 1989 foi caracterizado pelo maior número de árvores mortas (árvores que morreram após o levantamento de 1986) do período de estudo (50\% do total de árvores mortas).

A elevação repentina da mortalidade neste período está associada por um período prolongado de seca (4 meses) que ocorreu de maio a agosto do ano de 1987 (Figura 4). Jordy (1987) chama a atenção para esta marcante decidualidade que ocorre no inverno (período seco).

$\mathrm{Na}$ Figura 5 observa-se que o segundo período mais seco (maio a agosto de 1983) ao longo dos últimos 21 anos apresenta precipitação bem superior ao período seco do ano de 1987 (soma de maio a agosto de $1983=68,7 \mathrm{~mm}$ e soma de maio a agosto de $1987=23,2 \mathrm{~mm}$ ), demonstrando que o evento ocorrido em 1987 foi único entre 1975 e 1995.

E mesmo com essa elevada taxa de mortalidade, detectada em 1989, a floresta já se encontrava perfeitamente balanceada em 1992, demonstrando uma alta capacidade de resiliência em relação a este distúrbio. 
Figura 4. Distribuição da precipitação em 1987 e a média dos últimos 21 anos (RFL: 1975 a 1995)

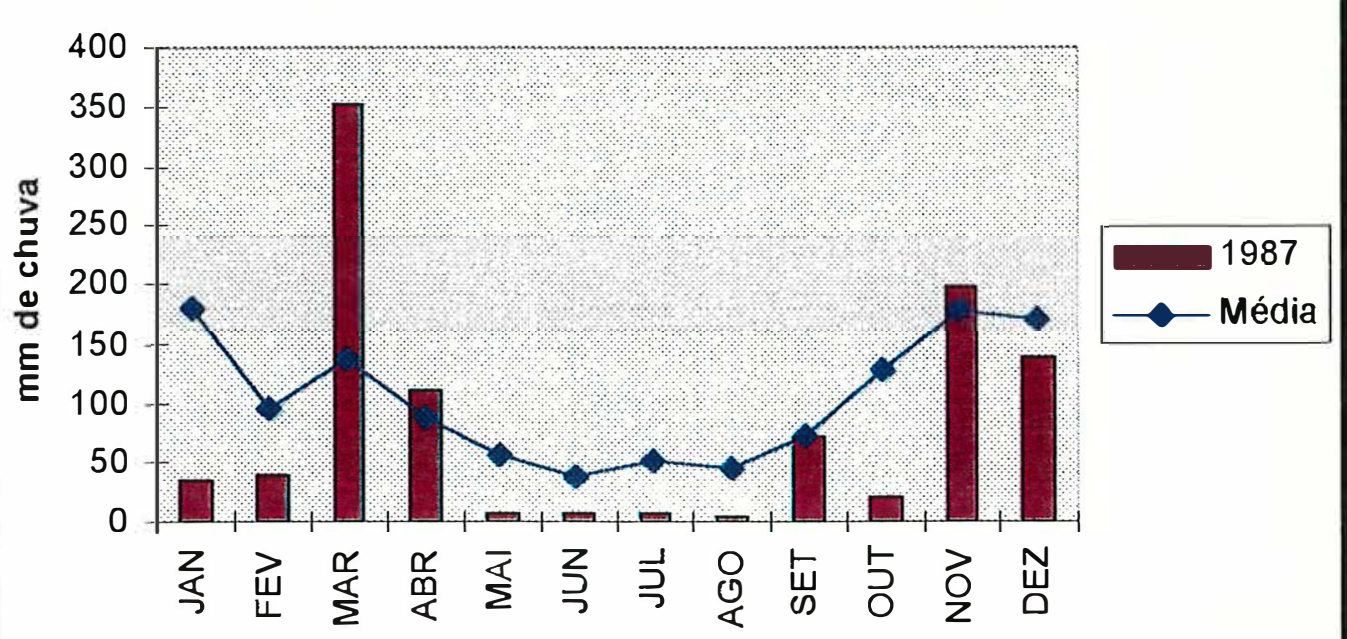

Figura 5. Distribuição da precipitação nos dois anos de inverno mais seco de 1975 a 1995 (RFL: maio a agosto).

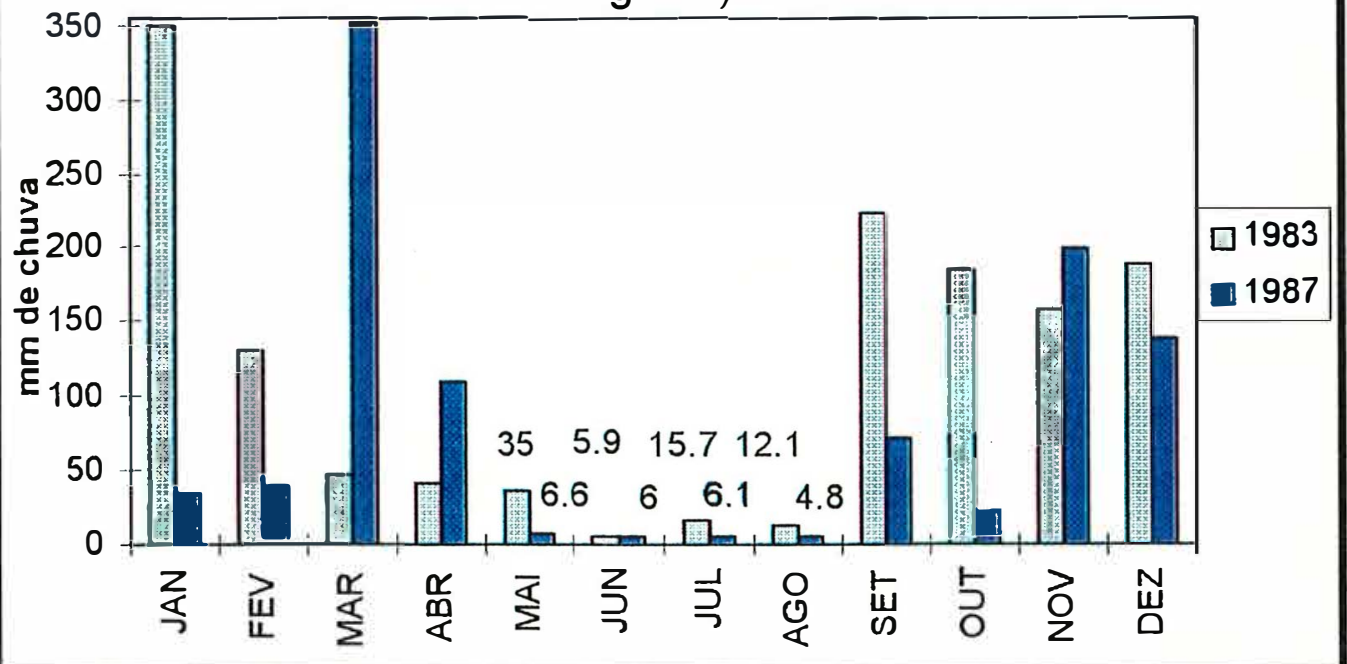


Distúrbios mais extremos são uma característica normal de florestas tropicais. Os processos de mortalidade, crescimento e recrutamento são influenciados por distúrbios, os quais podem operar sobre uma ampla variedade de escalas temporais e espaciais (White \& Pickett, 1985). Existe uma estreita adaptação da floresta a esses distúrbios, refletida na sua grande capacidade de resiliência, mas que é pouco explorada na literatura (Lugo, 1995).

Essa adaptação é tão estreita que a simples idéia de distúrbio como uma ruptura no "estado normal" do ecossistema, comunidades ou populações, com posterior "recuperação" é inapropriada e uma definição mais adequada para distúrbio seria "um evento relativamente discreto causando uma alteração na estrutura física do ambiente" (Clark, 1990).

Obviamente que só com uma boa caracterização do distúrbio ocorrido (tipos de danos e intensidade) é que se poderia inferir sobre a dinâmica do recrutamento. Seria de se esperar que com a morte de muitas árvores o recrutamento fosse significativo para espécies mais exigentes em luz como pioneiras e secundárias iniciais, já que este seria o mais imediato e talvez mais importante efeito da abertura de clareiras sobre as plantas (Denslow, 1987). Nota-se pela Tabela 3 que o recrutamento praticamente dobrou do ano de 1986 para o ano de 1989 e continuou alto nos intervalos posteriores, entretanto a densidade de pioneiras e secundárias iniciais não se alterou no período (Tabela 1).

Nem todas as árvores criam clareiras ("visíveis") quando morrem (Denslow \& Hartshorn, 1994). Mesmo com a elevação da mortalidade em 1989 o nivel de luz proporcionado ao sub-bosque pode não ter sido suficiente para o recrutamento de espécies mais exigentes, como as pioneiras. Entretanto também não deve ser descartado que o período de 8 anos (1987 a 1995) pode não ter sido suficiente para que estas espécies atingissem a classe mínima de DAP $(10 \mathrm{~cm})$. 
Mas, mesmo no caso da abertura de grandes clareiras, Vandermeer et. al. (1990) questionam que o processo de regeneração seja dominado por espécies pioneiras, mas sim pelo crescimento de espécies já existentes, via rebrotação epicórnica ou plântulas.

Esses resultados dão uma idéia da importância do componente probabilístico no recrutamento de árvores na floresta como colocado por Shugart (1987) e Schupp et al. (1989). Alguns fatores que proporcionam esse sucesso diferencial de espécies após um distúrbio são citados, entre outros, por Hartshorn (1978): dormência de sementes, grau de tolerância à sombra, disponibilidade de sementes (via chuva ou banco do solo) e plântulas no momento de abertura da clareira, condições do substrato, predação, intensidade e qualidade de luz, etc., inclusive com variações de algumas destas características ao longo do ano (Shugart, 1987) e considerando-se ainda que somente umas poucas das milhares de plântulas presentes num sítio alcançarão um "status reprodutivo".

Lieberman et. al. (1989) colocam que criou-se um paradigma onde há uma dicotomia de clareiras vs. não-clareiras. No desenho de muitos estudos fica implícita a noção de que a não-clareira é um padrão contra o qual as clareiras podem ser avaliadas. Esse conceito, que considera a floresta como um "queijo-suiço", não faz justiça à real complexidade de fatores atuantes no ambiente florestal. De fato as áreas de não-clareiras são tão heterogêneas quanto as clareiras e não devemos simplesmente entender a clareira como um buraco na floresta. Mais importante que o tamanho da clareira é o contínuo nível de luz ou grau de fechamento do dossel, experimentado pelas árvores dentro da floresta.

A relação de um distúrbio, como o registrado em Linhares (ES) e em outros estudos (Hubbell \& Foster, 1990a; Primack \& Hall, 1992), com a dinâmica da floresta é muito mais sutil que distúrbios provocados por 
furacões ou grandes tempestades que ocasionam a queda múltipla de árvores na floresta.

Esta sutileza de relações em sistemas naturais tem sido estudada por modelos fractais, que descrevem a geometria de uma ampla variedade de objetos naturais (Sugihara \& May, 1990). Um dos exemplos mais recentes dos avanços desta linha de pesquisa foi mostrar que a distribuição espacial de clareiras na floresta da llha de Barro Colorado (Panamá) exibe propriedade fractal (Solé \& Manrubia, 1995). Esta propriedade demonstra que existem padrões similares que se replicam em diferentes escalas, onde pequenos distúrbios envolveriam a criação de clareiras de todos os tamanhos. As plantas "percebem" clareiras muito diferentemente das pessoas e devemos reavaliar nossa idéia de "clareira" (Swaine, 1989). 


\section{Conclusões}

Existe uma flutuação na densidade de árvores da floresta, plenamente balanceada pelas taxas de mortalidade e recrutamento de árvores. Para uma adequada interpretação desta flutuação são necessários curtos intervalos entre medições (2 a 3 anos por exemplo).

A taxa de mortalidade de árvores na floresta atlântica em Linhares está dentro do esperado para uma floresta madura e a meia vida estimada para os grupos ecológicos reflete melhor a longevidade das espécies do que a meia vida calculada para a floresta como um todo. As espécies pioneiras apresentaram uma mortalidade significativamente maior que espécies de caráter mais tardio. Tanto a mortalidade como o recrutamento de árvores não são uniformemente distribuídos no espaço. Notou-se também uma maior taxa de mortalidade de grandes árvores, que geralmente está associada a distúrbios mais severos, como o que ocorreu em Linhares (ES). Estes resultados confirmam outros estudos.

A floresta demonstrou uma alta resiliência ao distúrbio ocorrido, indicando um equilíbrio estrutural da floresta no período. As espécies com mais indivíduos são mais adaptadas às condições de distúrbios tendendo a manter suas abundâncias por elevadas taxas de mortalidade e recrutamento. 


\section{CAPÍTULO IV}

\section{VARIAÇÕES TEMPORAIS E ESPACIAIS NA COMPOSIÇÃO FLORISTICA DA FLORESTA ATLÂNTICA EM LINHARES (ES): 1980 a 1995}

\section{Introdução}

O número de espécies arbóreas numa floresta é constante ao longo do tempo? A composição florística retorna à original após um distúrbio? Estas duas perguntas, a princípio bastante simples, têm concentrado os estudos de inúmeros pesquisadores nos últimos anos, que procuram as respostas através do uso de parcelas permanentes. Essa metodologia para estudos de longo prazo não é fato novo em florestas tropicais: J. Wyatt Smith iniciou em 1947 na Malásia um trabalho em 2,02 ha, nos quais todas as árvores com $30 \mathrm{~cm}$ ou mais de altura eram identificadas e marcadas. Uma das últimas análises deste estudo foi publicada por Manokaram \& Kochummen em 1987. Crow (1980) apresentou uma análise sobre um período de 33 anos (1943 a 1976) em 0,72 ha de uma floresta tropical em Porto Rico. Okali \& Ola-Adams (1987) apresentam uma análise sobre 2,25 ha, abrangendo o período de 1952 a 1981 numa Reserva na Nigéria.

Entretanto, só a partir da instalação de parcelas permanentes maiores em La Selva (Costa Rica - 1969/70) e em Barro Colorado (Panamá - 1980) e com a publicação dos resultados a partir de meados da década de 80 é que esta linha de pesquisa ganhou notoriedade. A parcela de Barro Colorado, sob coordenação da Smithsonian Tropical Research Institution, tornou-se um referencial importante por tratar-se de uma área contínua de 50 ha, na qual todos os indivíduos maiores que $1 \mathrm{~cm}$ de diâmetro à altura do peito (DAP) são medidos e mapeados. A influência foi tanta no meio científico que já 
existem parcelas equivalentes, onde são aplicadas as mesmas metodologias, nos seguintes locais: Pasoh e Lambir (Malásia), Mudumalai (Índia) e Huai Kha Khaeng (Tailândia) (Condit, 1995).

No Brasil esta linha também começa a ganhar espaço, havendo dados para a região Amazônica (Rankin-de-Merona et al. 1990; Jardim, 1990; Carvalho, 1992), para a mata ciliar do Rio Gama em Brasília (DF) (Felfili, 1995), para a floresta atlântica em Linhares (ES) (Jesus et al., 1992; Batista, 1994) e para florestas semi-decíduas em São Paulo (Santos et al., não publicado; Nascimento, 1997).

Estudos desse nível demandam um razoável investimento financeiro: Condit (1995) relata a quantia de U\$ 150.000 para o primeiro levantamento na parcela de 50 ha em Barro Colorado, e de U\$100.000 nos subsequentes. Entretanto esses valores variam amplamente de local para local, em função das instalações, do suporte existente e principalmente do tamanho da área. Já o valor das informações obtidas a partir destes estudos é praticamente inestimável, pois delas podem resultar métodos e técnicas de manejo florestal que conduzam ao uso sustentável dos recursos florestais.

Neste Capítulo pretende-se abordar as variações temporais e espaciais que ocorreram na composição florística da floresta atlântica em Linhares (ES) num período de 15 anos e sob condições naturais de distúrbios. 


\section{Método de Análise}

Para as análises das variações temporais e espaciais no número de espécies as variáveis independentes, ano e parcela, constituíram um delineamento experimental em blocos ao acaso, onde os anos de amostragem foram relacionados como blocos e as parcelas como tratamentos.

Foram consideradas duas hipóteses de nulidade:

1.) O número de espécies (S) não difere estatisticamente entre os anos de amostragem:

$H_{0}: S_{1980}=S_{1983}=S_{1986}=S_{1989}=S_{1992}=S_{1995}$

$H_{a}$ : pelo menos um dos anos de amostragem apresentou diferença significativa no número de espécies.

2.) O número de espécies (S) não difere estatisticamente entre as unidades de amostra (parcelas):

$H_{0}: S_{\text {par1 }}=S_{\text {par2 }}=S_{\text {par3 }}=S_{\text {par4 }}=S_{\text {par5 }}$

$H_{a}$ : pelo menos uma das parcelas difere significativamente das demais em relação ao número de espécies. 


\section{Resultados e Discussão}

\subsection{Flutuações no número de espécies}

$O$ número de espécies com DAP $\geq 10 \mathrm{~cm}$ amostrados no período de monitoramento foi de 266 (sendo 9 espécies identificadas como morfo-espécies e 20 ao nível genérico), distribuídos em 154 gêneros e 51 famílias, de acordo com o Sistema de Cronquist.

Esse resultado é altamente expressivo pois em 5 parcelas de 0,5 ha foram amostradas $42,4 \%$ das espécies arbóreas já identificadas em todos os tipos de vegetação da RFL, de acordo com a aproximação de janeiro de 1996. Ao longo de todo o período ocorreram em média 110,6 espécies por parcela de 0,5 ha ou 163 espécies/ha (DAP $\geq 10 \mathrm{~cm}$ ), considerando-se a média das 5 parcelas duas a duas. O número médio de espécies amostradas em cada levantamento foi de 241,3 (232 a 248).

Peixoto \& Gentry (1990) já citam que o aspecto mais surpreendente da Floresta Atlântica em Linhares é a grande riqueza de espécies vegetais. Em apenas 0,1 ha (10 faixas de $2 \times 50 \mathrm{~m}$ ) registraram 99 espécies com DAP $\geq 10 \mathrm{~cm}$, revelando mais espécies que amostras equivalentes feitas na Amazônia. Somente estudos feitos em florestas não sazonais na Amazônia Superior, na região de Chocó (Colômbia) e na floresta de Dipterocarpaceae em Bornéo mostraram áreas tão ricas em espécies.

Siqueira (1994) sugere que o local seja uma sobreposição das áreas de distribuição geográfica do Nordeste e Sudeste/Sul, ou seja, um centro de diversidade altamente importante. A origem de centros de diversidade na floresta atlântica pode estar associada à instabilidade geológica de sucessivos avanços e retrações da floresta (ver revisão em: Prance, 1982; Salgado-Labouriau, 1994). Além de Linhares no nordeste do Espirito Santo, outros centros de endemismo citados se localizam em Pernambuco, ao sul da Bahia e arredores da cidade do Rio de Janeiro. 
As espécies apresentaram a seguinte proporção por grupo ecológico: $3,76 \%$ no grupo de pioneiras, 30,8\% para as secundárias iniciais, $25,9 \%$ para as secundárias tardias e $39,5 \%$ para as climácicas. A pequena proporção de espécies pioneiras no total da flora é uma característica típica das florestas tropicais maduras (Whitmore, 1984), já que são mais dependentes de luminosidade para germinação e estabelecimento (Denslow, 1980). Além disso a baixa riqueza em espécies também é uma característica do grupo (Hartshorn, 1978; Martínez-Ramos, 1985; Whitmore, 1989).

A Tabela 6 apresenta o número de espécies ao longo do período para cada grupo ecológico e para toda a floresta:

Tabela 6. Número de espécies por grupo ecológico de 1980 a 1995 em 5 parcelas permanentes de 0,5 ha na RFL.

\begin{tabular}{ccccccc}
\hline Nivel & $\mathbf{1 9 8 0}$ & $\mathbf{1 9 8 3}$ & $\mathbf{1 9 8 6}$ & $\mathbf{1 9 8 9}$ & $\mathbf{1 9 9 2}$ & $\mathbf{1 9 9 5}$ \\
\hline \hline Pioneiras & 10 & 10 & 9 & 8 & 8 & 9 \\
Sec. Iniciais & 77 & 78 & 78 & 75 & 75 & 77 \\
Sec. Tardias & 64 & 65 & 65 & 58 & 59 & 61 \\
Climácicas & 90 & 95 & 93 & 91 & 93 & 100 \\
\hline \hline Floresta & 241 & 248 & 245 & 232 & 235 & 247 \\
\hline \hline
\end{tabular}

Entre o primeiro e o último levantamento foi observado um acréscimo geral de $2,48 \%$ no número de espécies. Para os grupos ecológicos as variações foram de $-10 \%$ para pioneiras, $-4,68 \%$ para secundárias tardias e $+11,11 \%$ para climácicas, não havendo alteração no número de espécies secundárias iniciais. Evidentemente que no caso das espécies pioneiras qualquer acréscimo resulta em altos valores percentuais, devido ao baixo número de espécies amostradas.

A Figura 6 detalha os níveis abordados na Tabela 6 , à medida que mostra as flutuações em cada uma das 5 parcelas monitoradas. 

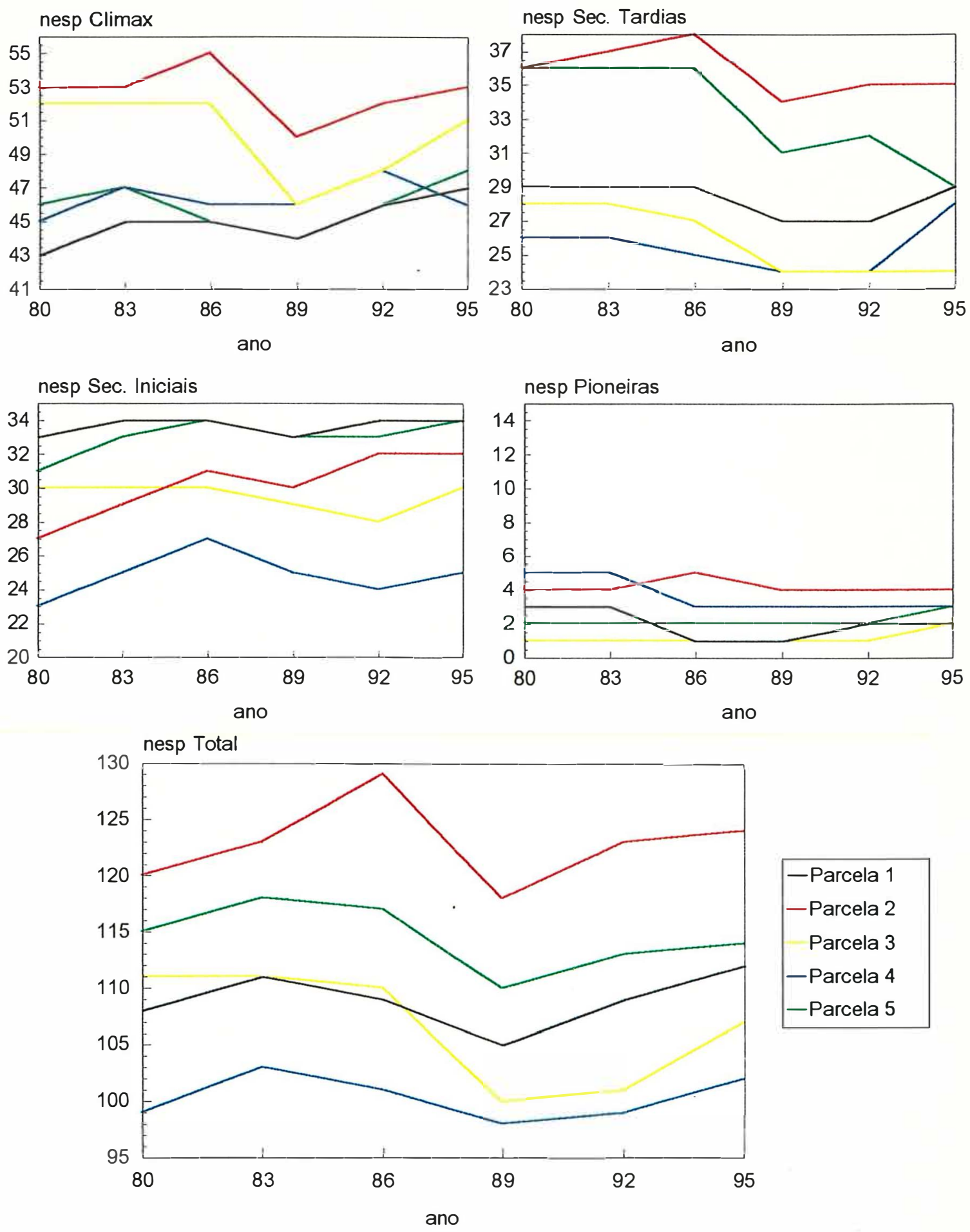

Figura 6 - Flutuacões Temporais no Número de Espécies Arbóreas (nesp) por Grupo Ecológico e para a Área total na Floresta Atlântica em Linhares(ES). 
O resultado é um padrão encontrado em inúmeros estudos de longo prazo em florestas tropicais, variando entretanto a amplitude que a curva assume em cada floresta, que é função direta da intensidade e freqüência de distúrbios ao qual a floresta está adaptada.

Mesmo numa mesma área, como nesse caso, a flutuação não ocorre da mesma maneira em todas as parcelas (trechos da floresta), ou seja, num mesmo intervalo de medição algumas parcelas apresentaram acréscimo enquanto outras apresentaram decréscimo no número de espécies.

Mas até que ponto estas flutuações são significativas? 0 teste $F$ rejeitou ambas as hipóteses de nulidade $(p<0.05)$ e os resultados apresentados na Tabela 7 mostram que para a floresta como um todo podem ser encontradas variações temporais significativas no número de espécies, mesmo em curtos intervalos de 3 anos e considerando-se apenas distúrbios naturais.

Deste modo, efeitos importantes da dinâmica florestal podem ser subestimados em intervalos longos de monitoramento. Da mesma maneira, os resultados apresentados na Tabela 8 mostram que ocorrem diferenças significativas no número de espécies, entre diferentes trechos da floresta.

Os resultados são esperados, considerando-se que a floresta é um mosaico sucessional, influenciada por eventos aleatórios como a formação de clareiras, a mortalidade e o recrutamento de espécies, mostrando que a riqueza florística e a diversidade não são constantes na escala deste estudo, mas mudam em resposta a distúrbios de curto a longo prazo (Bruenig, 1996). 
Tabela 7. Variações temporais do número de espécies em cada grupo ecológico e para o total da floresta (os resultados referem-se à media de 5 parcelas em cada levantamento).

\begin{tabular}{lcccccccc}
\hline NivellAno & $\mathbf{1 9 8 0}$ & $\mathbf{1 9 8 3}$ & $\mathbf{1 9 8 6}$ & $\mathbf{1 9 8 9}$ & $\mathbf{1 9 9 2}$ & $\mathbf{1 9 9 5}$ & $\mathbf{F}$ & Pr>F \\
\hline \hline Pioneiras & 3 & 3 & 2,4 & 2,2 & 2,4 & 2,8 & 1,34 & 0,288 \\
\hline Sec. Iniciais & 28,8 & 30,2 & 31,2 & 30 & 30,2 & 31 & 3,57 & 0,018 \\
\hline Sec. Tardias & 31 & 31,2 & 31 & 28 & 28,4 & 29 & 5,03 & 0,004 \\
\hline Climácicas & 47,8 & 48,8 & 48,6 & 46 & 47,8 & 49 & 2,92 & 0,038 \\
\hline \hline Floresta & $\mathbf{1 1 0 , 6}$ & $\mathbf{1 1 3 , 2}$ & $\mathbf{1 1 3 , 2}$ & $\mathbf{1 0 6 , 2}$ & $\mathbf{1 0 9}$ & $\mathbf{1 1 1 , 8}$ & $\mathbf{7 , 1 7}$ & $\mathbf{0 , 0 0 0 5}$ \\
\hline \hline
\end{tabular}

Tabela 8. Variações espaciais do número de espécies em cada grupo ecológico e para o total da floresta (os resultados referem-se à media de 6 levantamentos em cada parcela).

\begin{tabular}{cccccccc}
\hline \hline NivellParcela & $\mathbf{1}$ & $\mathbf{2}$ & $\mathbf{3}$ & $\mathbf{4}$ & $\mathbf{5}$ & $\mathbf{F}$ & Pr>F \\
\hline \hline Pioneiras & $\mathbf{2}$ & 4,1 & 1,1 & 3,6 & $\mathbf{2 , 1}$ & $\mathbf{2 0 , 9 4}$ & 0,0001 \\
\hline Sec. Iniciais & 33,6 & 30,1 & 29,5 & 24,8 & 33 & 72,51 & 0,0001 \\
\hline Sec. Tardias & 28,3 & 35,8 & 25,8 & 25,5 & 33,3 & 60,23 & 0,0001 \\
\hline Climácicas & 45 & 52,6 & 50,1 & 46,1 & 46 & 30,66 & 0,0001 \\
\hline Floresta & $\mathbf{1 0 9}$ & $\mathbf{1 2 2 , 8}$ & $\mathbf{1 0 6 , 6}$ & $\mathbf{1 0 0 , 3}$ & $\mathbf{1 1 4 , 5}$ & $\mathbf{8 4 , 1 8}$ & $\mathbf{0 , 0 0 0 1}$ \\
\hline \hline
\end{tabular}

A maior porcentagem de variação ocorre entre os anos de 1986 e 1989, (Tabelas 6 e 7). Essa variação pode ser observada na Figura 6 em todas as parcelas. Esse fato pode ser atribuído aos 4 meses de seca ocorrida de maio a agosto de 1987. A análise de dados climáticos na RFL mostra que, à exceção do ano de 1987, não houve nenhum outro período de 1975 a 1995 de 4 meses consecutivos de baixa precipitação $(4,8$ a 6,6 mm), sendo que a média nesses meses varia de 36,5 a 54,9 mm (ver Figuras 4 e 5 no Capítulo III).

Muitos atributos da estrutura e dinâmica das florestas tropicais se encontram intimamente relacionados com a variação espacial e temporal do ambiente abiótico. Diversos comportamentos fenológicos, tais como os padrões estacionais de floração e frutificação nas plantas, se relacionam com os ritmos estacionais do clima (Martínez-Ramos, 1991). 
O trabalho de Hubbell \& Foster (1990) mostra que o fenômeno conhecido como "El Niño" produziu um acentuado déficit hídrico na floresta de Barro Colorado/Panamá, afetando significativamente a estrutura de populações de algumas espécies e influenciando a dinâmica de regeneração da comunidade. Em estudo posterior Condit et al. (1992) mostraram que a floresta já apresentava uma tendência à recuperação.

Não pode ser desprezado que distúrbios como estes atuam como importantes fatores na estrutura e composição florística de comunidades e no controle populacional de plantas, talvez tão importantes como os processos de formação de clareiras em florestas tropicais.

Reice (1994) conclui que distúrbios são o maior mecanismo denso-independente na redução de populações. A remoção de indivíduos cria a oportunidade para a colonização de novas espécies, alterando a composição da comunidade e funcionando com um instrumento para gerar uma alta diversidade de espécies.

Uma constatação de que o déficit hídrico foi atípico (entendido aqui como um evento de baixa freqüência, porém de ocorrência natural) foi obtida com a exclusão deste período da análise estatística. Ao retirarmos o ano de 1989 da análise desaparecem as diferenças encontradas entre os anos de amostragem, para o parâmetro número de espécies $(p>0,05)$.

O mesmo efeito não foi obtido com a exclusão de outros anos de amostragem mostrando a importância do distúrbio, ocorrido em 1987 e refletido em 1989, na dinâmica da floresta.

Uma outra observação importante diz respeito à tendência de recuperação da floresta (para o parâmetro número de espécies) já em 1992 (Tabela 6 e Figura 6). Conforme as definições apresentadas na revisão, esse resultado demonstra uma alta resiliência da floresta para este tipo de distúrbio. 
Nota-se entretanto a ausência de recrutamento de novas espécies pioneiras após o distúrbio. Apesar da importância do distúrbio não houve, provavelmente, condições favoráveis de luminosidade ou tempo suficiente para recrutamento destas espécies.

Obviamente que após algum distúrbio, que proporcione a formação de grandes clareiras, esse grupo poderia ser beneficiado, já que este seria um evento crucial para o recrutamento de espécies deste grupo. Ao contrário, para as espécies mais tolerantes o recrutamento seria menos dependente de grandes clareiras.

\subsection{Alterações na composição florística}

Não podemos nos esquecer que ao retratarmos a dinâmica da floresta apenas em números estaremos fatalmente encobrindo o processo de substituição de espécies ao longo do período.

Das 241 espécies presentes no levantamento de 1980 (DAP $\geq 10 \mathrm{~cm}), 17(7,05 \%)$ desapareceram no período, sendo 1 pioneira, 5 secundárias iniciais, 7 secundárias tardias e 4 climácicas. Em contrapartida 23 (9,54\%) novas espécies foram amostradas no levantamento de 1995 , sendo 5 secundárias iniciais, 4 secundárias tardias e 14 climácicas. Este balanço foi mais positivo para o grupo de climácicas.

As 17 espécies que desapareceram das 5 parcelas apresentaram 2 características em comum: eram espécies com baixa densidade populacional ( 1 ou 2 indivíduos amostrados) e pertencentes às menores classes diamétricas.

Primack \& Hall (1992) colocam que espécies com tamanho populacional pequeno são mais propensas ao desaparecimento nas parcelas (causando o que se convencionou chamar de "extinção local de espécies") já 
que a mortalidade de apenas poucos indivíduos conduziria a uma perda total para a espécie naquela localidade.

É importante ressaltar que esse pequeno tamanho populacional está intimamente relacionado com o tamanho da amostra e seria muito pouco provável que esse fenômeno de desaparecimento de determinadas espécies nas parcelas represente um evento que estaria ocorrendo ao nível populacional nestas espécies.

Por serem espécies com baixa densidade populacional, pouco se pode dizer sobre sua estrutura demográfica em estudos de pequena escala ( 2,5 ha nesse caso).

Em relação ao tamanho populacional de espécies raras, diversos trabalhos (por exemplo Lepsh-Cunha, submetido) tem mostrado que devido ao fluxo gênico à longa distância, apresentam um tamanho de vizinhança grande, ou seja, estando os indivíduos distribuídos numa área muito grande não se pode extrapolar (ou mesmo definir) o desaparecimento de 1 ou 2 destes indivíduos (numa pequena área amostral) à ocorrência de extinção local.

Para ilustrar esse fato apresentamos na Tabela 9 a abundância (ou número de indivíduos amostrados) das 17 espécies que desapareceram das parcelas (de 1980 a 1995), em uma área amostral de 40 ha (não contínuos) na RFL (dados não publicados). 
Tabela 9. Espécies que desapareceram de 1980 a 1995 nas 5 parcelas de monitoramento e suas abundâncias (número de indivíduos) numa amostra de 40 ha não contínuos de floresta:

\begin{tabular}{lc}
\hline $\begin{array}{c}\text { Espécies com } 1 \text { ou } 2 \text { individuos que } \\
\text { desapareceram de } 1980 \text { a } 1995 \text { nas } 5 \text { parcelas } \\
\text { monitoradas (2,5 ha). }\end{array}$ & $\begin{array}{c}\text { Abundância numa } \\
\text { amostra de } 40 \text { ha na } \\
\text { RFL }\end{array}$ \\
\hline \hline Pourouma guianensis Aubl. ssp. Guianensis & 99 \\
Eugenia oblongata & 28 \\
Inga striata Benth & 25 \\
Eugenia aff. Oxyphylla Berg. & 21 \\
Swartzia apetala Raddi & 21 \\
Qualea magna Kuhlm. & 19 \\
Vitex cf. montevidensis Cham. & 17 \\
Citronella paniculata (Mart.) Howard. & 15 \\
Hirtella hebeclada Moric. ex. A. DC. & 15 \\
Casearia ulmifolia Vahl. ex Vent. & 14 \\
Myrciaria amazonica Berg. & 12 \\
Rauvolfia mattfeldiana Markgr. & 6 \\
Unonopsis linduanii R. E. Fr. & 6 \\
Hirtella insignis Briq. Ex. Prance & 1 \\
Platymiscium floribundum Vogel & 1 \\
Schizolobium parahyba (Vell.) Blake & 1 \\
Myrcia clausseniana (Berg.) Barroso et Peixoto & 0 \\
\hline \hline
\end{tabular}

Esses resultados mostram um problema estatístico para o monitoramento de espécies com baixa densidade populacional. Nesse sentido, somente um monitoramento em grande escala é que poderia responder sobre o comportamento temporal de espécies de baixa densidade populacional e mesmo nessa escala ainda teríamos muitas espécies muito raras que necessitariam de maior área de monitoramento (Hubbell \& Foster, 1986; Rolim \& Nascimento, submetido). 
Uma outra análise deste fenômeno de "extinção local" e recrutamento foi realizada, desta vez procurando observar o que ocorreu em cada parcela separadamente. Alguns dos resultados encontrados são apresentados a seguir:

- 60 espécies desapareceram de 1 das parcelas de 1980 a 1995.

- 04 espécies desapareceram de 2 das parcelas de 1980 a 1995.

- 03 espécies desapareceram de 1 das parcelas após 1980 e foram recrutadas nas mesmas até 1995.

- 58 espécies foram recrutadas em 1 das parcelas após 1980.

- 07 espécies foram recrutadas em 2 das parcelas após 1980.

- 06 espécies foram recrutadas em 1 das parcelas após 1980 e desapareceram das mesmas até 1995.

Pode ser notado que em relação ao ano de $1980,27,8 \%$ das espécies $(60+4+3)$ desapareceram de pelo menos 1 das parcelas, contra $29,4 \%(58+7+6)$ de espécies que foram recrutadas para a classe de $10 \mathrm{~cm}$ de DAP em pelo menos uma das parcelas ao longo do período.

Notam-se espécies que foram "extintas" e recrutadas posteriormente, ou vice-versa. Há ainda muitas espécies que apresentaram "extinção local" numa determinada parcela, mas tiveram sua abundância aumentada ou diminuída em outra. Outras não apresentaram alterações no período.

Como pode ser observado muitas espécies desaparecem, sendo que algumas podem mesmo não retornar, enquanto que outras aparecem e podem se estabelecer e há ainda aquelas que ocorrem somente como componentes efêmeros da comunidade (van der Maarel, 1984; Hubbell \& Foster, 1986). 
Isso mostra que pelo menos numa escala reduzida a composição florística da floresta tropical não é estática, mas varia em pequenas e médias escalas temporais e espaciais (Bruenig, 1996). Apesar da pequena escala do estudo, parece haver uma aproximação dos resultados com a teoria da biogeografia de ilhas, a qual prediz que as comunidades estão em equilíbrio com respeito ao número de espécies (um balanço entre imigração e extinção local de espécies), porém em desequilíbrio taxonômico (Hubbell \& Foster, 1987).

Para Hubbell \& Foster $(1986,1987)$ a manutenção da alta diversidade de espécies arbóreas em florestas tropicais parece estar relacionada com a riqueza regional e subcontinental de espécies e com a disponibilidade de imigrantes potenciais. Todos esses fatores por sua vez controlados pelas interações entre o clima, história de vida e processos de especiação.

A fonte dessa variação estaria então associada ao que podemos chamar de potencial florístico da comunidade. A comunidade funcionaria como um sistema aberto, com intensa troca de propágulos a um nivel local e com um balanço entre extinção local e imigração de espécies a um nivel regional ou subcontinental.

A Figura 7 esquematiza esse potencial apenas para as espécies amostradas em 2,5 ha ao longo de 15 anos. Numa escala maior, para - caso específico da RFL o potencial florístico seria formado num primeiro momento pelas 657 espécies arbóreas (incluindo-se palmeiras) já identificadas na sua área de quase 22000 ha. Como uma importante fonte de troca numa escala regional para a RFL podemos citar a Reserva Biológica de Sooretama, um pouco maior que a RFL, com uma área de 24250 ha. 

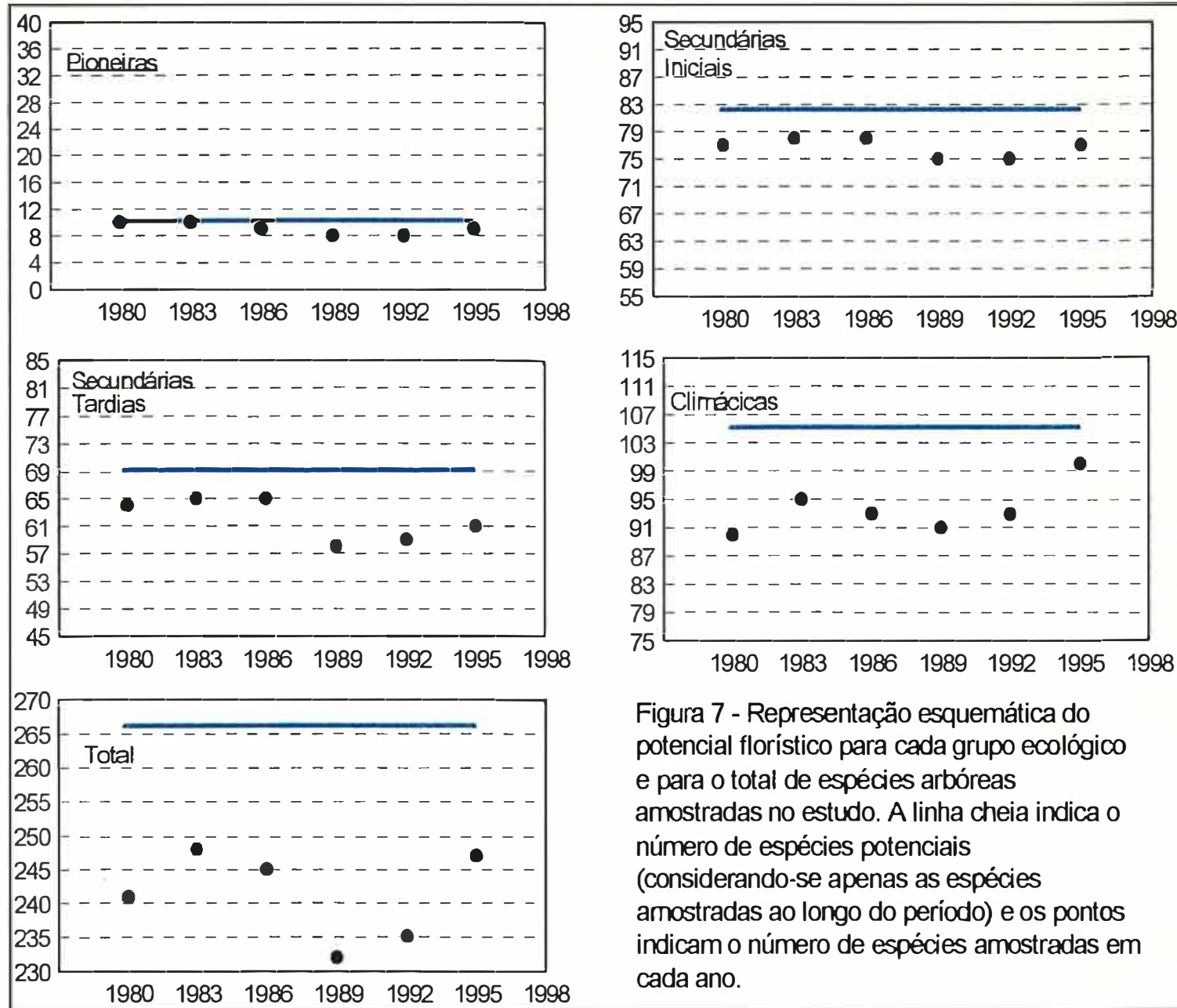

Figura 7 - Representação esquemática do potencial florístico para cada grupo ecológico e para o total de espécies arbóreas amostradas no estudo. A linha cheia indica 0 número de espécies potenciais (considerando-se apenas as espécies amostradas ao longo do periodo) e os pontos indicam o número de espécies amostradas em cada ano.

Lieberman et al. (1985) colocam que existe um conjunto grande de espécies disponíveis para preencher "espaços desocupados" na comunidade. A forma com que essa ocupação se dá sofre forte influência do acaso, sugerindo que esse é um importante fator que afeta a composição florística de uma comunidade.

Esse acaso estaria presente em todas as etapas do ciclo de vida do indivíduo: da dispersão de sementes à chegada num determinado habitat, na germinação, na sobrevivência à predação de sementes e plântulas, na competição, na sobrevivência a danos físicos e patógenos, no aproveitamento de eventos que favoreçam o crescimento e estabelecimento até 
a fase reprodutiva, etc. Em qualquer ponto no espaço e no tempo o conjunto de espécies potenciais para recrutamento é altamente variável (Reice, 1994).

O conceito de extinção local é muito mais amplo do que tem sido utilizado na literatura. As populações flutuam e são nômades, mudando suas posições ao longo do tempo, às vezes se ampliando ou se retraindo, até às vezes se extinguindo (Kageyama \& Gândara, 1994).

Os resultados indicam que a chamada "extinção local de espécies" é um evento temporal, dependente do sucesso de estabelecimento e recrutamento da regeneração natural de cada espécie. A origem desse processo de substituição deve se dar a partir das variações espaciais e temporais na composição dos bancos de sementes e de plântulas (Strong et al., 1989).

Outras situações devem ser consideradas com cautela na análise da "extinção local", como o DAP mínimo de amostragem ou o caso de espécies que são ocasionais e que desaparecem sob condições limitantes, ou ainda as espécies que recentemente migraram para o local (Bawa \& Ashton, 1991). Estas espécies podem levar milhares de anos para atingir uma determinada área ou região, mas antes que se estabeleçam, e por simples obra do acaso, podem desaparecer sem nem mesmo deixar vestígios. Há ainda aquelas espécies que são raras em alguns locais (restritos ou desfavoráveis), mas são comuns em outros (Bawa \& Ashton, 1991) e espécies que são raras porque são relíquias, fósseis vivos ou raras por terem origem recente (Kesseli, 1992).

Discutir o tamanho de populações fica praticamente impossivel para a maioria das espécies amostradas neste trabalho, nem tampouco é esse o objetivo proposto. Do mesmo modo não podemos discutir as causas da extinção de populações, mesmo porque além da destruição de 
habitats por atividades humanas, estas são pouco conhecidas (Futuyma, 1992).

Um outro fator geralmente colocado como importante é que espécies que apresentam falhas na regeneração também estariam mais propensas ao desaparecimento. Hubbell \& Foster (1987) citam que as razões sobre a presença ou ausência de regeneração de uma espécie são tão variadas como as causas de êxito ou fracasso reprodutivo de árvores tropicais.

Possíveis explicações para a ausência de regeneração incluem a ausência de clareiras (para as pioneiras), altas taxas de predação ou doenças em sementes e plântulas, fracasso na competição intra e interespecífica ou na competição por agentes polinizadores e dispersores, reprodução atrasada ou episódica, etc.

Por exemplo, Newstrom et al. (1994) mostram que 55\% das espécies em La Selva apresentam um padrão irregular e sub-anual de florescimento, $29 \%$ florescem anualmente, $7 \%$ florescem continuamente e $9 \%$ apresentam um padrão supra-anual. Mostram ainda que os padrões sub-anuais podem variar entre indivíduos de uma mesma espécie na floresta, incidindo profundamente na organização da comunidade (Martínez-Ramos, 1991).

Clark (1994) apresenta uma discussão para a espécie Dipteryx panamensis que é comum como adulto na floresta em La Selva (Costa Rica) e pouco comum no estágio juvenil. Entretanto a espécie não demostra declínio populacional. Esse fato parece ser muito comum em florestas tropicais. Clark (1994) cita o trabalho de Jones (1955) que encontrou para algumas espécies numa floresta nigeriana uma "deficiência" em algumas classes de tamanho. Entretanto o baixo número de indivíduos é compensado com uma alta taxa de crescimento nestas classes.

Turkington \& Aarssen (1984) citam que são comuns exemplos na literatura sobre a diferenciação sobre curtas distâncias em 
populações de plantas, que respondem à heterogeneidade ambiental (no espaço e no tempo) com a plasticidade fenotípica. O trabalho de Hubbell \& Foster (1987) mostra que ocorre grande variação espacial na estrutura populacional de uma mesma espécie, de um hectare a outro na floresta, tanto em espécies pioneiras como em espécies mais tardias. Poorter et al. (1996) também apresentam resultados que mostram variações na estrutura de tamanho de espécies do dossel em 5 sítios diferentes no oeste da África.

Todos esses fatores podem produzir distribuições de tamanho pouco comuns, não significando, necessariamente, que a espécie esteja em declínio populacional. Por um outro lado um possível declínio populacional pode estar indicando um ajuste da espécie a distúrbios naturais que criem novas condições ambientais ou então um ajuste à evolução do estágio sucessional da floresta.

\subsection{Implicações para conservação}

Populações pequenas são realmente muito mais susceptíveis de extinção, principalmente quando restritas a pequenas áreas, o que teoricamente implica em ambientes relativamente mais homogêneos. Uma análise mais aprofundada da susceptibilidade de espécies raras a distúrbios mereceria levar em conta os diferentes tipos de raridade, como colocado por Rabinowitz et al. (1986), Bawa \& Ashton (1991), Kesseli (1992) e Lepsh-Cunha (submetido). Entretanto parece bem razoável que espécies com baixa densidade populacional, mas distribuídas sobre uma área florestada muito ampla estariam mais protegidas da extinção, já que, por exemplo, sobreviveriam a mudanças ambientais que não sejam igualmente distribuídas de maneira ampla (Futuyma, 1992).

Em florestas fragmentadas muitas espécies de baixa densidade teriam sua mobilidade restrita se tornando mais vulneráveis à extinção local. Sob este ponto de vista as espécies raras tornam-se um 
importante referencial para a definição de tamanhos de reservas e conservação in situ de recursos genéticos, como já discutido por Kageyama \& Gândara (1994). Aliás, o debate em torno do tamanho de reservas em florestas tropicais se intensificou nas duas últimas décadas. Futuyma (1992) coloca que grandes áreas incluem mais habitats que mantêm diferentes espécies e podem abrigar grandes populações, as quais terão menor risco de extinção que pequenas populações.

É obvio que haveriam espécies tão raras que realmente poderiam estar no limiar de uma extinção populacional em uma determinada área. Entretanto não podemos nos esquecer que a extinção de espécies no seu sentido mais amplo ocorreu e ocorre na história da Terra e a seleção natural é um importante processo destas extinções. Ela fixa os indivíduos da população que se adaptam às novas condições, expurga outros, ou extingue a espécie (Salgado-Labouriau, 1994). Hubbell \& Foster (1987) citam estudos teóricos recentes (Wright \& Hubbell, 1983; Hubbell \& Foster, 1986) que indicam que o tempo para eliminar espécies idênticas é de centenas a milhares de gerações.

Mas nessa análise não podemos desconsiderar um fenômeno importante que é a perda da continuidade dos ecossistemas devido à fragmentação florestal, perda de habitats e poluição (Pimm, 1986; Martins, 1988). As primeiras conseqüências das alterações causadas pelo homem nos ecossistemas ocorrem normalmente sobre os padrões de distribuição geográfica e de abundância, podendo levar tanto à extinção (caso de espécies endêmicas), como à descontinuidade na distribuição geográfica, com implicações na estrutura demográfica e genética das populações (Martins, 1988).

Hubbell \& Foster (1986) sugerem que as espécies de baixa densidade na floresta tropical podem sofrer declínios catastróficos que levem à extinção local, obrigando que se leve em conta o tamanho populacional das espécies em programas de conservação. Pimm (1986) cita que estudos 
experimentais mostram poucas comunidades estáveis à perda de espécies, com ampla variação das conseqüências destas perdas. É bem provável que as florestas se ajustem a perdas naturais de espécies, mas problemas como os que se relacionam com a exploração irracional e indiscriminada de espécies, como é o caso do mogno e do pau-rosa na Amazônia ou como foi o caso do pau-brasil e jacarandá na floresta atlântica trazem implicações significativas sob o ponto de vista genético de suas populações (Martins, 1988; Kageyama \& Gândara, 1994). 


\section{Conclusões}

Para a escala e período abrangidos pelo estudo pode-se concluir que há uma estabilidade no número de espécies da comunidade através do tempo, sendo que esta estabilidade pode ser significativamente afetada por distúrbios naturais como o que ocorreu em 1987 e foi detectado pelo levantamento de 1989 , mas por um outro lado há uma grande capacidade de recuperação da comunidade, detectada já no levantamento de 1992, demonstrando uma alta resiliência da floresta ao distúrbio ocorrido.

Essas flutuações observadas na comunidade indicam a exigência de grandes áreas para a conservação "in situ", que sejam capazes de absorver essas flutuações sem prejudicar as estruturas genéticas e demográficas das populações.

Afirmar que as alterações florísticas indicam um desequilíbrio taxonômico na comunidade talvez seja prematuro para a escala deste estudo, entretanto são muito significativas as trocas locais de espécies de baixa densidade populacional.

Numa escala maior e em condições naturais provavelmente veríamos o movimento das populações ao longo do tempo na comunidade. Poderíamos até mesmo observar o fenômeno de "extinção local" só que muito mais associado àquelas espécies cuja raridade não é um padrão demográfico, mas cuja baixa densidade se deve a outros fatores, como já discutido, e portanto são componentes efêmeros da comunidade.

Essas colocações mostram a necessidade de se levar em conta o planejamento da fragmentação onde esse processo ainda é possivel (caso da Amazônia). Para o caso da floresta atlântica a situação é bem diferente, já que o alto nível de fragmentação e o alto grau de isolamento de muitas reservas mostram não só a necessidade de proteção do pouco que resta como também de recuperação de fragmentos e áreas degradadas. 
$E$, além de grandes reservas, também há uma necessidade de que o planejamento possibilite a manutenção do fluxo gênico entre as mesmas, de modo a permitir o movimento migratório das populações e níveis adequados de extinção local e recrutamento de novas espécies que proporcionem a manutenção da alta biodiversidade regional. 


\section{CAPITULO V \\ CONSIDERAÇÕES FINAIS}

Gostaria de perguntar para onde é que vocês eståo indo?

Ailton Krenak (In: Dean, 1996)

\section{Apresentação}

Foi apresentado nos Capitulos III e IV uma conclusão sobre os resultados encontrados neste estudo. As considerações que agora serão feitas são, antes de uma conclusão geral, muito mais uma análise sobre toda a literatura consultada ao longo do desenvolvimento deste trabalho.

\section{Conclusão Geral}

A importância dos distúrbios em florestas constitui extensa literatura ecológica, sendo destacados como importantes geradores de clareiras, que reconhecidamente se constituem no local onde 0 processo renovador da floresta é mais evidente. As florestas estão plenamente adaptadas aos distúrbios naturais, possuindo grande capacidade de resiliência.

Nos últimos anos a atenção dos pesquisadores tem se voltado para a existência de relações mais sutis (entre as plantas e os fatores abióticos, dentre os quais se destaca o fator luz) fora das áreas de clareiras ou que não induzam à formação de clareiras perceptíveis. O distúrbio ocorrido em Linhares (ES) e já detectado como importante componente na estruturação e organização de florestas da Ásia e América Central é um exemplo desta relação mais sutil, onde a mortalidade de árvores, apesar de intensa, não proporciona a abertura de clareiras.

Também tem ganho destaque entre os pesquisadores a importância do componente probabilístico em todas as fases do ciclo de vida 
das espécies arbóreas tropicais, particularmente na chegada, sobrevivência e recrutamento de plântulas.

Nesse sentido podemos dizer que na floresta predominam os processos estocásticos definido por Kinas (1986) como "uma famillia de variáveis aleatórias descrevendo um processo empírico cuja evolução é governada por leis probabilisticas".

Ou seja, comunidades arbóreas em florestas tropicais se constituem num sistema dinâmico aberto onde ocorre uma intensa e constante troca de propágulos a um nível local e onde existe um balanço adequado entre extinção e imigração de espécies a um nível regional (ou subcontinental), numa movimentação imperceptível a olhos humanos, mas que permite a manutenção da elevada diversidade de espécies.

Hastings et al. (1993) apresenta uma discussão sobre sistemas dinâmicos. Os sistemas estocásticos são impredizíveis sobre qualquer escala de tempo devido à natureza probabilística de seus componentes. A distinção entre dinâmica estocástica e determinística tem uma importante aplicação prática. Se flutuações nos tamanhos de populações são dirigidas primariamente por fatores determinísticos e estes fatores são conhecidos, então as dinâmicas destas populações são predizíveis sobre curtos períodos de tempo e o manejo destas populações é possivel.

Este seria o caso das espécies arbóreas mais comuns da floresta tropical. São espécies que possuem uma maior estabilidade estrutural de suas populações, regenerando-se facilmente sob o dossel da floresta e estando muito mais adaptada a distúrbios de diferentes escalas. O principal exemplo na mata atlântica é o palmito (Euterpe edulis), possuindo diversos polinizadores e dispersores de seus frutos e regenerando-se bem nos ambientes com boas condições de umidade. Por um outro lado se as flutuações são dirigidas primariamente por forças estocásticas exógenas, então a predição e manejo tornam-se muito mais difícil. 
Os sistemas silviculturais precisam ser desenvolvidos baseados no conhecimento dos principais distúrbios que ocorrem numa floresta, já que as atividades de manejo nada mais são que distúrbios aplicados sob diferentes formas e intensidades. Para viabilizar o sucesso do manejo há uma necessidade de se ter como prioridade de pesquisa as populações de espécies:

- como as populações de espécies arbóreas reagem a distúrbios de diferentes tipos e intensidades?

- em que situação elas expandem e retraem suas populações?

Se um controle adequado das populações envolvidas no manejo for realizado, os ajustes mais finos podem ficar por conta da natureza, com sua propriedade reguladora, que vem de sua alta capacidade resiliente.

Resultados de pesquisa (Tilman, 1996) levam à conclusão que a biodiversidade possui uma propriedade estabilizadora de processos do ecossistema e de comunidades, mas não para processos populacionais. Essa hipótese confirma as predições de May (1973), a respeito dos efeitos da diversidade sobre a estabilidade de populações, e as de Hubbell \& Foster (1987) de que as florestas se encontram em equilíbrio estrutural, mas em desequilíbrio taxonômico.

São questões que não podem ser desprezadas e foi a base deste conhecimento, que teve muito de observação e empiricismo, sendo passado de geração a geração, que permitiu aos antigos povos da floresta um convívio com seu ambiente. 


\section{Referências Bibliográficas}

ALMEIDA, O. T. (Org.) A evolução da fronteira amazônica: oportunidades para um desenvolvimento sustentável. Belém, IMAZON, 1996, 139p.

ARRIAGA, L. Gap dynamics of a tropical cloud forest in northeast in México. Biotropica, 20(3):178-185, 1988.

ATTIWILL, P. M. The disturbance of forest ecosystems: the ecological basis for conservative management. Forest Ecology and Management, 63:247-270, 1994.

AUBRĖVILLE, A. La forêt coloniale: les foréts d'Afrique équatoriale. Boi Foréts Trop., 2:24-35, 1938.

BARRETO, P.; AMARAL, P; VIDAL, E.; UHL, C. Impactos do manejo florestal na economia da exploração madeireira na Amazônia Oriental. Artigo não publicado, 1997.

BATISTA, J. L. F. Spatial dynamics of trees in a Brazilian Atlantic Tropical Forest under natural and managed condition. Washington 1994, 327p. Thesis (PhD), University of Washington.

BAWA, K. S.; ASHTON, P. S. Conservation of rare trees in tropical rain forest: a genetic perspective. pp: 62-71. In: D.A. FALK \& K.E. HOLSINGER (eds.) Genetics and conservation of rare plants. New York, Oxford, Oxford Univ. Press, USA, 1991, p.62-71.

BAZZAZ, F. A. Characteristics of population in relation to disturbance in natural and man-modified ecosystem. In: H.A. MOONEY \& M. GODRON (eds.) Disturbance and Ecosystems. Springer-Valag, Berlim Herdelberg, New York, Tokio, 1983, p.259-275.

BROKAW, N. V. L. The definition of treefall gap and its effect on measure of forest dynamics. Biotropica, 14(2): 158-160, 1982a.

BROKAW, N. V. L. Tree falls: frequency, time and consequences. In: E. G. LEIGH JR.; A. S. RAND \& D. M. WINDSOR (eds.) The ecology of a tropical forest seazonal rhytms and long-term changes, 1982b.

BROKAW, N. V. L. Treefalls, regrowth, and community structure in tropical forest. In: PICKETT, S. T. A. \& WHITE, P. S. The ecology of natural disturbance and patch dynamics. Orlando, Academic Press, 1985a, p.5368.

BROKAW, N. V. L. Gap-phase regeneration in a tropical forest. Ecology, 66(3):682-687, 1985b.

BRUENIG, E. F. Conservation and management of tropical rainforest: an integrated approach to sustainability. CAB international, 1996, 339p. 
CAREY, E. V.; BROWN, S.; GILLESPIE, A. J. R.; LUGO, A. E Tree Mortality in Mature Lowland Tropical Moist and Tropical Lower Montane Moist Forests of Venezuela. Biotropica 26(3): 255-265, 1994.

CARVALHO, J. O. P. Structure and dynamics of a logged over Brazilian Amazonian rain forest. Oxford, 1992. Thesis (PhD), Univ. Oxford.

CHESSON, P. L. ;WARNER, R. R. Environmental variability promotes coexistence in lottery competitive systems. American Naturalist, 117:923943, 1981.

CLARK, J. S. Ecological disturbance as a renewal process: theory and application to fire history. Oikos 56:17-30, 1989.

CLARK, D. A. Plant demography. pp: 90-105. In: MCDADE, L.A.; K.S. BAWA; H. HESPENHEIDE \& G.S. HARTSHORN (eds.) La Selva: ecology and natural history of a neotropical rain forest. Univ. of Chicago Press, Chicago, Illinois, USA, 1994.

CLARK, D. B. The role of disturbance in the regeneration of neotropical moist forest. In: A. G. POMPA \& T. C. WHITMORE. Rain forest regeneration and management. M. Hadley, Unesco, 1990.

CLEMENTS, F. E. Plant Succession. Carnegie Institute of Washington Publication 242, 1916.

CLOUDSLEY-THOMPSON, J. L Microecologia. Coleção Temas de Biologia, v2. EPU/EDUSP, 58p., 1980.

CONDIT, R. Research in large, long-term tropical forest plots. Tree, 10(1):1822, 1995.

CONDIT, R.; HUBBELL, S. P.; FOSTER, R. B. Short-term dynamics of a neotropical forest. Bioscience, 42(11):822-828, 1992.

CONNELL, J. H. Diversity in tropical rain forests and coral reefs. Science, 199:1302-1310, 1978.

CROW, T. R. A rainforest chronicle: a 30 year record of change in structure and composition at El Verde, Puerto Rico. Biotropica, 12 (1):42-55, 1980.

DEAN, W. A Ferro e Fogo: A história e a devastação da Mata Atlântica brasileira. Companhia das Letras, 1996, 484p.

DENSLOW, J. S.; HARTSHORN, G. S. Tree-fall gap environments and forest dynamic. p.120-127. In: MCDADE, L.A.; K.S. BAWA; H. HESPENHEIDE \& G.S. HARTSHORN (eds.) La Selva: ecology and natural history of a neotropical rain forest. Univ. of Chicago Press, Chicago, Illinois, USA, 1994.

DENSLOW, J. S. Gap-partioning among tropical rain forest trees. Biotropica, 12(sup.):47-55, 1980. 
DENSLOW, J. S. Tropical rainforest gaps and tree species diversity. Annual Review of Ecology and Systematic, 18:431-451, 1987.

DIEGUES, A. C. S. 0 mito moderno da natureza intocada. NUPALB, USP, 1994, 163p.

ELTON, C. Animal Ecology. London. Sidgwick and Jackson, 1927.

FELFILI, J. M. Growth, recruitment and mortality in the Gama gallery forest in central Brazil over six-year period (1985-1991). Journal of Tropical Ecology, 11: 67-83, 1995.

FLENLEY, J. R. The equatorial rain forest: a geological history. Butterworth: London, 1979.

FRANKLIN, J. F.; SHUGART, H. H.; HARMON, M. E. Tree Death as an Ecological Process. Bioscience, 37(8):550-556, 1987.

FUNDAÇÃO SOS MATA ATLÂNTICA ; INPE Evolução dos remanescentes florestais e ecossistemas associados do domínio da mata atlântica. São Paulo, Fundação SOS mata atlântica e INPE, 46p., 1993.

FUTUYMA, D. J. Biologia Evolutiva. Tradução de Mário de Vivo e coord. De Fábio de Melo Sene, $2^{\circ}$ edição, Ribeirão Preto, Sociedade Brasileira de Genética/CNPq, 1992, 646p.

GARCIA, A. Influência de diferentes níveis de exploração florestal em uma floresta tropical na região de Marabá-PA. Piracicaba 1991. Dissertação de Mestrado, ESALQ/USP.

GENTRY, A. H. ; TERBORGH, J. Composition and dynamics of the Cocha Cashu "Mature" Floodplain Forest.. In: GENTRY, A.H. (ed.) Four neotropical rainforests. Yale Univ. Press. New Haven, 1990. Pp.542-564.

GLEASON, $\mathrm{H}$. The individualistc concept of the plant association. Bulletin of the Torrey Botany Club, 53:1-20, 1926.

GOMEZ-POMPA, A. ; BURLEY, F. W. The management of natural tropical forest. In: A. GOMEZ-POMPA; T. C. WHITMORE \& M. HADLEY (eds.). Rain forest regeneration and management, Unesco, 1990.

GRAAF, N. R. A silvicultural system for natural regeneration of tropical rain forest in Suriname. Wageningen, 1986. Univ. of Wageningen, 250p.

GRAZIANO NETO, F. Questão agrária e ecologia: crítica da moderna agricultura. Ed. Brasiliense, $2^{\circ}$ edição, 1985, 154p.

HALLÉ, F.; OLDEMAN, R. A. A.; TOMLINSON, P. B. Tropical trees and forest: An Architectural Analysis. Springer-Verlag. New York, 1978, 411p.

HARCOMBE, P.A. - Tree life tables. Bioscience,37:557-568, 1987. 
HARTSHORN, G. S. Treefalls and tropical forest dynamics. In: P.B. TOMLINSON AND M.H. ZIMMERMMAN (eds.) Tropical trees as living systems. Cambridge Univ. Press, 1978, p.617-638.

HARTSHORN, G. S. Neotropical forest dynamics. Biotropica, 12(sup.):23-30, 1980.

HARTSHORN, G. S. An overview of neotropical forest dynamics. In: GENTRY, A.H. (ed) Four Neotropical rainforests. Yale Univ. Press. New Haven, 1990, p585-599.

HERWITZ, S. R. ; YOUNG, S. S Mortality, recruitment and growth rates of Montane Tropical Rain Forest Canopy Trees on Mount Bellenden-Ker, Northeast Queensland, Austrália. Biotropica, 26(4): 350-361, 1994.

HIGUCHI, N. Short-term growth of an undisturbed tropical moist forest in the Brasilian Amazon. Michigan, 1987. Thesis (PhD). Michigan State University, Department of Forestry.

HIGUCHI, N. Experiências e resultados de intervenções silviculturais na floresta tropical úmida brasileira. In: SEMINÁRIO "O DESAFIO DAS FLORESTAS NEOTROPICAIS", Curitiba, 1991, p.138-151. Anais.

HIGUCHI, N. Utilização e manejo dos recursos madeireiros das florestas tropicais úmidas. Acta Amazônica, 1995.

HIGUCHI, N. ; VIEIRA, G. Manejo sustentado da floresta tropical úmida de terra-firme na região de Manaus. Um projeto de pesquisa do INPA. $6^{\circ}$ CONGRESSO FLORESTAL BRASILEIRO,1990. Anais

HUBELL, S. P.; FOSTER, R. B. Commonness and rarity in a neotropical forest: implications for tropical tree conservation. In: SOULÉ, M. (ed). Conservation Biology: science of scarcity and diversity. Sinauer Associates, Sunderland, Massachusetts, USA, 1986, pp.205-231.

HUBELL, S. P.; FOSTER, R. B. La estructura espacial en gran escala de un bosque neotropical. Revista de Biologia Tropical, 35(supl. 1):7-22, 1987.

HUBELL, S. P.; FOSTER, R. B. Structure, dynamics and equilibrium status of old-growth forest on Barro Colorado Island.. In: GENTRY, A.H. (ed), Four neotropical rainforests. Yale Univ. Press. New Haven, USA, 1990a. pp.522-541.

HUBELL, S. P.; FOSTER, R. B. The fate of juvenile trees in a neotropical forest: implications for the natural maintenance of tropical tree diversity. In: A. G. POMPA AND T. C. WHITMORE. Rain forest regeneration and management, M. Hadley, Unesco, 1990b. 
HUSTINGS, A.; HOM, C. L.; ELLNER, S.; TURCHIN, P.; GODFRAY, H. C. J. Chaos in ecology: is mother nature a strange attractor? Annual Review of Ecology and Systematic, 24:1-33, 1993.

HUSTON, M. A general hypothesis of species dversity. American Naturalist, 113:81-101, 1979.

IBGE Manual técnico da vegetação brasileira. Manuais técnicos em geociências, número 1. Rio de Janeiro: IBGE, 1992, 92p.

JARDIM, F. C. S. Comportamento da regeneração natural de espécies arbóreas em diferentes intensidades de desbaste por anelamento, na região de Manaus-AM. Viçosa, 1995. Tese de Doutrado, UFV.

JARDIM, F. C. S. Mortalidade e crescimento na floresta equatorial de terra firme. Boletim do Museu Paraense Emílio Goeldi. Série Botânica 6(2):227-234, 1990.

JESUS, R. M. A Reserva Florestal da CVRD, Linhares (ES). In: Seminário sobre desenvolvimento e impacto ambiental em áreas do Trópico Úmido Brasileiro - A experiência da CVRD, Belém (PA), 1987.

JESUS, R. M. ; SOUZA, A. L. Produção sustentável em mata secundária de transição - oito anos de monitoramento. Documento SIF (14), 1995.

JESUS, R. M.; SOUZA, A. L.; GARCIA, A. Produção sustentável de floresta atlântica. Documento SIF (7), 1992.

JORDY, S. F. As regiões fitoecológicas, sua natureza e seus recursos econômicos. Estudo Fitogeográfico. In: IBGE, Folha SE-24 Rio Doce. Rio de Janeiro, 1987.

KAGEYAMA, P Y.; GÂNDARA, F.B. Dinâmica de populações de espécies arbóreas: implicações para manejo e conservação. III Simpósio de Ecossistemas da Costa Brasileira: subsídios a um gerenciamento ambiental. Publicação ACIESP número 87, volume 2, 1994. Anais.

KESSELI, R. V. Population biology and conservation of rare plants.. In: S.K. JAIN \& L.W. BOTSFORD (eds.) Applied Population Biology, 1992, pp.6990.

KINAS, P. G. Estudo de estimadores de mortalidade e abundância animal a partir de informações de captura e esforço. Dissertação de mestrado, IME/USP, 1986.

LANG, G. E.; KINGHT, D. K. Tree growth, mortality, recruitment and canopy gap formation during a 10 year period in a tropical moist forest. Ecology, 64(5): 1075-1080, 1983. 
LEITÃO FILHO, H.F. (coord.) Ecologia da mata atlântica em Cubatão (SP). Editoras da Unesp e Unicamp, 1993, 184p.

LEPSCH-CUNHA, N. Rare tropical tree species: demographic and genetic responses of a very heterogeneous group. In: Gascon, C. \& Bierregaard Jr., R. Lessons from amazonia, submetido.

LIEBERMAN, M. ;LIEBERMAN, D. ; PERALTA, R. Forest area not just swiss cheese: canopy stereogeometry of non-gaps in tropical forest. Ecology, 70(3):550-552, 1989.

LIEBERMAN, D.; LIEBERMAN, M. Forest tree growth and dynamics at La Selva, Costa Rica (1969-1982). Journal of Tropical Ecology, 3:347-358, 1987.

LIEBERMAN, M.; LIEBERMAN, D.; HARTSHORN, G.S. \& PERALTA, R. Smallscale altitudinal variation in lowland wet tropical forest vegetation. Journal of Ecology, 73:505-516, 1985.

LIEBERMAN, D; HARTSHORN, G. S.; LIEBERMAN, M.; PERALTA, R. Forest dynamics at La Selva Biological Station, 1969-1985. Pg 509-521. In: GENTRY, A.H. (ed.) Four neotropical rainforests. Yale Univ. Press: New Haven, 1990.

LOBATO, C. Áreas de conservação ambiental para o Estado do Pará. Pará desenvolvimento, Belém, 24:20-40, 1988.

LOPES, J. C. A. Demografia e flutuações temporais da regeneração natural após uma exploração florestal: Flona do Tapajós (PA). Piracicaba, 1993. Dissertação de mestrado, ESALQ/USP.

LUGO, A. E. Management of tropical biodiversity. Ecological Applications, 5(4):956-961, 1995.

MANOKARAM, N.; KOCHUMMEN, K. M. Recruitment, growth and mortality of tree species in a lowland dipterocarp forest in Peninsular Malaysia. Journal of Tropical. Ecology, 3:315-330, 1987.

MANTOVANI, W. Estrutura e dinâmica da Floresta Atlântica na Juréia (SP). São Paulo, 1993. Tese de Livre-Docência, IB/USP.

MARTÍNEZ-RAMOS, M. Claros, ciclos vitales de los arboles tropicales y regeneratión natural de las selvas altas perenifolias. In: GOMEZ-POMPA, A. AND DEL AMO, S. Investigaciones sobre la regeneración de las selvas altas en Veracruz, México, 1985, v2:p.191-239.

MARTÍNEZ-RAMOS, M Patrones, processos y mecanismos en la comunidad de plantulas de una selva humeda tropical. México, 1991. Tesis de Doutorado. Univ. Nacional Autonoma de México, 154p. 
MARTINS, P. S. Preservação e Genética Evolutiva. In: ARAUJO, S.M.C. \& OSUNA, J.A (eds.) Encontro sobre Recursos Genéticos. Jaboticabal (SP), 1988, p.62-66. Anais.

MAY, R. Stability and complexity of models ecosystems. Princeton, NJ: Princeton Univ. Press, 1973, 235p.

MILLER, T. E. Community diversity and interactions between the size and frecquency of disturbance. American Naturalist, 120:533-536, 1982.

MOONEY, P. R. O escândalo das sementes: o domínio na produção de alimentos. Ed. Nobel, São Paulo, 1987, 146p.

NASCIMENTO, H. E. M. Estudo da dinâmica de populações arbóreas em um fragmento de floresta de planalto na região de Piracicaba (SP). Piracicaba, Relatório FAPESP, 1997, 31 p.

NEVES, E. G. Arqueólogos brigam pela idade dos primeiros passos humanos no Brasil. Folha de São Paulo, Caderno Mais, 21 de abril de 1996.

NEWSTROM, L. E.; FRANKIE, G. W.; BAKER, H. G ; COLWELL, R. K. Diversity of long-term flowering patterns. pp: 142-160. In: MCDADE, L.A.; K.S. BAWA; H. HESPENHEIDE \& G.S. HARTSHORN (eds.) La Selva: ecology and natural history of a neotropical rain forest. Univ. of Chicago Press, Chicago, Illinois, USA, 1994.

O'BRIEN, M. J. P. ; O'BRIEN, C. M. Ecologia e modelamento de florestas tropicais. FCAP, Belém, 1995.

OKALI, D. U. U. ; OLA-ADAMS, B. A. Tree population changes in treated rain forest at Omo Forest Reserv, south-western Nigeria. Journal of Tropical Ecology, 3:291-313, 1987.

OLDEMAN, R. A. A. Architecture and energy exchange of dicotyledonous trees in the forest. In: P. B. TOMLINSON ; M. H. ZIMMERMMAN (eds.) Tropical trees as living systems. Cambridge Univ. Press, 1978, p.535-560.

ORIANS, G. H. The influence of tree falls in tropical forest on tree species richness tropical. Ecology, 23:255-279, 1982.

PEET, R. K.; CHRISTENSEN, N. L Competition and tree death. Bioscience, 37(8): 586-595, 1987.

PEIXOTO, A. L.; GENTRY, A. Diversidade e composição florística da mata de tabuleiro na Reserva Florestal de Linhares (ES). Revista Brasileira de Botânica, 13(1):19-26, 1990.

PERALTA, R.; HARTSHORN, G. S.; LIEBERMAN, D.; LIEBERMAN, M Reseña de estudios a largo plazo sobre composición florística y dinámica del 
bosque tropical en La Selva, Costa Rica. Revista de Biologia Tropical (supl. 1):23-39, 1987.

PETRAITIS, P. S.; LATHAM, R. E.; NIESENBAUM, R. A. The maintenance of species diversity by disturbance. The Quarterly Review of Biology, 64:393418, 1989.

PHILLIPS, O. L. ; GENTRY, A. H. Increasing turnover through time in tropical forests. Science, 263:954-958, 1994.

PIMM, S. L. Community stability and structure.. In: SOULÉ, M. (ed.) Conservation Biology: science of scarcity and diversity. Sinauer Associates, Sunderland, Massachusetts, USA, 1986, p: 309-329.

PLATT, W. J. ; STRONG, D. R. Gaps in forest ecology. Ecology, 70(3), 1989.

POORTER, L.; BONGERS, F.; POMPAEY, R. S. A. R. van; KLERK, M. de Regeneration of canopy tree species at five sites in west African moist forest. Forest Ecology and Management, 84:61-69, 1996.

PRADO JÚNIOR., C. - História Econômica do Brasil. São Paulo, Ed. Brasiliense, $16^{\circ}$ edição, 1973.

PRADO, E. I. K. L.; ENGEL, V. L.; MENDES, F. G. Padrões de mortalidade de árvores em uma mata pluvial atlântica em Linhares (ES). Revista do Instituto Florestal, volume único, parte 3:773-777, 1992.

PRANCE, G. T. (ed.) Biological diversification in the tropics. Columbia, new York, 1982.

PRIMACK, R. B. Regeneration: comentary. In: A. G. POMPA \& T. C. WHITMORE (EDS.) Rain forest regeneration and management, $M$. Hadley, Unesco, 1990.

PRIMACK, R. B. Tropical community dynamics and conservation biology. Bioscience, 42(11):818-821, 1992.

PRIMACK, R. B.; HALL, P. Biodiversity and forest change in Malaysian Borneo. Bioscience, 42(11):829-837, 1992.

PRIMACK, R. B.; ASHTON, P. S.; CHAI, P.; LEE, H. S. Growth rates and population structure of Moraceae trees in Sarawak, East Malasia. Ecology 66:577-588, 1985.

PUTZ, F. E.; MILTON, K. Tree mortality rates on Barro colorado island. In: E. G. LEIGH JR.; A. S. RAND AND D. M. WINDSOR (eds.). Ecology of a tropical forest seazonal rhytms and long-term changes, 1982.

RABINOWITZ, D.; CAIRNS, S.; DILLON, T. Seven forms of rarity and their frequency in the flora of the British Isles.. In: SOULÉ, M. (ed). Conservation 
Biology: science of scarcity and diversity. Sinauer Associates, Sunderland, Massachusetts, USA, 1986, p.182-204.

RANKIN-DE-MERONA, J. M.; HUTCHINGS, R. W.; LOVEJOY, T. E. Tree mortality and recruitment over a five-year period in undisturbed upland rainforest of the Central Amazon.. In: GENTRY, A.H. (ed.) Four neotropical rainforests. Yale Univ. Press. New Haven, 1990, p. 573-584.

REICE, S. R. Nonequilibruium determinants of biological community structure. American Scientist, 82(5):424-435, 1994.

REIS, A.; REIS, M. S.; FANTINI, A. C. Manejo de rendimento sustentado de Euterpe edulis. UFSC, apostila de curso, 1993, 47p.

RIZZINI, C. T. Tratado de Fitogeografia do Brasil. Ed. Hucitec, São Paulo, 1979.

ROBERTS, M. R.; GILLIAM, F. S. Patterns and mechanisms of plant diversity in forest ecosystems: implications for forest management. Ecological Applications 5(4):969-977, 1995.

ROLIM, S. G.; NASCIMENTO, H. E. M. Estrutura mínima de comunidades arbóreas tropicais: uma análise através da relação espécie-abundância. Cientia Forestalis, no prelo.

SALGADO-LABOURIAU, M. L. História Ecológica da Terra. Editora Edgard Blucher Ltda, 1994, 307p.

SANFORD, R. L.; SALDARRIAGA JÚNIOR, J.; CLARK, K. E.; UHL, C.; HERRERA, R. Amazon rainforest fires. Science, 227:53-55, 1985.

SANTOS, F. A. M.; TAMASHIRO, J. Y.; RODDRIGUES, R. R. \& SHEPHERD, G. $J$. The dynamics of tree population in a semideciduous forest at Santa Genebra Reserve, SE Brazil, (não publicado).

SAS INSTITUTE Sas/Stat users guide, version 6, Cary, North Caroline, USA, 1989.

SCHUPP, E. W.; HOWE, H. F.; AUGSPURGER, C. K.; LEVEY, D. J. Arrival and survival in tropical treefall gaps. Ecology, 70(3):562-565, 1989.

SHEIL, D.; MAY, R. M. Mortality and recruitment rate evaluations in heterogeneous tropical forests. Journal of Ecology, 84:91-100, 1996.

SHEILL, D.; BURSLEM, D. F. R. P. ; ALDER, D. The interpretation and misinterpretation of mortality rate measures. Journal of Ecology, 83, 331333, 1995.

SHUGART, H. H. A Theory of Forest Dynamics. New York: Springer-Verlag, 1984. 
SHUGART, H. H. Dynamic ecosystem consequences of tree birth and death patterns. Bioscience, 77(8):596-602, 1987.

SILVA, J. N. M. A experiência do manejo sob rendimento sustentado em florestas tropicais úmidas. In: $1^{\circ}$ CONGRESSO FLORESTAL PANAMERICANO E $7^{\circ}$ CONGRESSO FLORESTAL BRASILEIRO, Curitiba, 1993, p.202-206. Anais.

SILVA, J. N. M. The behaviour of the tropical rain forest of the Brasilian Amazon after logging. Oxford, 1989. Thesis (PhD). Oxford University, 1989.

SIQUEIRA, M. F. Análise florística e ordenação de espécies arbóreas da mata atlântica através de dados binários. Campinas, 1994. Dissertação de mestrado, UNICAMP, 142p.

SOKAL, R. R.; ROHLF, F. J. Biometry. Freeman, San Francisco, 1981.

SOLÉ, R.V.; MANRUBIA, S. C. Are Rainforests Self-organized in a critical State? Journal of Theoretical Biology, 173:31-40, 1995.

SOUZA, A. L. Análise multivariada para manejo de florestas naturais: alternativas de produção sustentada para serraria. Curitiba, 1989. Tese de Doutorado, UFPR, 245p.

SOUZA, A. L.; JARDIM, F. C. S. Sistemas silviculturais aplicados às florestas tropicais. Documento SIF (8), 1993.

SOUZA, W. P. The role of disturbance in natural communities. Annual Review of Ecology and Systematic, 15:352-391, 1984.

STRONG, D. R. Epiphyte loads tree falls and higher tree species richness in tropics without animals. Journal of Biogeography, 4:215-218, 1977.

STRONG, D. R.; GLITZENSTEIN, J. S.; HARCOMBE, P. A. Wood seedling dynamics in a east Texas foodplain forest. Ecological Monographs, v59, n2:177-204, 1989.

SUGIHARA, G.; MAY, R. M. Applications of Fractals in Ecology. Tree 5(3):7986. 1990.

SWAINE, M. D. Population dynamics of tree species in tropical forests. In: L.B. HOLM-NIELSEN; I.C.NIELSEN \& H. BALSLEV (Eds). Tropical Forests: botanical, dynamics, speciation and diversity. Academic Press Limited, London, 1989, 380p.

SWAINE, M. D.; LIEBERMAN, D. Note on the calculation of mortality rates. Journal of Tropical Ecology, 83:331-333, 1987.

SWAINE, M. D.; HALL, J. B.; ALEXANDER, I. J. Tree population dynamics at Kade, Gana (1968-1982). Journal of Tropical Ecology, 3:331-345, 1987a. 
SWAINE, M. D.; LIEBERMAN, D.; PUTZ, F. E. The dynamics of tree populations in a tropical forest: a review. Journal of Tropical Ecology, 3:359-369, 1987b.

TILMAN, D. Biodiversity: population versus ecosystem stability. Ecology, 77(2):350-363, 1996

TURKINGTON, R.; AARSSEN, L. W. Local-scale differentiation as a result of competitive interactions.. In: DIRZO, R. \& J. SARUKHÁN (eds). Perspectives on Plant Population Ecology. Sunderland, Massachussetts, USA, 1984, p.107-127.

UHL, C. Tree dynamics in a rich tierra-firme forest in Amazonia Venezuela. Acta Cientifica Venezolana, 33:72-77, 1982.

UHL, C.; MURPHY, P. G. Composition, structure and regeneration of a tierrafirme forest in the Amazon Basin Venezuela. Journal of Tropical Ecology, 35:1-22, 1981.

UHL, C.; CLARK, N.; DEZZEO, N; MAQUINO, P. Vegetation dynamics in Amazoniam treefall gaps. Ecology, 69:751-763, 1988.

UHL, C.; VERÍSSIMO, A.; BARRETO, P.; MATTOS, M.; TARIFA, R. O desafio da exploração sustentada. Ciência Hoje 14(81), 1992.

van DAALEN, J. C. Forest growth: a 35-year southern cape case study. SuidAfrikaanse Bosboutydskrif , n 159, december 1991.

van der MAAREL, E. Dynamics of plant population from a synecology viewpoint. pp: 66-82. In: DIRZO, R. \& J. SARUKHÁN (eds.) Perspectives on Plant Population Ecology. Sunderland, Massachussetts, USA, 1984.

VANDERMEER, J.; ZAMORA, N.; YIH, K.; BOUCHER, D. Regeneración inicial en una selva tropical en la costa caribeña de Nicarágua después del huracán Juana. Revista de Biologia Tropical, 38(2b):347-359, 1990.

VANZOLINI, P. E. Paleoclimas e especiação de animais da América do Sul. Estudos Avançados, USP, 6(15), 1992.

VELOSO, H. P; GÓES FILHO, L. Fitogeografia brasileira: classificação fisionômico-ecológica da vegetação neotropical. Boletim Técnico do Projeto Radambrasil, série vegetação, n 1. Salvador, 80p., 1982.

VIANA, V. M. Conservação da biodiversidade de fragmentos de florestas tropicais em paisagens intensivamente cultivadas. Conferência internacional: Abordagens Interdisciplinares para a conservação da Biodiversidade e Dinâmica do uso da Terra, Belo Horizonte (MG), 1995. Anais. 
WATT, A. S. Pattern and process in the plant community. Journal of Ecology, 43:490-506, 1947.

WELDEN, C. W.; HEWETT, S. W.; HUBBELL, S. P.; FOSTER, R. B. Sapling survival, growth and recruitment: relationship to canopy height in a neotropical forest. Ecology, 71:35-50, 1991.

WHITE, P.S.; PICKETT, S.T.A. Natural disturbance and patch dynamics: an introduction. In: PICKETT, S.T.A. \& WHITE, P.S. (eds.) The ecology of natural disturbance and patch dynamics. Orlando, Academic Press, 1985, p.3-13.

WITHMORE, T. C. Gaps in the forest canopy. In: P. B. TOMLINSON \& M. H. ZIMMERMMAN (eds.) Tropical trees as living systems. Cambridge Univ. Press, 1978, p535-560.

WHITMORE, T. C. Gap size and species richness in tropical rain forests. Biotropica 16(139), 1984.

WHITMORE, T. C. Canopy gaps and the major groups of forest trees. Ecology 70:536-538, 1989.

WITHMORE, T. C. Tropical rain forest dynamics and its implications for management. In: A. GOMEZ-POMPA; T. C. WHITMORE \& M. HADLEY (eds.) Rain forest regeneration and management, Unesco, 1990.

YARED, J. A. G. et al. Silvicultura como atividade econômica na região amazônica. In: $1^{\circ}$ Encontro Brasileiro de Economia Florestal, Curitiba, 1988, p.15-42. Anais.

YARED, J.A.G. ;SOUZA, A. L. Análise dos impactos ambientais do manejo de florestas tropicais. Documento SIF (9), 1993. 